$$
\begin{gathered}
\text { Universidade de São Paulo - Escola Politécnica } \\
\text { RAFAEL TEDIM TERRA }
\end{gathered}
$$

\title{
AVALIAÇÃO DO DESEMPENHO DINÂMICO DE VEÍCULO, DEVIDO AO INCREMENTO DE MASSA NÃO SUSPENSA, DECORRENTE DE SISTEMA DE PROPULSÃO ELÉTRICA.
}


RAFAEL TEDIM TERRA

\section{AVALIAÇÃO DO DESEMPENHO DINÂMICO DE VEÍCULO, DEVIDO AO INCREMENTO DE MASSA NÃO SUSPENSA, DECORRENTE DE SISTEMA DE PROPULSÃO ELÉTRICA.}

Dissertação apresentada à Escola

Politécnica da Universidade de São Paulo para a obtenção do título de Mestre em Ciências. 
RAFAEL TEDIM TERRA

\title{
AVALIAÇÃO DO DESEMPENHO DINÂMICO DE VEÍCULO, DEVIDO AO INCREMENTO DE MASSA NÃO SUSPENSA, DECORRENTE DE SISTEMA DE PROPULSÃO ELÉTRICA.
}

\author{
Dissertação apresentada à Escola \\ Politécnica da Universidade de São Paulo \\ para a obtenção do título de Mestre em \\ Ciências. \\ Área de Concentração: \\ Engenharia Mecânica
}

Orientador:

Prof. Dr. Roberto Spinola Barbosa 
Este exemplar fol revisado e corrigido em relaç̧̌ a versăo original, sob responsabildade única do autor e com a anuencla de seu orlentador.

కăo Paulo, de de

Assinatura do autor:

Assinatura do orientador:

Terra, Rafael Tedim

Avaliação do desempenho dinâmico de veículo, devido ao incremento de massa não suspensa, decorrente de sistema de propulsão elétrica. / R. T. Terra - versão corr. São Paulo, 2017. $102 \mathrm{p}$.

Dissertação (Mestrado) - Escola Politécnica da Universidade de São Paulo. Departamento de Engenharia Mecânica.

1.Dinâmica veicular 2.Carro elétrico I.Universidade de São Paulo. Escola Politécnica. Departamento de Engenharia Mecânica II.t. 


\section{Agradecimentos}

Agradeço aos meus pais por terem me dado as condições propícias ao longo da minha vida para que eu estudasse, e à minha esposa Amanda que me apoiou ao longo destes últimos anos.

Aos amigos Antonio Carlos Botosso, Daniel Vilela e Diego Moreno Bravo que, de alguma maneira, me auxiliaram na confecção deste trabalho, e também a todos os colegas do tempo de graduação que participaram comigo do projeto Fórmula SAE, que me introduziu no mundo da dinâmica veicular e dos carros elétricos.

À General Motors do Brasil, minha empregadora, que me cedeu o tempo necessário para a realização das matérias e confecção do trabalho.

Ao meu orientador Roberto Spinola que me guiou ao longo deste mestrado.

E, por fim, ao Contribuinte Paulista que, através da Universidade de São Paulo, financiou o meu estudo. 


\section{SUMÁRIO}

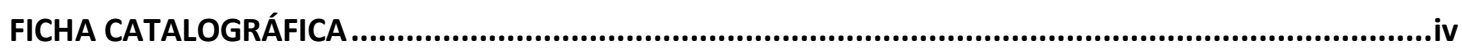

Agradecimentos

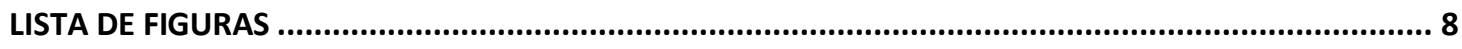

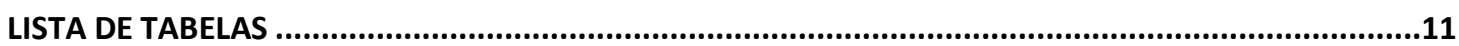

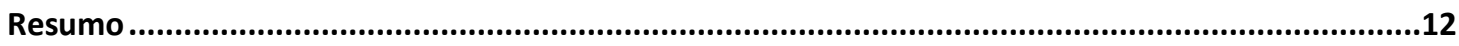

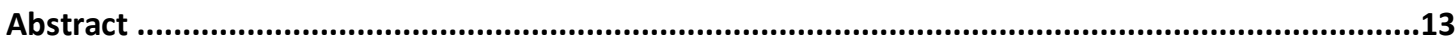

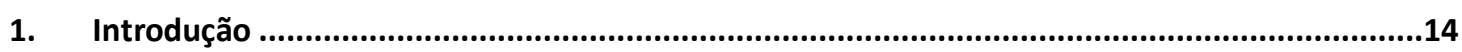

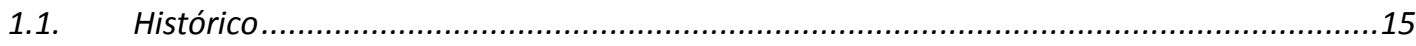

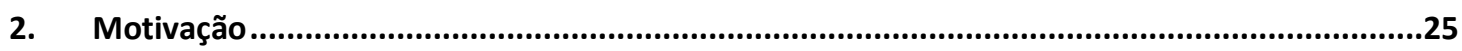

2.1. Impacto sócio econômico e ambiental....................................................................25

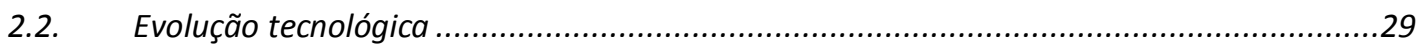

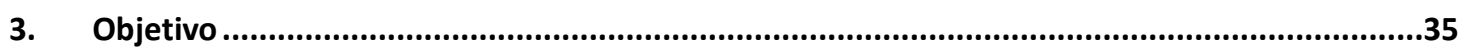

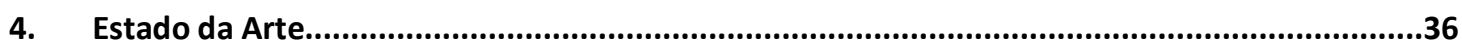

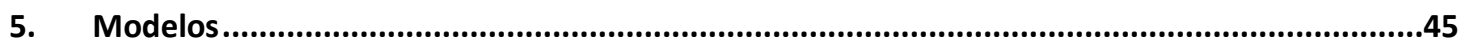

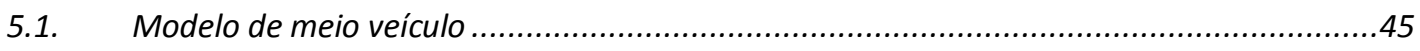

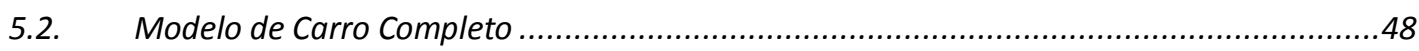

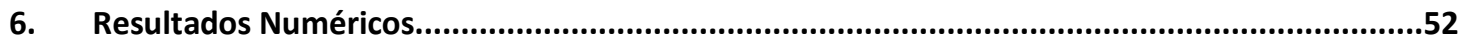

6.1. Análise modal através do modelo de um quarto de veículo.........................................52

6.2. Resposta em frequência através do modelo de meio veículo.........................................53

6.3. Análise modal através do modelo completo .....................................................5

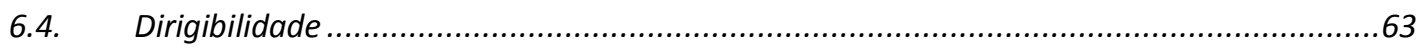

6.4.1. Manobras em regime permanente .....................................................................63

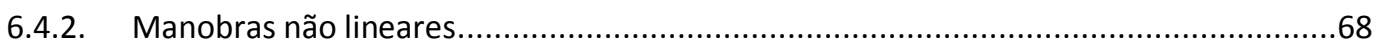

6.5. Otimização através de análise de sensibilidade ..................................................79 


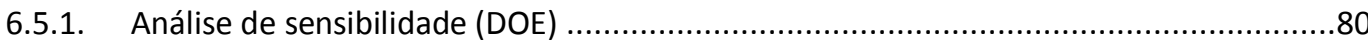

6.5.2. Confirmação da Otimização.......................................................................................

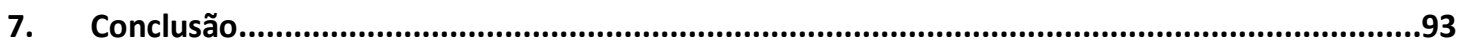

8. Recomendações ...................................................................................................................95

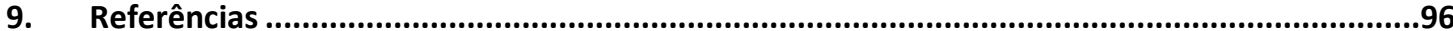

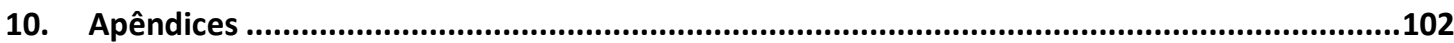




\section{LISTA DE FIGURAS}

Figura 1- Jeantaud Duc Profilée (Car Blues print, s.d.) ..........................................................................16

Figura 2 - Porsche C2 Phaeton exposto no museu da Porsche na Alemanha (Jalopnik, s.d.) ............................17

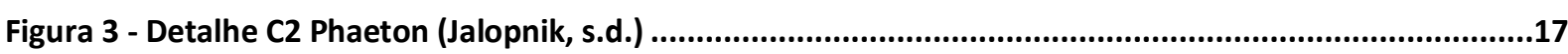

Figura 4 - "Woods gasoline-electric" (Bravo, 2016)....................................................................................19

Figura 5 - Gurgel Itaipu E-150 (Fórum do carro antigo, s.d.) .....................................................................20

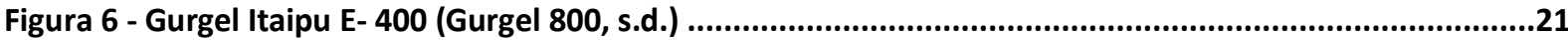

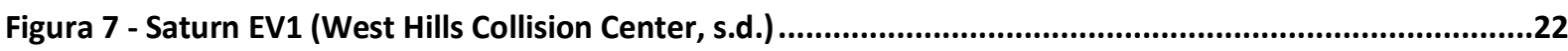

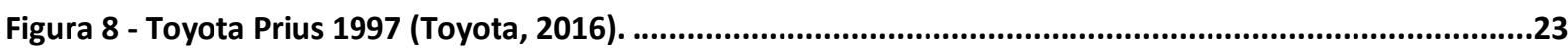

Figura 9 - Porsche 919 Hybrid (Porsche, 2016) ......................................................................................24

Figura 10 - Variação da temperatura média global levando em consideração como marco zero o ano de 1951

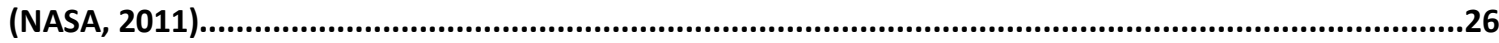

Figura 11 - Preço médio do barril do petróleo e acontecimentos históricos ao longo dos últimos 150 anos (BP, 2015) .27

Figura 12 - Exemplificação das massas suspensas e não suspensas ...............................................................30

Figura 13 - Evolução da relação peso potência dos motores elétricos ao longo dos anos (WEG, 2016)...........31

Figura 14 - Massa e potência dos diferentes conceitos de motores elétricos presentes no mercado...............32

Figura 15 - Schaeffler "hub drive" (Fischer, 2014) .......................................................................................33

Figura 16 - Comparação das densidades de potência e energia de diversos meios de armazenamento de energia, que podem ser aplicadas aos automóveis (Fuhs, 2009) ..................................................34

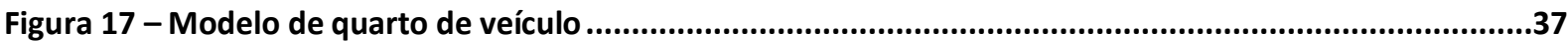

Figura 18 - Frequências naturais do corpo humano (Swedish Road Engineering Division, 2000) .....................39

Figura 19 - Espectro das acelerações de pista para diferentes frequências naturais da massa suspensa

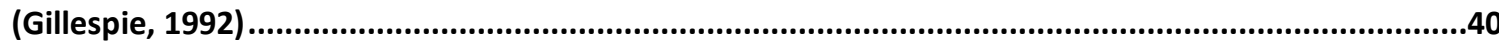

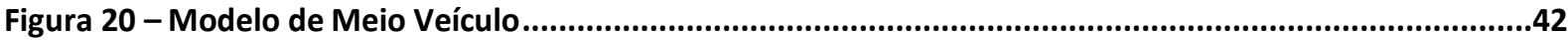

Figura 21 - Definição e nomenclatura das rotações do veiculo (Botosso, 2015) ...........................................42

Figura 22 - Modelo de veículo completo (Yang, et al., 2015) ..................................................................43

Figura 23 - Analise espectral (PSD) dos esforços do Pneu variando a frequência de roda através da alteração da rigidez do pneu traseiro (Yang, et al., 2015), sendo "a" referente ao eixo dianteiro e "b" referente ao eixo traseiro.

Figura 24 - Analise espectral (PSD) dos esforços do Pneu variando a frequência de roda através da alteração da rigidez da suspensão traseira (Yang, et al., 2015), sendo “a” referente ao eixo dianteiro e "b" referente ao eixo traseiro. . .44

Figura 25 - Modelo de meio veículo e suas coordenadas generalizadas .45

Figura 26 - Exemplo de modelo de veículo completo modelado através da técnica de multicorpos (Terra, et al., 2015). 
Figura 27 - Curva dos amortecedores

Figura 28 - Normal mínima dianteira, observada quando do modelo excitado fora de fase entre dianteira e traseira

Figura 29 - Normal mínima dianteira, observada quando do modelo excitado em fase entre dianteira e traseira

Figura 30 - Normal mínima traseira, observada quando do modelo excitado fora de fase entre dianteira e traseira

Figura 31 - Normal mínima traseira, observada quando do modelo excitado em fase entre dianteira e traseira .55

Figura 32 - Aceleração de arfagem, observada quando do modelo excitado fora de fase entre dianteira e traseira

Figura 33 - Aceleração de arfagem, observada quando do modelo excitado em fase entre dianteira e traseira

Figura 34 - Aceleração vertical, observada quando do modelo excitado fora de fase entre dianteira e traseira

Figura 35 - - Aceleração vertical, observada quando do modelo excitado em fase entre dianteira e traseira .58

Figura 36 - Rolagem com pivotamento inferior "Lower Sway"

Figura 37 - Combinação entre movimentos de arfagem e vertical com pivotamento traseiro “Rear end bounce" .60

Figura 38 - Combinação entre movimentos de arfagem e vertical com pivotamento dianteiro “Front end

bounce"

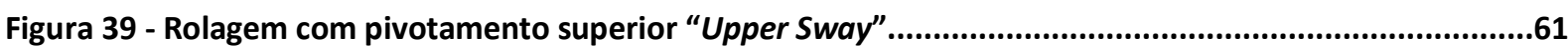

Figura 40 - Movimento vertical da massa não suspensa traseira fora de fase .............................................61

Figura 41 - Movimento vertical da massa não suspensa traseira em fase ..................................................61

Figura 42 - Movimento vertical da massa não suspensa dianteira fora de fase .............................................62

Figura 43 - Movimento vertical da massa não suspensa dianteira em fase .................................................62

Figura 44 - Trajetória descrita durante o veículo na manobra de velocidade constante com esterço incremental.

Figura 45 - Aceleração lateral medida ao longo da manobra de velocidade constante e incremento gradual de esterço

Figura 46 - Coeficiente de subesterço em função da aceleração lateral capturado durante a manobra de raio constante com incremento gradual de velocidade.

Figura 47 - Manobra de troca de faixa .68

Figura 48 - Normal dos pneus dianteiros na manobra de troca de faixa feita a $100 \mathrm{~km} / \mathrm{h}$............................69

Figura 49 - Normal dos pneus traseiros na manobra de troca de faixa feita a $100 \mathrm{~km} / \mathrm{h}$..............................70

Figura 50 - Exemplificação da trajetória da manobra do anzol (HLDI, 2004) ...............................................71

Figura 51 - Ângulo de esterçamento do volante e taxa de rolagem para a manobra do anzol (National

Highway Traffic Safety Administration, 2004) 
Figura 52 - Taxa de rolagem, para os três casos estudados, na manobra do anzol a $120 \mathrm{~km} / \mathrm{h}$.

Figura 53 - Normal dos pneus dianteiros direitos, para os três casos estudados, na manobra do anzol a

$120 \mathrm{~km} / \mathrm{h}$.

Figura 54 - Normal dos pneus dianteiros esquerdos, para os três casos estudados, na manobra do anzol a $120 \mathrm{~km} / \mathrm{h}$.

Figura 55 - Normal dos pneus traseiros direitos, para os três casos estudados, na manobra do anzol a

$120 \mathrm{~km} / \mathrm{h}$.

Figura 56 - Normal dos pneus traseiros esquerdos, para os três casos estudados, na manobra do anzol a $120 \mathrm{~km} / \mathrm{h}$. .76

Figura 57 - Detalhe da força normal do pneu, quando do descolamento do solo, para a roda dianteira direita na manobra do anzol.

Figura 58 - Gráfico da sensibilidade das variáveis de controle em relação aos coeficientes de desempenhos combinados dos eixos dianteiros e traseiros.

Figura 59 - Gráfico da sensibilidade das variáveis de controle em relação ao coeficiente de desempenho do eixo dianteiro

Figura 60 - Gráfico da sensibilidade das variáveis de controle em relação ao coeficiente de desempenho do eixo traseiro. .85

Figura 61 - Comparação do tempo de perda de contato para várias velocidades ..........................................89

Figura 62 - Comparação da força normal mínima para várias velocidades. ...................................................90

Figura 63 - Ângulo de Rolagem do veículo, em suas diversas configurações, durante a manobra do anzol a

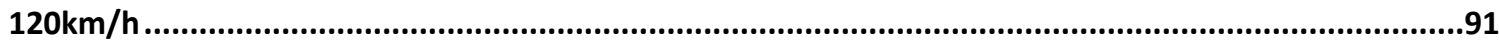

Figura 64 - Modelo de meio veículo em Simulink .............................................................................102 


\section{LISTA DE TABELAS}

Tabela 1 - 'Ride Frequency' recomendado para diversos tipos de carro) (Milliken \& Milliken, 1995).

Tabela 2 - Valores aplicados nos modelos de meio veículo....................................................................47

Tabela 3 - Massas e sua disposição no modelo de meio veículo ................................................................48

Tabela 4 - Massas adotados para os três diferentes casos...........................................................................50

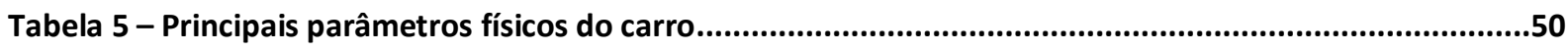

Tabela 6 - Frequências naturais não amortecidas, obtidas através do modelo de um quarto de veículo ........52

Tabela 7 - Resultado comparativo das análises modais ....................................................................59

Tabela 8 - Resultados da Manobra de raio constante e velocidade constante para diferentes acelerações

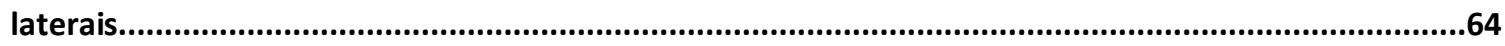

Tabela 9 - Medição da sensibilidade da direção com ajuda da manobra de busca do centro.........................64

Tabela 10 - Máxima aceleração lateral identificada durante a manobra de velocidade constante e incremento gradual de esterço.

Tabela 11 Máxima aceleração lateral identificada durante a manobra raio constante com incremento de velocidade .67

Tabela 12 - Força normal mínima identificada nos eixos através da manobra do anzol.................................77

Tabela 13 - Tempo de levantamento de roda identificado pela manobra do anzol .......................................79

Tabela 14 - Parâmetros de controle e seus níveis .......................................................................................81

Tabela 15 - Matriz ortogonal L18 da formulação de D.O.E. com os seus resultados brutos e normalizados....83

Tabela 16 - Variáveis estudadas em seus níveis para o desempenho ótimo. ................................................86

Tabela 17 - Resultado final da manobra do anzol a $120 \mathrm{~km} / \mathrm{h}$ do veículo com massa acrescida na traseira comparando com sua configuração inicial

Tabela 18 - Resultado final da manobra do anzol a $120 \mathrm{~km} / \mathrm{h}$ do veículo com massa acrescida na traseira comparando com a configuração sem massa acrescida

Tabela 19 - Comparação da Força normal mínima em Newtons entre o carro ótimo e os casos anteriores....88

Tabela 20 - Comparação do tempo de perda de contato em segundos entre o carro ótimo e os casos anteriores. 


\section{Resumo}

A utilização de motores elétricos diretamente nos cubos de roda é uma alternativa de propulsão para um veiculo elétrico ou híbrido muito interessante, pois não necessita do uso de sistemas complexos de transmissão, tornando o conjunto mecânico muito mais simples e, consequentemente, reduzindo a sua massa, atritos e custos.

Entretanto, a adição dos motores nas rodas causa o incremento da massa não suspensa, e isto irá afetar o comportamento de dirigibilidade do veículo. Dessa forma, com ajuda da ferramenta de multicorpos, será identificado o que ocorrerá devido ao acréscimo de massa compatível com os motores elétricos de última geração.

Para isto, uma série de análises comparativas será realizada, com modelos de veículos baseados na técnica de multicorpos, para o caso de um carro de passeio compacto.

Primeiramente, uma análise modal comparando um carro convencional aos carros com a utilização dos motores, no eixo traseiro ou no dianteiro, e uma posterior avaliação das frequências obtidas.

Em sequência, também foram realizadas manobras padrão com o modelo de veículo completo e foram observadas maiores influências nos resultados das análises em regime transiente, como a manobra de troca de faixa e a manobra do anzol ("fishhook"). Com a ajuda destes resultados, foi possível identificar que as instalações dos motores elétricos nos cubos traseiros causam uma menor influência negativa no desempenho de dirigibilidade, quando comparado com o caso instalado no eixo dianteiro.

Através de uma otimização realizada com a ajuda de uma análise de sensibilidade das variáveis do sistema (D.O.E.), baseada na manobra do anzol, foi possível identificar que alterações nas molas, amortecedores e barra estabilizadora são capazes de mitigar os efeitos indesejáveis causados pelo incremento de massa não suspensa. 


\section{Abstract}

The electric motors directly in wheel hubs usage is an alternative of propulsion for a electric or hybrid vehicle, since it does not need the use of complex systems of transmission, making the mechanical assembly simpler and, consequently, reducing its mass, frictions and costs.

However, the addition of the motors in the wheels causes an increase unsprung mass, and this will affect the vehicle handlings behavior. In that way, with the assistance of the multibody tool, it will be identified the consequences of mass addition, compatible with the moderns electric motors of. In this work, a series of comparative analyzes will be carried out, with vehicle models based on multibody techniques, in the situation of a compact car.

First, a modal analysis comparing a conventional car to with the vehicle using hub driven motors, in rear or front axle, and an evaluation of the obtained frequencies.

In the sequence, standard maneuvers were also performed with the complete vehicle model, and greater influences were observed in the transient analysis results, such as lane change and fishhook maneuver. With help of these results, it was possible to identify; that the installation of the electric motors in the rear hubs causes a smaller negative influence on the handling performance when compared to the case installed on the front axle.

Through an optimization performed with the aid of a system variable sensitivity analysis (D.O.E.) based on the fish hook maneuver, it was possible to identify thtat changes on springs, shock absorbers and stabilizer bar are able to mitigate the undesirable effects caused by the increase of unsprung mass. 


\section{Introdução}

O mundo, nos últimos anos, vem abrindo seus olhos sobre a imensa dependência de uma única fonte de energia, oriunda dos combustíveis fósseis.

Alguns setores da sociedade atentam para este fato por causa dos preços instáveis do petróleo, que geram inúmeros transtornos no mundo dos negócios.

Enquanto isso, outra camada da sociedade se preocupa com a possibilidade do aquecimento global decorrente do efeito estufa, gerado pelo nosso modo de vida, alterar drasticamente o planeta chegando ao ponto de pôr em risco a existência humana. Assim, surgiu uma preocupação em reduzir a emissão de gases do efeito estufa revendo a maneira como vivemos, como citado por Al Gore.

"Cada um de nós é uma causa de aquecimento global; mas cada um de nós pode se tornar parte da solução - em nossas decisões sobre o produto que compramos, a eletricidade que usamos, o carro que dirigimos, o nosso estilo de vida. Podemos até fazer opções que reduzam a zero as nossas emissões de carbono." (Gore, 2008)

Há algumas tentativas em curso para amenizar estes problemas. Uma delas, no campo dos transportes, é a criação de veículos energeticamente mais eficientes e com possibilidades de suprirem sua energia através de fontes renováveis.

Os veículos elétricos e híbridos apresentam uma eficiência energética extremamente maior quando comparados com os automóveis convencionais, além da possibilidade de mescla dos modais de energia que utilizam.

Estes carros podem ser carregados com energia elétrica proveniente de diversas fontes alternativas, mesmo que os híbridos possam ter parte da sua motorização a combustão suprida pelos velhos derivados de petróleo (podendo ser substituída por biocombustíveis), só que com um rendimento extremamente maior.

Ao se avaliar os conceitos de carros elétricos e híbridos, há um paradigma que se destaca por sua simplicidade: são os carros com motores elétricos aplicados diretamente nas rodas. Estes carros, também conhecidos como "hub driven" possuem um conceito mecânico extremamente simplificado, sem a necessidade de peças de transmissão, além dos motores independentes possibilitando um eficiente controle da tração e da frenagem (que pode ser regenerativa). 
Entretanto, ao se adicionar o motor nas rodas, um acréscimo da massa não suspensa é gerado, causando efeitos indesejáveis no comportamento dinâmico do carro. Este acréscimo terá influência em dirigibilidade que necessita ser avaliada.

Com ajuda das ferramentas da dinâmica veicular tradicional pode-se avaliar este efeito gerado pelo acréscimo da massa. Com esta avaliação, é possível fazer uma comparação com o desempenho dos carros atuais e mensurar o quão diferente ele é.

Uma vez sabendo o real tamanho dos problemas gerados, pode-se readequar a suspensão do veículo com parâmetros diferentes dos utilizados pelos carros atuais, para dessa forma atingir desempenhos mais próximos destes. Assim, torna-se possível utilizar o motor elétrico diretamente nas rodas e, consequentemente, desfrutar de todo o potencial de eficiência energética que este conceito tem para agregar.

\subsection{Histórico}

No século XIX, a mobilidade sofria uma grande expansão. Os trens a vapor já eram uma realidade consolidada. Mas o homem sempre buscava por mais, e o desejo de desenvolver um veículo automotor com capacidade de andar por diversos lugares sem a necessidade de trilhos e nem de tração animal levou o homem a inventar o Automóvel.

Um dos primeiros automóveis de que se tem notícia foi apresentado e patenteado na Alemanha em 1886 por Karl Benz, com o nome de Benz PatentMotorwagen, Patente № 37435, (Benz, K., 1886). Este carro era movido por um motor traseiro, monocilíndrico, a combustão, 4 tempos, 0,954cc e capacidade de gerar 550W. É considerado o pai do carro moderno e o início de uma corrida tecnológica protagonizada por alemães, franceses, ingleses e norte-americanos.

Entretanto, a força motriz dos veículos nessa época não era um paradigma fechado. Existia outro conceito que era considerado: o motor elétrico. Já se utilizava esta opção para locomotivas e bondes e, naturalmente, este conceito também foi considerado para os veículos de menor porte unipessoais e multipessoais.

Também em 1886, o luxemburguês Henri Tudor criou o processo industrial capaz de produzir em larga escala as baterias de chumbo ácido, que possuem a capacidade de se recarregar e ainda tem relações de energia, volume e massa 
compatíveis com os veículos da época, abrindo caminho para que se pudessem fazer carros elétricos.

Em 1888, a empresa sediada em Londres "Immisch \& Company", a pedido do Sultão do Império Otomano, construiu uma carruagem movida por um motor elétrico alimentado por baterias, sendo um dos primeiros carros elétricos de que se tem notícia.

No ano de 1898, o recorde de carro mais veloz do mundo foi alcançado por um veículo elétrico. O automóvel "Duc Profilée”, construído pelo extinto fabricante francês "Jeantaud (1893-1906)", atingiu a incrível marca de 66 km/h (Figura 1).

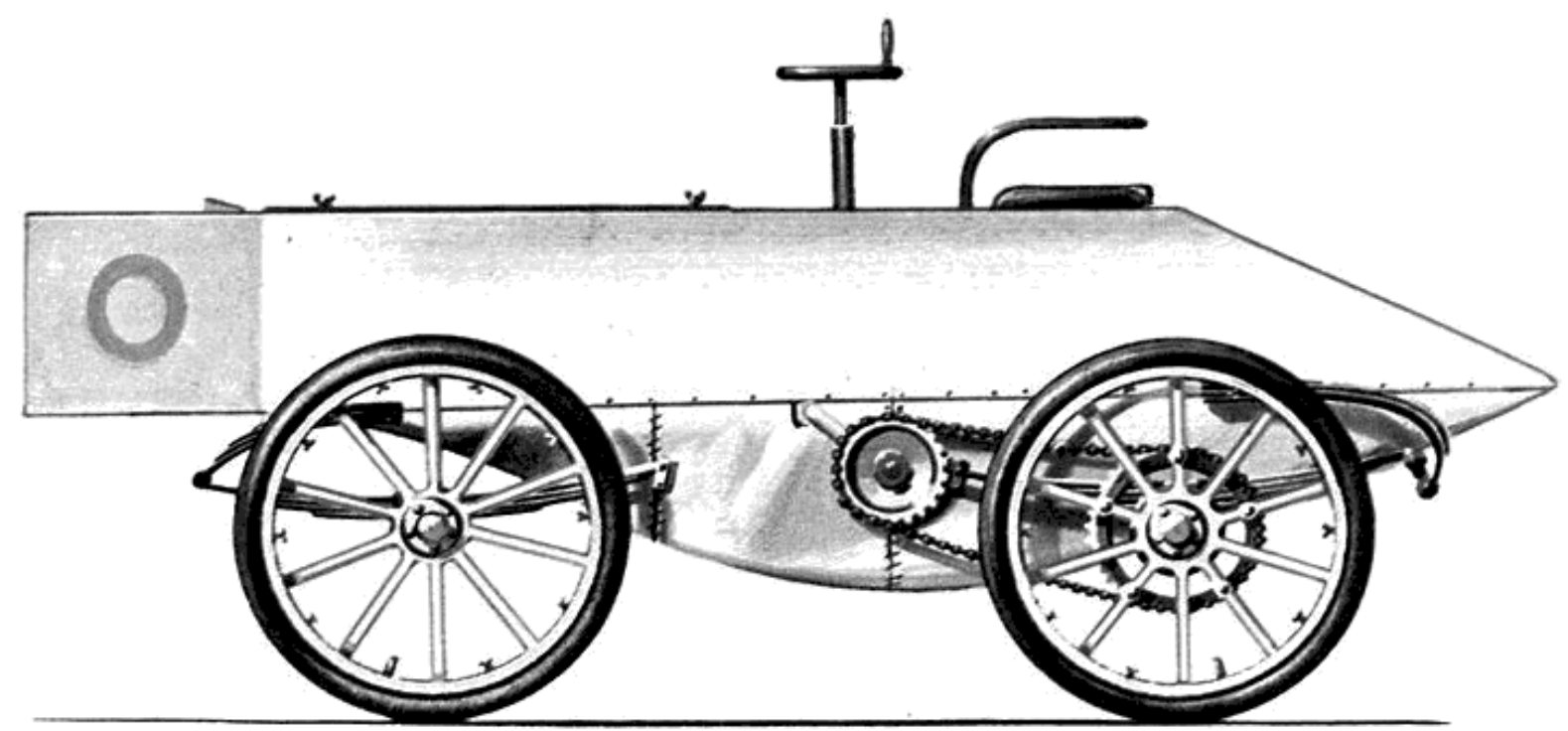

Figura 1- Jeantaud Duc Profilée (Car Blues print, s.d.)

Também em 1898, o lendário austríaco Ferdinand Porsche, sendo mais tarde conhecido pela criação do Volkswagen Fusca, constrói o primeiro veículo híbrido. Neste automóvel, um motor a combustão interna gera energia para carregar as baterias do carro C2 Phaeton, também conhecido como P01. As baterias, por sua vez, alimentam os quatro motores elétricos que estavam instalados um em cada roda, sendo o primeiro carro com os motores elétricos aplicados diretamente nas rodas, também conhecidos como motores de cubo.

O Porsche C2 Phaeton era capaz de percorrer $65 \mathrm{~km}$ com uma velocidade máxima de $56 \mathrm{~km} / \mathrm{h}$, sendo o vencedor de várias corridas na época, como o Rali de Exelberg em 1901. Hoje, o P01 encontra-se exposto no museu da Porsche em Stuttgart, na Alemanha (Figura 2 e Figura 3) 


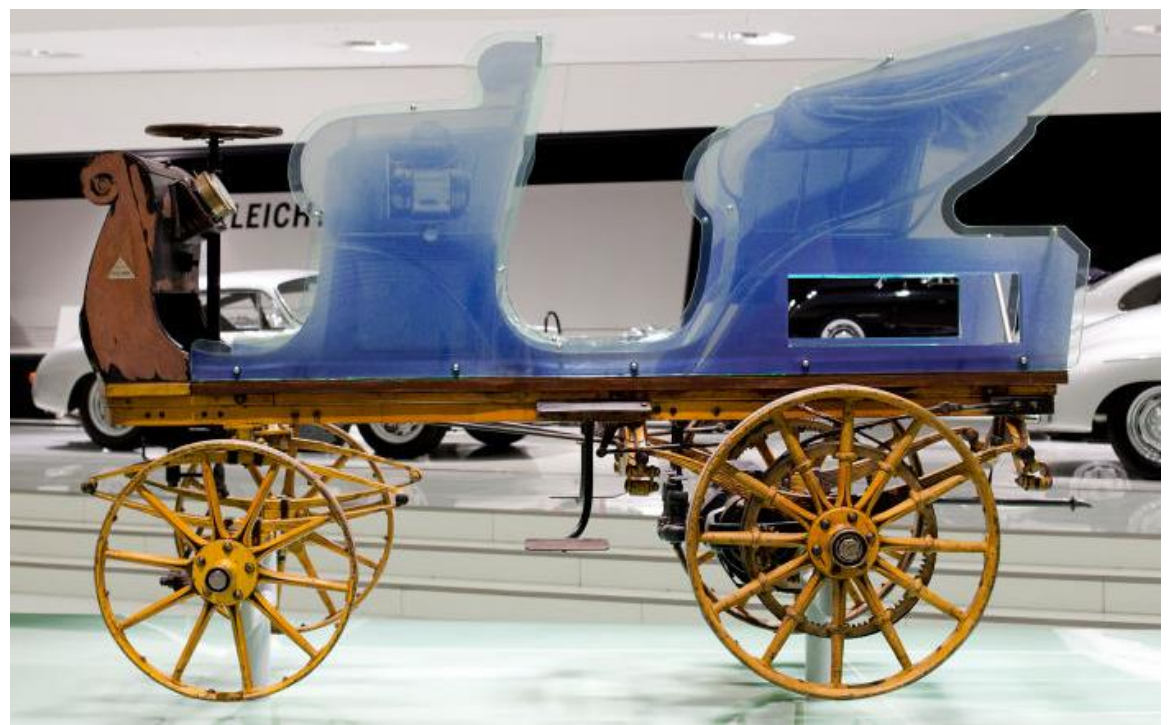

Figura 2 - Porsche C2 Phaeton exposto no museu da Porsche na Alemanha (Jalopnik, s.d.)

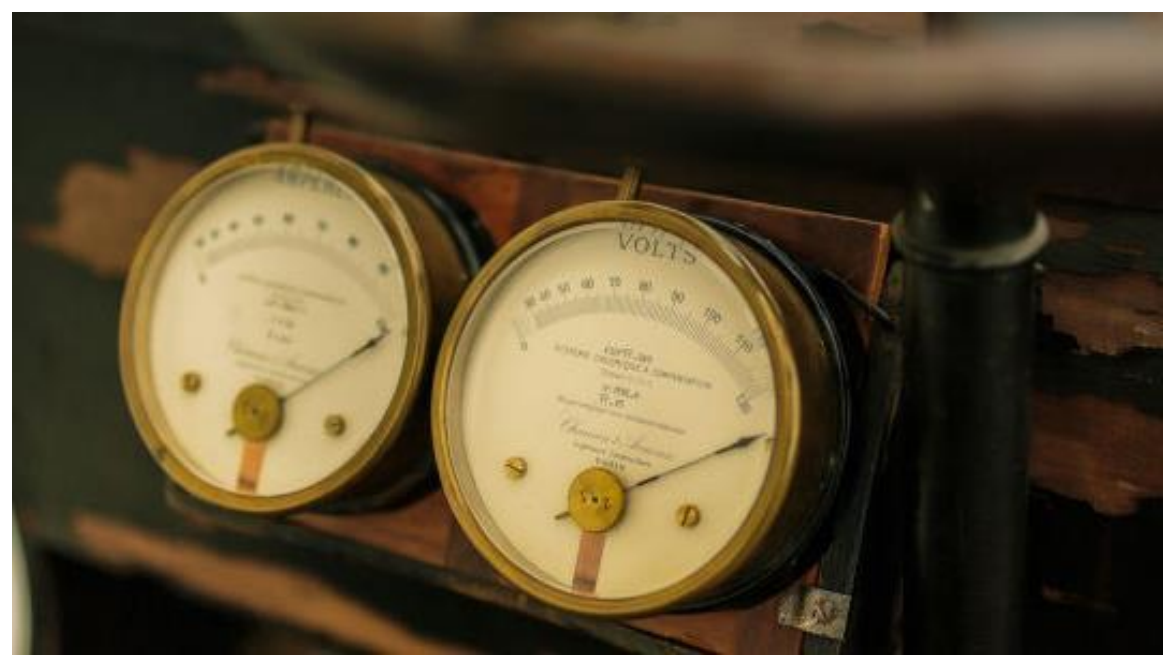

Figura 3 - Detalhe C2 Phaeton (Jalopnik, s.d.)

Em 1899, o sueco Waldemar Jungner inventou a bateria de Níquel Cádmio e, em 1903, o grande inventor estadunidense Thomas Edison (mundialmente conhecido por viabilizar a lâmpada elétrica) apresenta ao mundo as baterias de Níquel-Ferro. Estas novas baterias possibilitaram uma maior autonomia dos veículos elétricos, evoluindo-os e os colocando como uma opção extremamente viável do ponto de vista técnico.

E assim, os desenvolvimentos das tecnologias de veículos elétricos, a combustão e híbridos, caminharam simultaneamente durante o final do século XIX e início do século XX. 
Em 1900, a "Electric Vehicle Company", fundada em 1897, sediada nos Estados Unidos da América e fabricante exclusivamente de automóveis elétricos, era a maior fornecedora de táxis para o seu país natal.

No dia 23 de novembro de 1905, o engenheiro americano H. Piper deu entrada na patente de um veículo híbrido, que utilizaria o motor elétrico paralelamente ao motor de combustão interna, com a finalidade de melhorar o desempenho do veículo. Até então, os carros da época alcançavam $40 \mathrm{~km} / \mathrm{h}$ em cerca de 30 segundos. Este novo conceito possibilitou uma queda neste tempo para 10 segundos. A patente demorou cerca de 3 anos e meio para ser aprovada e, neste período, os motores a gasolina evoluíram de forma a atender este critério de performance sem o auxílio do motor elétrico. Entretanto, alguns veículos experimentais foram construídos nesse espaço de tempo. Eles se encontram expostos no museu da Ford, na cidade estadunidense de Deaborn, no estado de Michigan (Jedicke, 2001).

Em 1907, nos Estados Unidos da América, é fundada a "Detroit Electric", que produziu cerca de 13 mil carros elétricos entre 1907 e 1939, quando encerrou suas atividades.

Em 1908, a montadora de automóveis Ford inicia a produção em massa do Ford $\mathrm{T}$, com o intuito de ser o primeiro carro comercializado a um preço acessível à classe média estadunidense. O Ford T era movido por um motor a gasolina.

Em 1914 a canadense "Galt Motor company", disponibilizava no mercado o "Woods Gasoline-Electric", que era um carro hibrido com capacidade de rodar $100 \mathrm{~km}$ com 4litros de gasolina, o que é um desempenho comparável com os automóveis modernos (Anderson \& Anderson, 2005). Porém, devido à sua maior complexidade técnica e maior quantidade de subsistemas, os veículos híbridos apresentavam um preço consideravelmente maior quando comparados aos outros conceitos de sua época (Wakefield, 1998). 


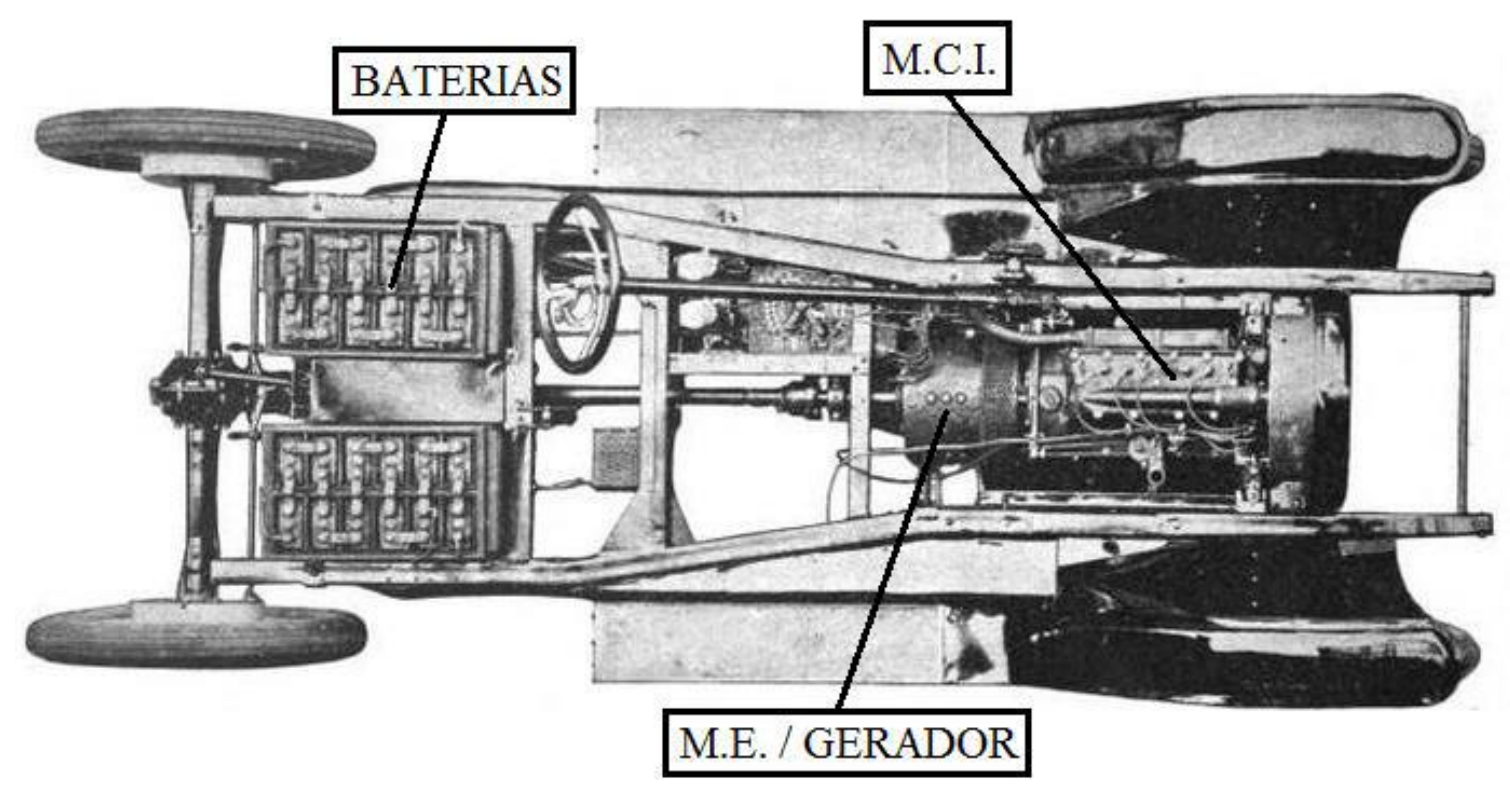

Figura 4 - “Woods gasoline-electric” (Bravo, 2016)

Na década de 1920, havia grande disponibilidade de gasolina a baixo custo, especialmente nos Estados Unidos da América, e este fator, aliado à maior autonomia dos veículos a combustão e às novas tecnologias, como a partida elétrica e o seus custos mais favoráveis, colocaram os carros elétricos em segundo plano. O Ford T era um grande sucesso de vendas. Para se ter idéia, foram comercializadas mais de 15 milhões de unidades entre os anos de 1908 e 1927.

Nos anos subsequentes, houve grande evolução nos motores a combustão, melhorando o seu desempenho, confiabilidade e facilidade de operação, deixando assim os veículos automotores elétricos e híbridos esquecidos por vários anos.

Em 1973 e em 1979, o preço do petróleo sofreu grandes aumentos devido a guerras, crises políticas e a cartelização promovida pelos países árabes. Com isso, o mundo começou a procurar por fontes alternativas à gasolina e ao diesel, que eram predominantemente utilizados na época. Neste período, a produção de veículos elétricos e híbridos foi vista como uma solução.

Àquela época, no entanto, as tecnologias disponíveis para os motores elétricos e híbridos não possibilitavam chegar a níveis de desempenho e custos minimamente próximos aos carros de motor a combustão interna. Porém, o interesse foi novamente despertado e retomou-se 0 desenvolvimento desta tecnologia com estudos acadêmicos, a produção de automóveis experimentais e alguns lançamentos comerciais pouco relevantes. 
Em 1974 a montadora brasileira de Rio Claro, Gurgel Motores, lança um veículo elétrico no mercado brasileiro: o Gurgel Itaipu E150 (Figura 5). Este veículo era destinado para o uso urbano e tinha capacidade para dois passageiros. Ele utilizava baterias de chumbo ácido que podiam ser recarregadas em uma simples tomada doméstica. Com apenas $780 \mathrm{~kg}$ e um motor de $4 \mathrm{hp}$, o seu desempenho estava bem aquém dos veículos da época, com uma velocidade máxima de $50 \mathrm{~km} / \mathrm{h}$ e autonomia máxima de 60 km a 80 km, não obtendo êxito comercial.

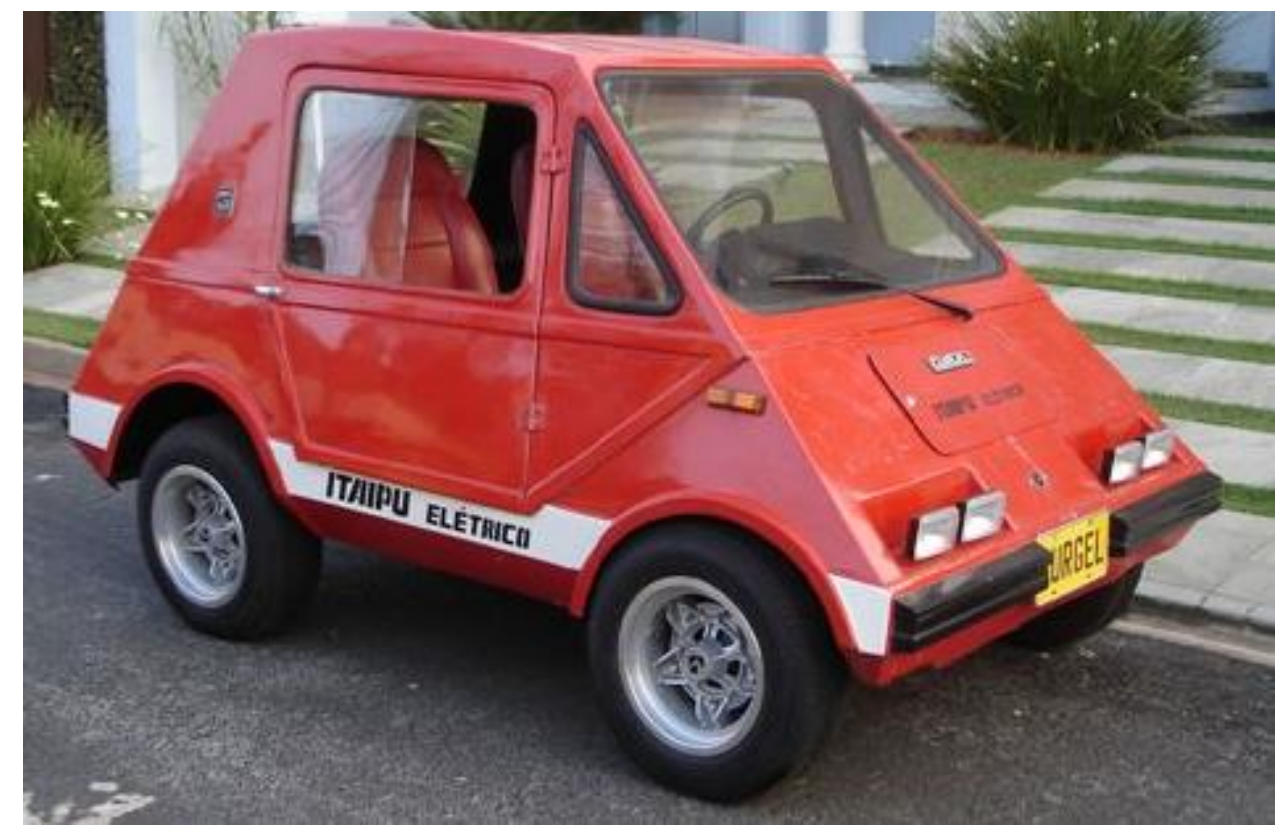

Figura 5 - Gurgel Itaipu E-150 (Fórum do carro antigo, s.d.)

Em 1980, numa nova tentativa, a montadora Gurgel Motores lança o Gurgel Itaipu E400 (Figura 6), um pequeno furgão puramente elétrico, sendo lançada também uma versão com caçamba aberta, destinada ao transporte de pequenas cargas a curtas distâncias no ambiente urbano. Novamente, o desempenho não era animador: o seu motor de $11 \mathrm{hp} \mathrm{não} \mathrm{era} \mathrm{o} \mathrm{suficiente} \mathrm{para} \mathrm{os} \mathrm{seus} 1470 \mathrm{~kg}$, mas o desempenho era um pouco melhor do que seu irmão menor, o Gurgel Itaipu E-150, quanto a sua autonomia. Ele tinha como velocidade máxima, limitada eletronicamente em $45 \mathrm{~km} / \mathrm{h}$; a sua autonomia um pouco maior, de $80 \mathrm{~km}$ até $100 \mathrm{~km}$, não foi suficiente para render à fabricante de carros tupiniquim um sucesso de vendas. 


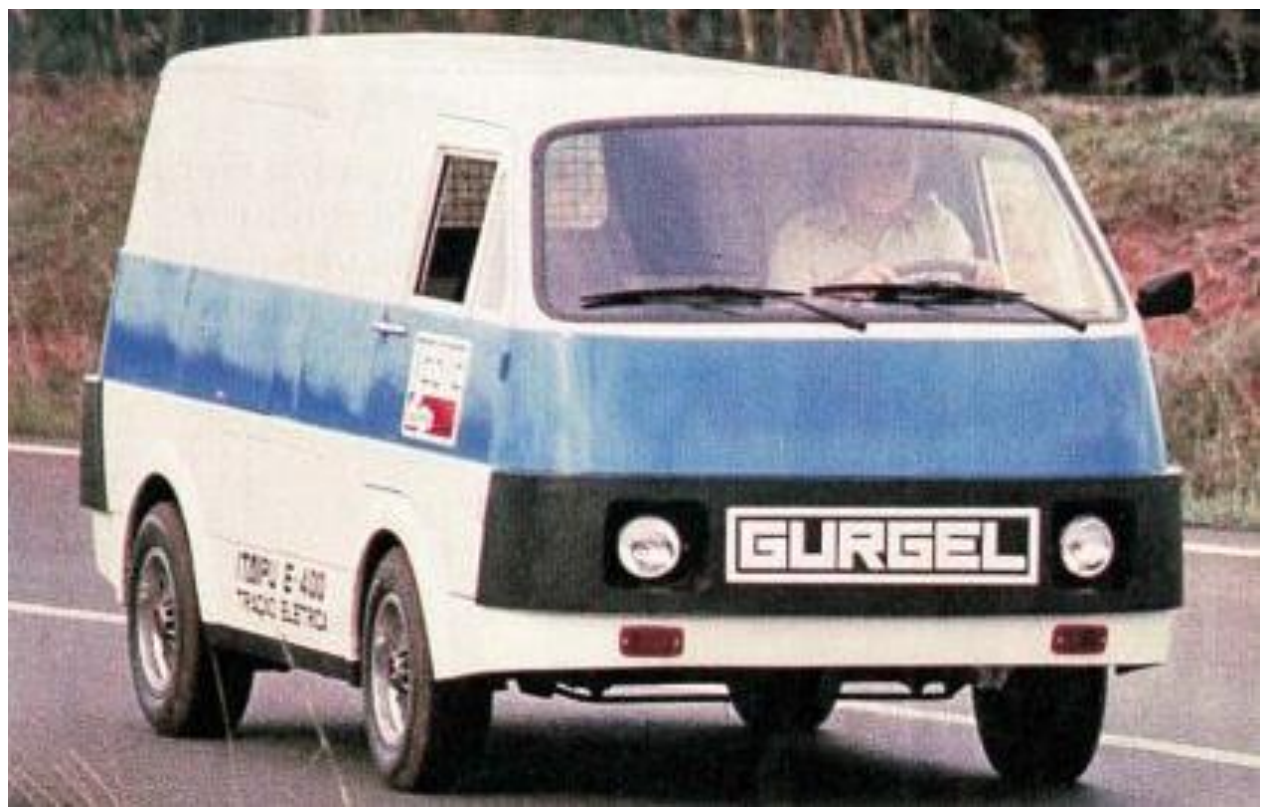

Figura 6 - Gurgel Itaipu E- 400 (Gurgel 800, s.d.)

Em 1988, Roger Smith, o CEO da montadora norte americana General Motors, anuncia um grande esforço em pesquisa para se criar um automóvel elétrico.

Em 1996, a General Motors lança o primeiro carro puramente elétrico de nova Geração: o "coupé" EV1. Este automóvel possuía desempenho plenamente compatível com os veículos da época, tinha $1319 \mathrm{~kg}$ de massa, um motor de $137 \mathrm{hp}$, aceleração de 0 a $80 \mathrm{~km} / \mathrm{h}$ em $6.3 \mathrm{~s}$, velocidade máxima limitada eletronicamente de $128 \mathrm{~km} / \mathrm{h}$ e câmbio automático.

O EV1 (Figura 7) trazia uma infinidade de soluções de engenharia para reduzir a sua massa, arrasto aerodinâmico e resistência à rolagem, obtendo assim, em uma única carga, a autonomia de até $160 \mathrm{~km}$ em sua primeira geração, com baterias de chumbo ácido, e de $225 \mathrm{~km}$ em sua segunda geração, já equipada com baterias de Níquel Cádmio. Mas devido a seu alto custo, complexidade de manutenção e desinteresses públicos e políticos, o EV1 foi retirado de produção em 1999 com 1117 unidades produzidas (Fuhs, 2009). 


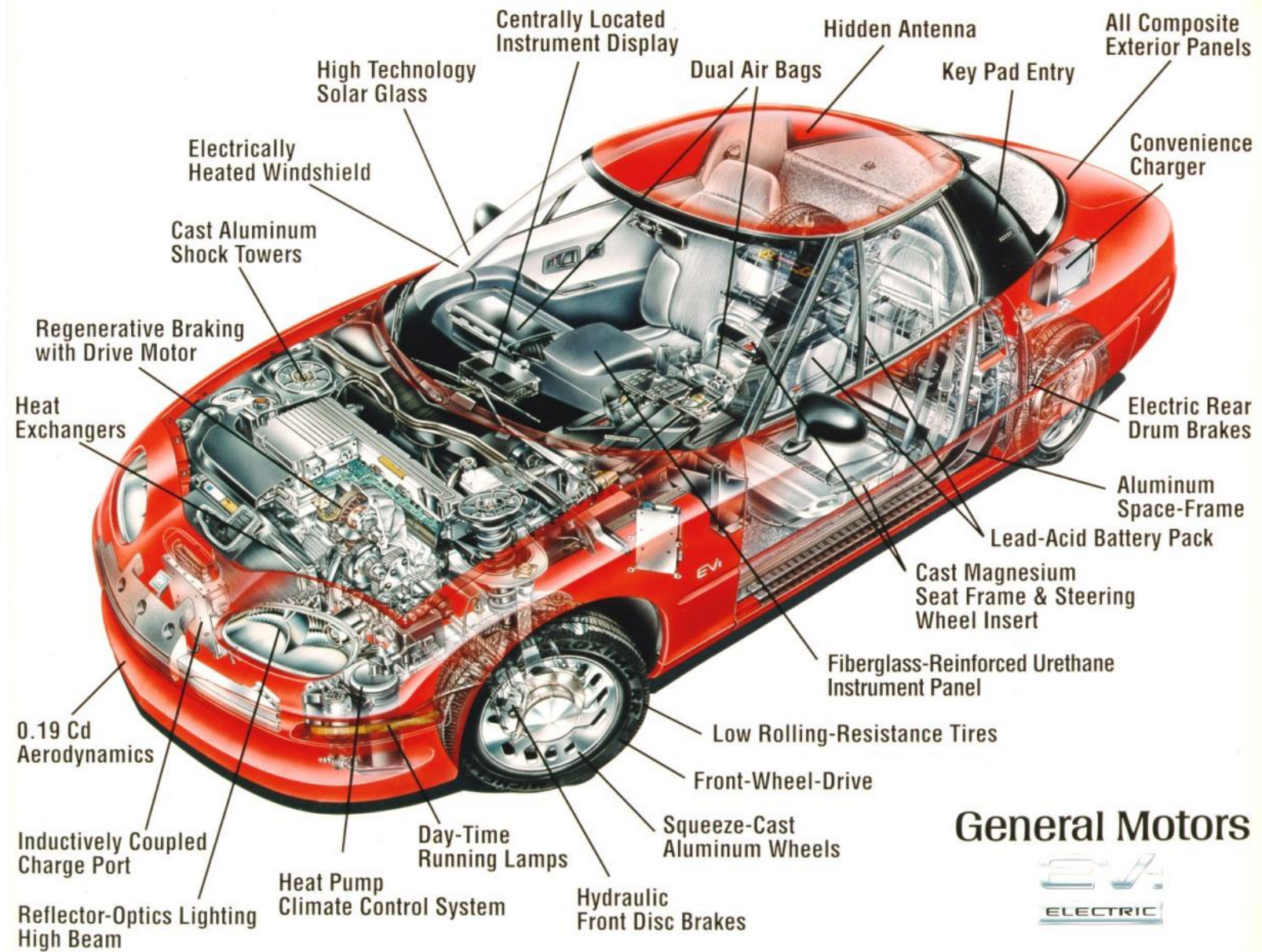

Figura 7 - Saturn EV1 (West Hills Collision Center, s.d.)

Em 1997, a montadora nipônica Toyota anuncia a produção em massa do automóvel Prius, que era movido com a ajuda de um trem de potência híbrido e desempenho plenamente compatível com os automóveis de sua época. Este carro é um grande sucesso, tendo vendido cerca de 18mil unidades apenas em seu primeiro ano. Graças ao interesse do público, ele continua em linha, passando por atualizações. Atualmente em sua quarta geração, o carro hibrido da Toyota continua alcançando resultados comerciais extremamente positivos (Figura 8). 


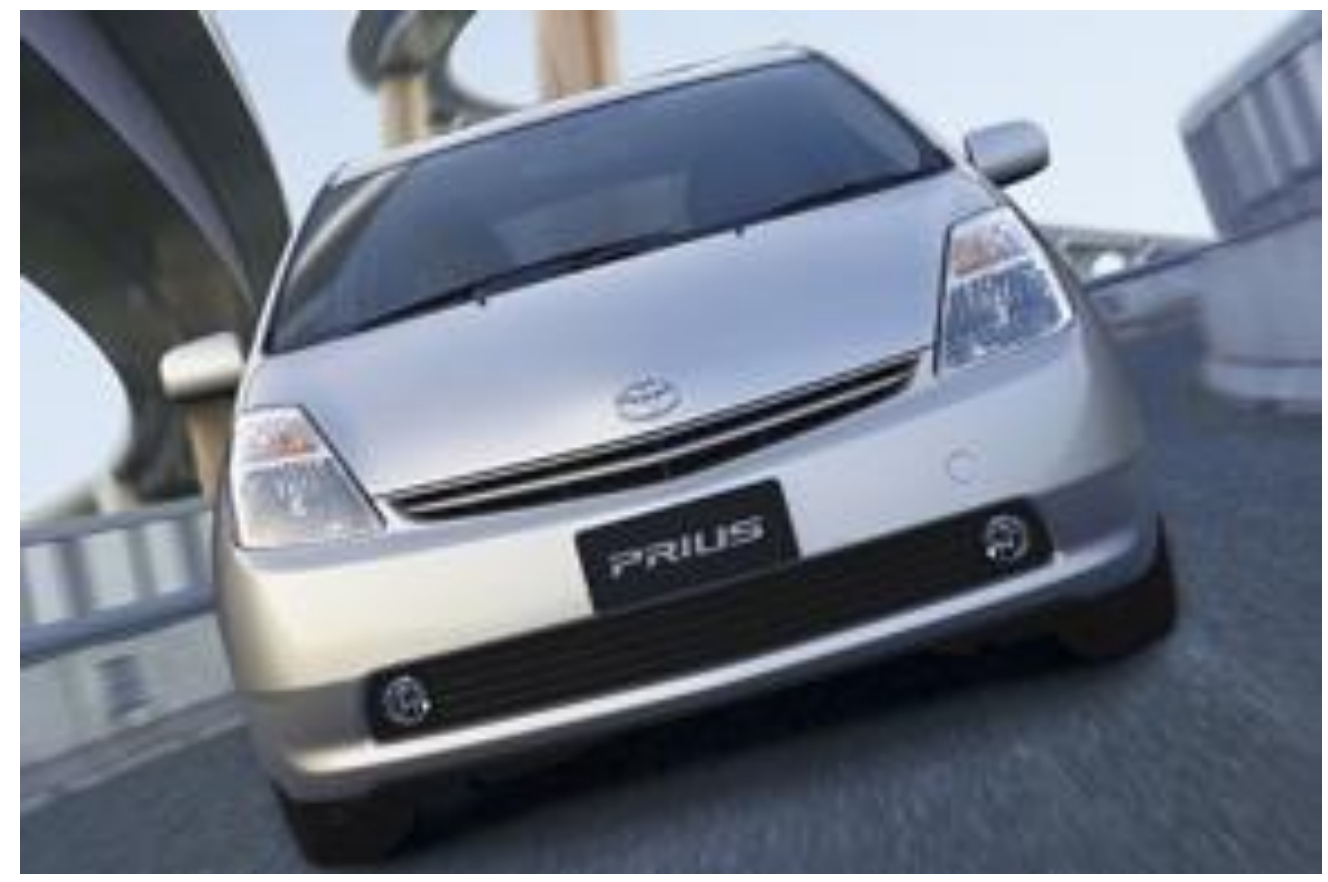

Figura 8 - Toyota Prius 1997 (Toyota, 2016).

Nos anos 2000, o interesse do consumidor em veículos elétricos e híbridos cresceu substancialmente, impulsionado pela alta do preço do petróleo e os problemas ambientais decorrentes dos gases de efeito estufa. Adicionalmente, pelos mesmos motivos, alguns países começaram a incentivar este tipo de veículo de maneira oficial, com redução de impostos, aumento do fomento à pesquisa e até mesmo subsídios para a sua produção, especialmente nos países da União Europeia. Com isso, várias montadoras começaram a investir neste tipo de automóvel, promovendo o seu desenvolvimento tecnológico.

A partir de outubro de 2015, o governo federal brasileiro, acompanhando a tendência adotada pelos países europeus e Estados Unidos, lança um pacote de estímulos fiscais para os automóveis elétricos e híbridos, sendo que os automóveis puramente elétricos terão isenção nos impostos de importação ou produção (Conhecido como IPI) e, no caso dos híbridos, a alíquota pode variar da isenção até $7 \%$ de imposto, dependendo da cilindrada de seu motor a combustão e sua eficiência energética, como maneira de incentivar o consumidor brasileiro a adotar este tipo de veículo.

Em 19 de junho de 2016 um veículo hibrido da marca Porsche (Figura 9) venceu a tradicional corrida das 24 horas de Le Mans, coroando a tecnologia não só como sinônimo de eficiência energética, mas também como de alta performance, sendo capaz de acelerar de 0 a $96 \mathrm{~km} / \mathrm{h}$ em apenas 2,2s. 


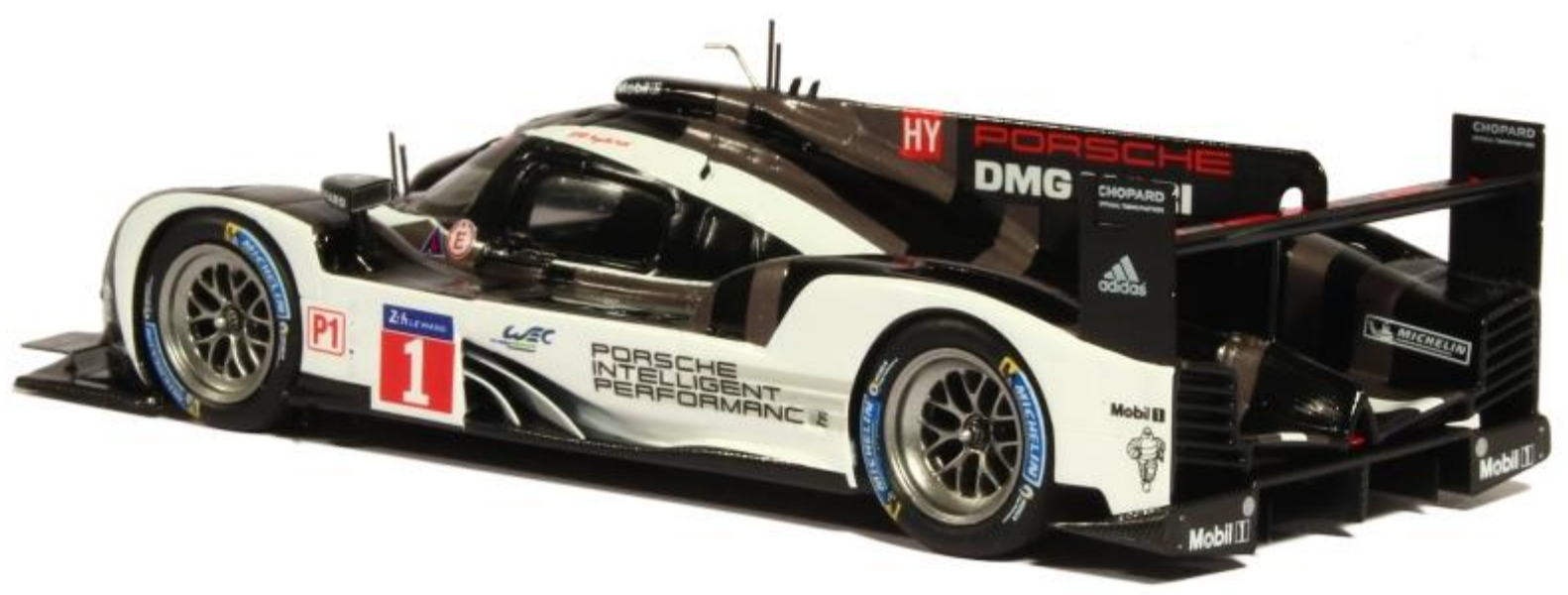

Figura 9 - Porsche 919 Hybrid (Porsche, 2016)

Também em junho de 2016, o Vice-Ministro da Economia da Alemanha, Rainer Blake, anunciou que os carros produzidos a partir de 2030 deverão ser livres de emissão de poluentes, o que na prática irá inviabilizar os veículos movidos puramente com motores a combustão. Adicionalmente, há a meta de que até 2020 , com ajuda de subsídios e isenção de impostos, ao menos $40 \%$ da frota Alemã seja composta por veículos elétricos ou híbridos (Quatro Rodas, 2016).

Sendo assim, produzir automóveis elétricos e híbridos com um desempenho igual ou superior ao dos veículos a combustão vai ser um dos grandes desafios da mobilidade, juntamente à popularização dos sistemas de carros compartilhados e com a introdução dos sistemas autônomos de condução.

Essas três novas vertentes prometem revolucionar a maneira como vemos 0 carro no século 21 , fazendo-o se tornar parte da solução de vários problemas que enfrentamos na atualidade, principalmente nas grandes metrópoles, tais como trânsito caótico, engarrafamentos, falta de lugares para estacionamento, poluição atmosférica e sonora, abuso de combustíveis fósseis e saturação dos sistemas de transporte público. 


\section{Motivação}

\subsection{Impacto sócio econômico e ambiental}

O crescimento sustentável da economia mundial é um dos maiores desafios do século XXI. A questão principal é garantir que a economia global continue em expansão, a fim de incorporar o crescimento de países ainda em desenvolvimento, e garantir que as suas populações tenham acesso aos mesmos recursos que os países desenvolvidos já desfrutam, sem que, com isso, o planeta entre em colapso ambiental.

No entanto, o desenvolvimento tecnológico esbarra, infalivelmente, nos limites dos recursos naturais do planeta Terra. Num planeta com quase sete bilhões de habitantes e com o crescimento econômico de nações de grande densidade populacional, como a China e a Índia, cujas economias crescem vigorosamente há alguns anos, não é possível que se mantenha o mesmo padrão de consumo que as nações desenvolvidas atingiram no século XX.

O aquecimento global (Figura 10) é um dos grandes impactos da expansão das atividades humanas. Grande parte desse aquecimento global é causada por gases oriundos da queima de combustível fóssil pela indústria e modais de transporte, este efeito de aquecimento decorrente da emissão de gases é também conhecido como efeito estufa. 


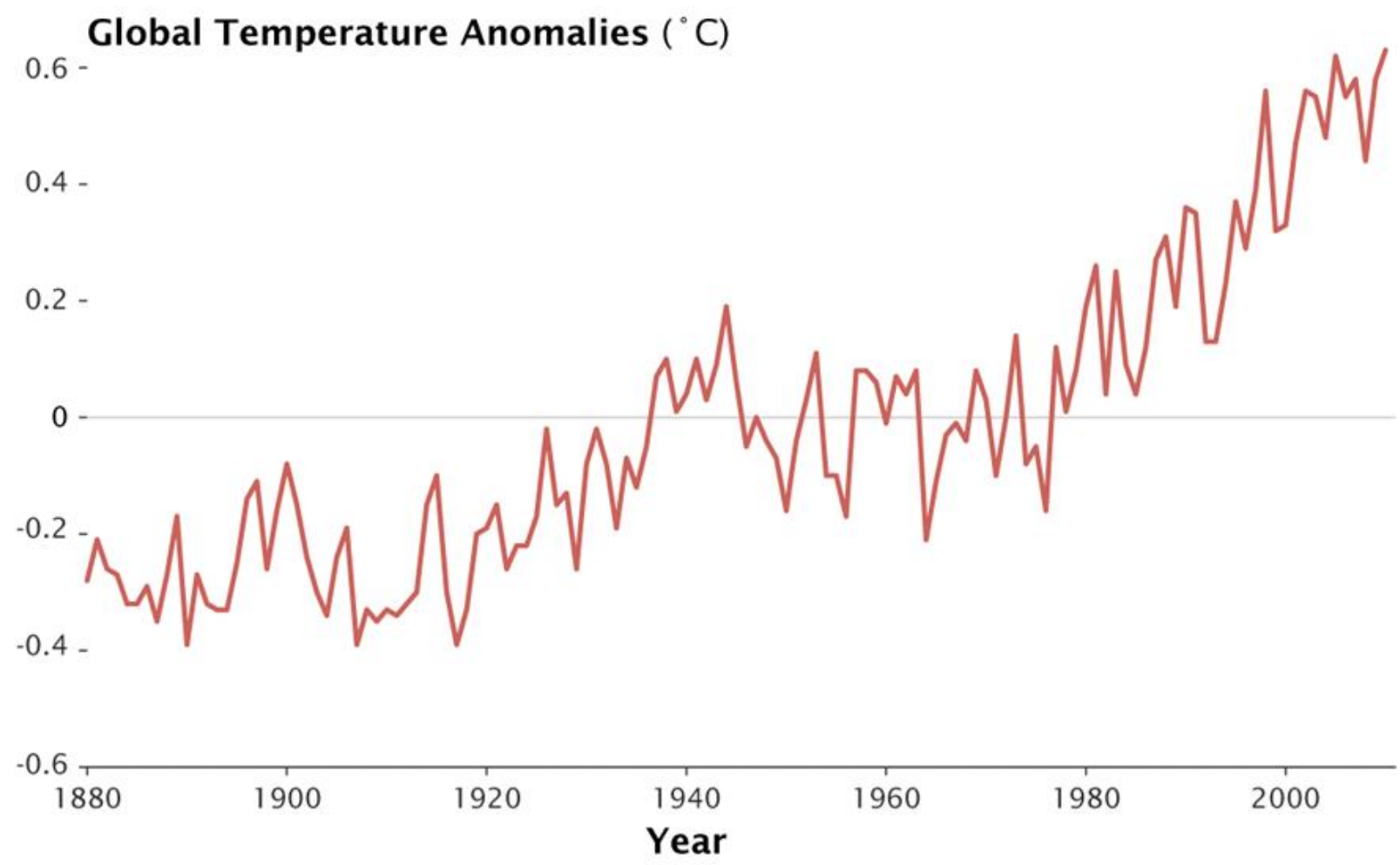

Figura 10 - Variação da temperatura média global levando em consideração como marco zero o ano de 1951 (NASA, 2011)

Além do dano ambiental causado pela queima dos combustíveis fósseis, existe o fato de haver um estoque limitado de petróleo no globo e os seus preços serem historicamente instáveis. Mesmo estando em um momento de baixa nos preços do petróleo no ano de 2017, historicamente seus valores são altos (Figura 11), tendo um peso considerável na economia. Além disso, seus maiores produtores estão em zonas politicamente instáveis, como a Venezuela e países do Oriente Médio.

Portanto, veículos mais eficientes e que consumam menos combustíveis possuem a possibilidade de serem economicamente viáveis, desde que seus custos equivalham aos de veículos a combustão tradicionais. 
Crude oil prices 1861-2014

US dollars per barrel

World events

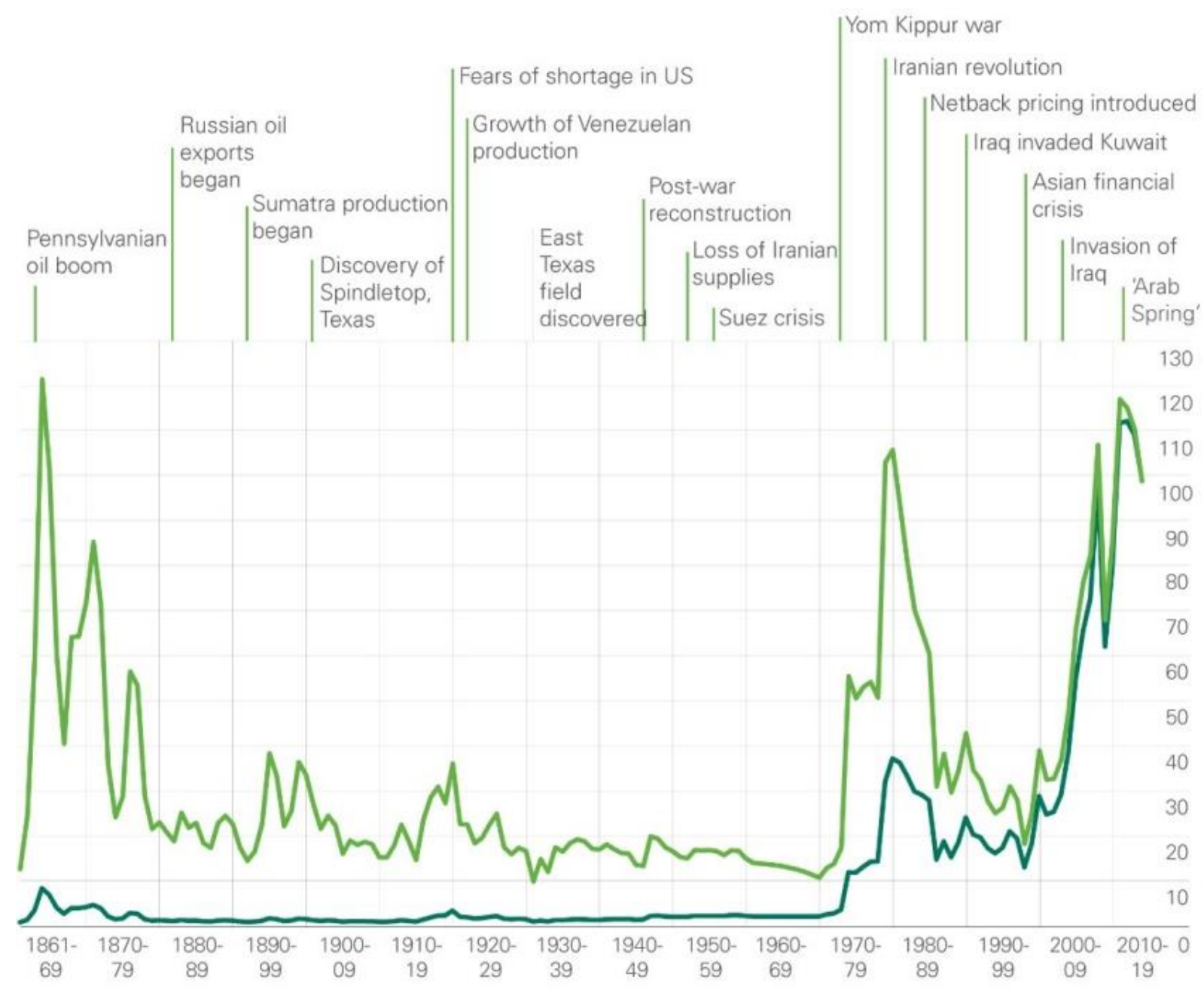

1861-1944 US average.

$\$ 2014$

1945-1983 Arabian Light posted as Ras Tanura.

1984-2014 Brent dated.

$\$$ money of the day

BP Statistical Review of World Energy 2015

(C) 2015 BP p.I.c.

Figura 11 - Preço médio do barril do petróleo e acontecimentos históricos ao longo dos últimos 150 anos (BP, 2015)

Com o fato de o carro atual ter um rendimento muito baixo do ponto de vista energético, Ricardo Abramovay cita o trabalho de Amory Lovins sobre a ineficiência energética dos veículos a combustão. 
"Da energia do combustível que ele consome, ao menos $80 \%$ é perdida, principalmente no aquecimento do motor e no escapamento, ou seja, $20 \%$ é realmente usada para girar as rodas. Do que resta, 95\% move os carros e apenas $5 \%$ os motoristas, proporcionalmente a seus respectivos pesos. Cinco por cento de $20 \%$ são iguais a $1 \%$, um resultado não muito gratificante para os carros americanos, que queimam seu próprio peso em gasolina a cada ano." (ABRAMOVAY, 2012 apud LOVINS, LOVINS e HAWKEN, 1999).

Portanto uma saída para amenizar os problemas decorrentes dos gases do efeito estufa é tornar os veículos automotores mais eficientes. Os automóveis elétricos e híbridos apresentam um rendimento energético consideravelmente maior quando comparado aos veículos movidos a um motor a combustão tradicional. Além do aumento de eficiência, a energia elétrica que carrega as baterias que pode vir de inúmeras fontes, entre elas fontes renováveis de energia, como a energia eólica e a hidroelétrica.

Adicionalmente, eles representariam uma redução considerável da poluição do ar em ambiente urbano, o que o torna de interesse público. O uso deste modal de automóvel representaria um aumento da qualidade de vida para a população e uma economia para os cofres públicos, visto que, apenas na região metropolitana de São Paulo gasta-se cerca de 300 milhões de dólares anualmente em tratamentos médicos de enfermidades decorrentes da má qualidade do ar (Bravo, et al., 2014).

Sendo assim a alternativa dos veículos elétricos e híbridos é uma opção para melhorar o panorama energético mundial, aumentando a sua eficiência energética e reduzindo as emissões de poluentes, sem perder a comodidade fornecida por um automóvel, indo de acordo com as ideias de Azevedo e Goldenstein, que dizem que é possível através da mudança do consumo melhorar o cenário energético sem haver perda de qualidade de vida.

"Deve-se observar que a redução (ou diminuição do crescimento) dos impactos ambientais causados pelo uso intensivo das fontes não renováveis de energia, não se considerando qualquer perda na qualidade de vida alcançada com sua utilização, pode ser obtida através de ações do lado do consumo, pelo uso mais eficiente desta energia, e do lado da oferta, pelo aumento percentual da participação das fontes renováveis de energia. 
Evidentemente que os melhores resultados advirão da implementação simultânea destas duas abordagens." (Azevedo \& Goldenstein, 2006)

Desta maneira, utilizá-los representaria um ganho para a sociedade. Mas para isso acontecer, este paradigma de automóvel tem que ser desenvolvido a ponto de ter tanto um desempenho quanto um custo, similares ou melhores do que os automóveis atuais. Portanto, desenvolvê-lo tecnologicamente pode ser a chave para um futuro mais sustentável.

\subsection{Evolução tecnológica}

Dentro do paradigma de veículos elétricos e híbridos existem inúmeras configurações de motores e sistemas de transmissão, cada qual com suas características específicas descritas na norma J1715 (SAE, 2014). Cada uma delas possui vantagens e desvantagens em relação às demais.

Entre os inúmeros tipos de configuração de veículos elétricos e híbridos, existe uma que chama a atenção por sua simplicidade mecânica e o grande potencial de eficiência energética que é a configuração onde os motores elétricos são montados diretamente nas rodas.

Este conceito utiliza os motores diretamente nas rodas, simplificando o projeto mecânico e retirando a necessidade de eixos, mancais e caixas de transmissão. A retirada destes componentes aumenta a sua eficiência energética pelo fato de reduzir a massa do veículo e reduzir inércias rotativas e atritos além das perdas causadas pelo simples acoplamento diferenciais e caixas de transmissão (Momoh \& Omoigui, 2009).

Além do que, esta tecnologia possibilita o uso de frenagem regenerativa sem auxílio dos sistemas de freios convencionais, não regenerativos, aumentando consideravelmente a sua eficiência energética (Bravo, 2016). O fato de se ter um motor por cada roda possibilita que, através de um sistema de controle dos torques, o diferencial seja substituído por um sistema eletrônico, além da possibilidade de se utilizar o torque vetorizado como forma de se ter controles de tração e estabilidade extremamente eficientes. 
Adicionalmente, este conceito possibilita a conversão de veículos já produzidos em híbridos com um baixo nível de modificação (Gupte, 2015). Isto possibilitaria para a indústria oferecer a opção de motorização híbrida em veículos que poderiam ter ou não este conceito, sem a necessidade do desenvolvimento de uma arquitetura exclusiva, possibilitando ganhos de escala.

Apesar das grandes vantagens de se utilizar os motores elétricos diretamente nas rodas, tecnologia também conhecida pelo nome em inglês "hub driven", há uma desvantagem. Com este tipo de construção, mesmo culminando em uma redução da massa total do veículo, há um aumento da porção conhecida como massa não suspensa.

A massa não suspensa é o conjunto de peças que estão localizadas entre a carroceria e o solo (Figura 12). Como exemplo, as rodas, pneus, amortecedores, molas, discos e pinças de freio, entre outros, fazem parte deste conjunto. Ao se adicionar mais um componente a este conjunto, o incremento de massa do mesmo é inevitável.

\section{Massa \\ Suspensa}
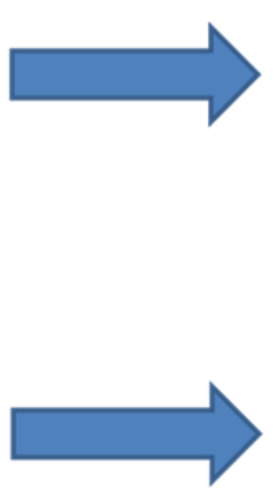
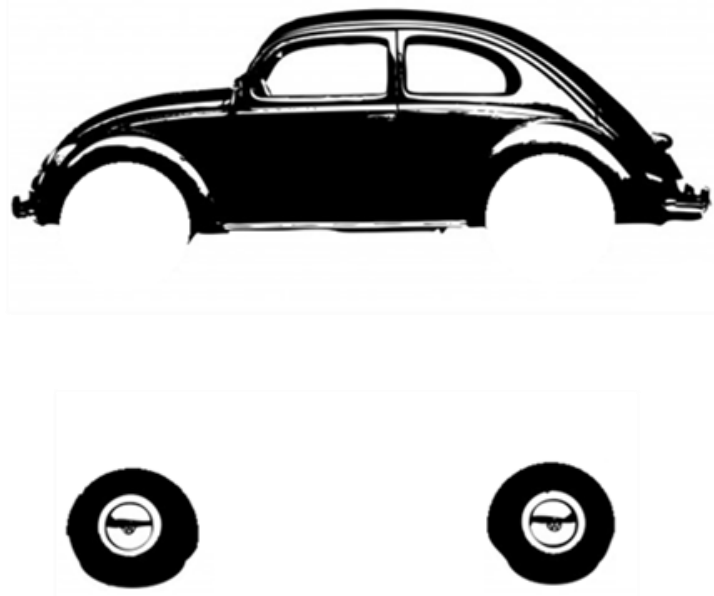

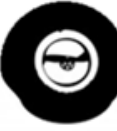

Figura 12 - Exemplificação das massas suspensas e não suspensas

O incremento desta massa gera efeitos indesejados no comportamento de dirigibilidade e conforto do automóvel, prejudicando especialmente a sua capacidade de copiar o perfil do solo. Com a capacidade reduzida da suspensão de copiar o solo, pode haver flutuações da roda, que são percebidas pelos ocupantes como quedas e solavancos, dando a sensação de desconforto e insegurança. Adicionalmente, a perda de contato ou a simples diminuição da força normal do pneu em relação ao solo pode induzir a uma redução da força de atrito, ocasionando o deslizamento da 
superfície de contato do pneu, popularmente conhecido como derrapagem, prejudicando consideravelmente o seu desempenho de dirigibilidade (Omar \& Ozkan, 2015).

Mas ao longo dos anos, desde que o conceito do motor elétrico foi abandonado para os veículos automotores, a sua evolução tecnológica persistiu, e suas massas te tamanhos foram reduzidos, como visto na Figura 13.

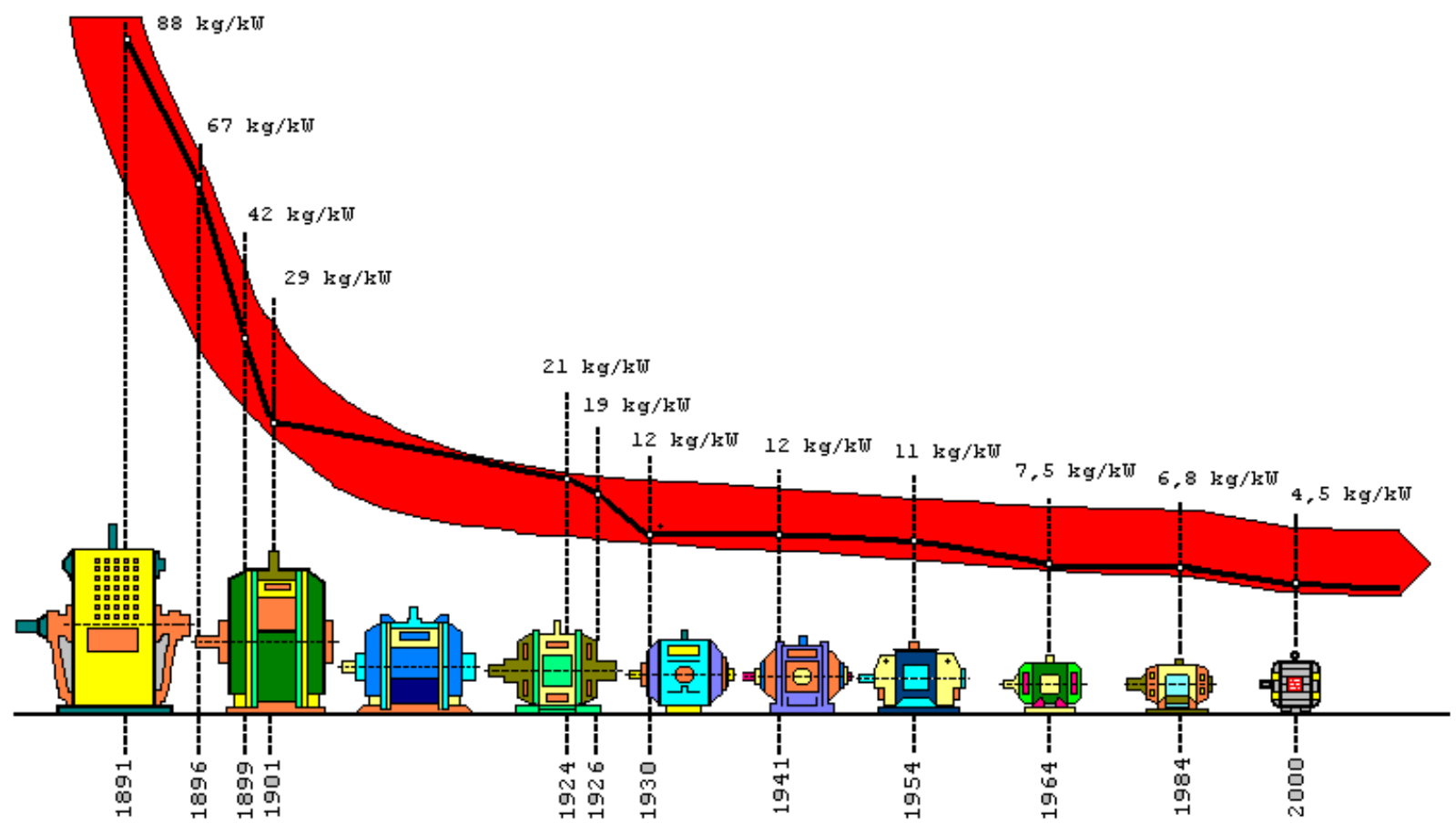

Figura 13 - Evolução da relação peso potência dos motores elétricos ao longo dos anos (WEG, 2016)

E novamente nos anos 2000, houve uma nova redução substancial de suas massas e tamanhos, com a adição de novas tecnologias no campo dos motores elétricos. Por exemplo, o motor de fluxo axial com refrigeração forçada, fazendo possível a obtenção de motores capazes de gerar o torque necessário para mover o carro a partir do repouso, com um desempenho compatível aos carros a combustão atuais e com massas relativamente baixas, quando comparados com os antigos motores elétricos (Figura 14), além de serem extremamente compactos com uma razão de aspecto (relação entre seu diâmetro e comprimento) que lhe dá uma aparência semelhante a um disco, sendo favorável para sua alocação dentro de uma roda.

Então, a possibilidade de utilizar motores diretamente nas rodas, retorna como uma possibilidade de engenharia (Rahman, et al., 2006). Para que isto se torne 
realidade, é necessário que os aparentes ganhos da simplicidade mecânica do sistema possam compensar a perda de desempenho dinâmico, que é proporcional ao incremento da massa não suspensa, que já não é tão grande quanto era no passado.

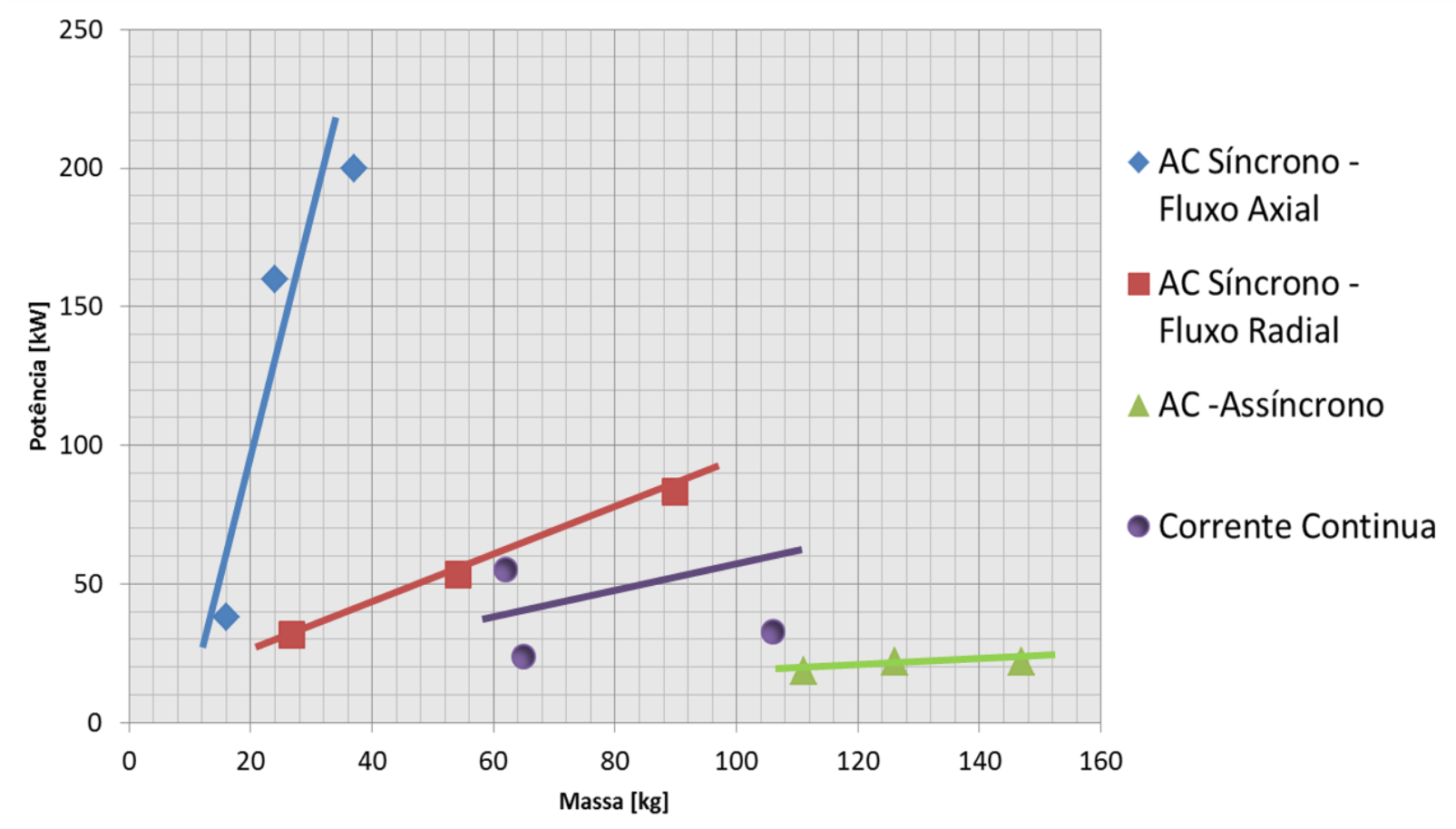

Figura 14 - Massa e potência dos diferentes conceitos de motores elétricos presentes no mercado.

Um dos conceitos mais avançados do motor de cubo, foi apresentado pelos germânicos do grupo Schaeffler (Figura 15) sendo capaz de gerar 350 N.m de torque continuo e picos de torque de até $700 \mathrm{~N}$.m, ou seja, um valor máximo de até $1400 \mathrm{~N} . \mathrm{m}$ por eixo.

Este desempenho é comparável, e até mesmo superior, ao conjunto de motores de combustão e transmissão, utilizados nos veículos convencionais. Toda essa força está contida em um motor de apenas $53 \mathrm{~kg}$, com refrigeração liquida forçada e com dimensões que o tornam capaz de ser acomodado dentro de uma roda padrão de 16 polegadas.

Porém outras empresas de autopeças, conjuntamente com produtores de motores elétricos, já desenvolveram conjuntos semelhantes em diversas variações como com a inclusão de freios de emergência e estacionamento no mesmo conjunto, além de tamanhos e torques adequados, abrangendo desde carros de passeio até veículos de carga, criando diversas opções para as montadoras que optarem em desenvolver um veículo com este tipo de tecnologia. 


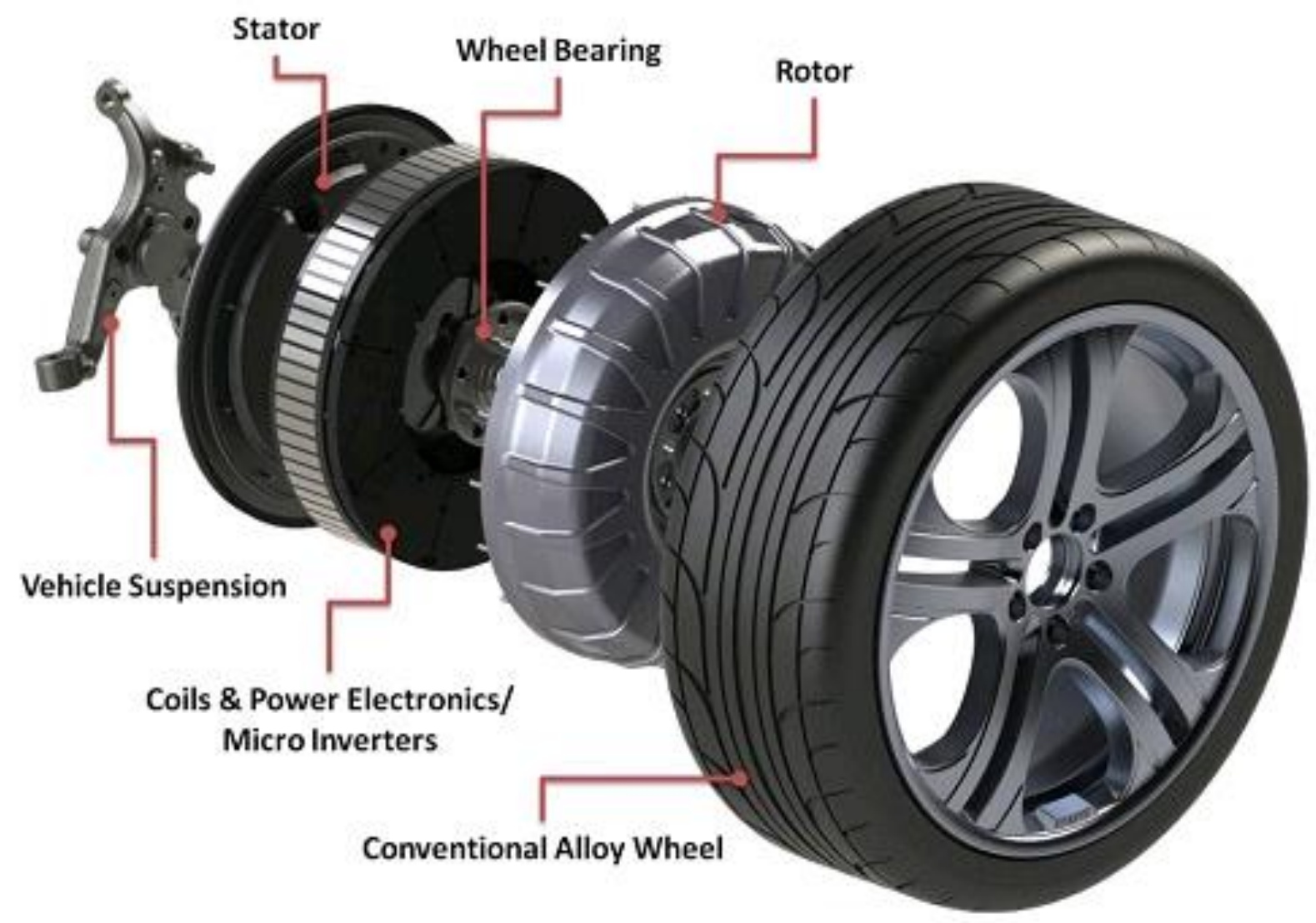

Figura 15 - Schaeffler "hub drive" (Fischer, 2014)

Complementarmente, da mesma maneira que houve uma considerável evolução dos motores elétricos, as baterias que armazenam a energia utilizada por estes automóveis, que são instaladas junto a massa suspensa, evoluíram consideravelmente após os anos 2000. Este progresso foi impulsionado principalmente pela indústria de telefones celulares.

A introdução da tecnologia das baterias de Lítio íon melhorou consideravelmente a densidade energética das baterias quando comparada com os conceitos anteriores, possibilitando assim conjuntos mais leves (Figura 16). 


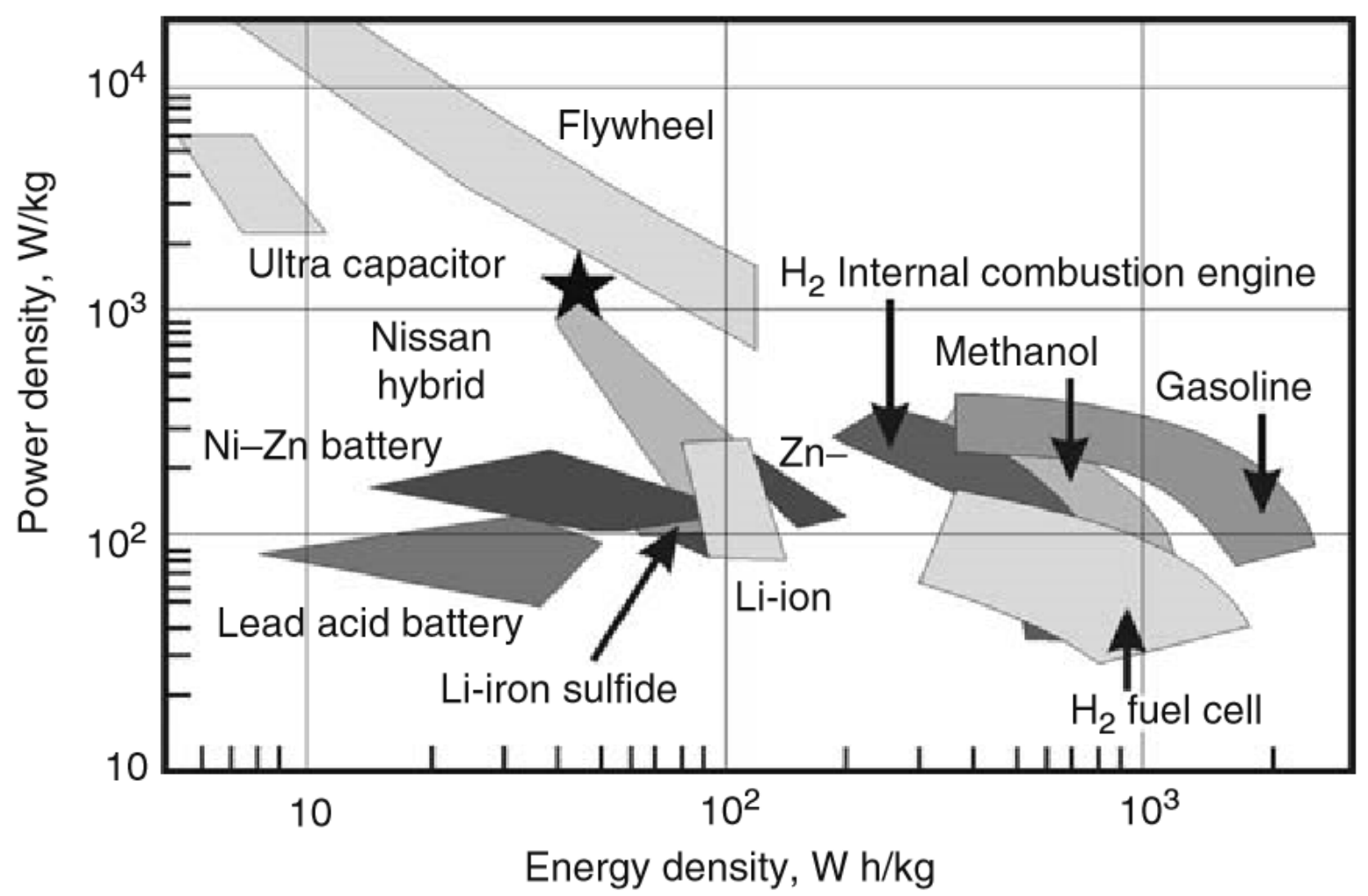

Figura 16 - Comparação das densidades de potência e energia de diversos meios de armazenamento de energia, que podem ser aplicadas aos automóveis (Fuhs, 2009).

Visto que há um conjunto de tecnologias que possibilitam a construção de carros elétricos e híbridos e a possibilidade de simplicidade mecânica de se instalar o motor diretamente nas rodas, pode-se afirmar que é necessário avaliar como o incremento de massa não suspensa pode afetar o desempenho do carro e entender se as tecnologias de motores de cubos podem ser utilizadas maciçamente por veículos automotores de passeio. 


\section{Objetivo}

Com a ajuda de análises numéricas realizadas com modelos de multicorpos, identificar a influência em dirigibilidade devido ao incremento da massa não suspensa, decorrente da utilização de motores elétricos diretamente instalados nos cubos, através de análises modais e execução de manobras padrão.

Caso exista uma influência negativa, avaliar maneiras de como revertê-la, com alterações nos componentes da suspensão que não sejam capazes de incrementar a complexidade do sistema.

Secundariamente este trabalho também tem como objetivo utilizar as técnicas correntes de modelagem de multicorpos indicadas para a solução de problemas de dinâmica veicular.

Também tem-se como meta, dominar as possíveis rotinas de otimização e ou planos de racionalização de experimentos afim de se encontrar o conjunto dos parâmetros da suspensão que amenizam ou revertam a influência negativa da adição de massa não suspensa. 


\section{Estado da Arte}

O inerente incremento de massa não suspensa, decorrente do uso de motores elétricos de cubo, gerará efeitos indesejados no comportamento dinâmico do veículo. Tradicionalmente, a literatura nos indica que o melhor caminho para reduzir estes efeitos é reduzir ao máximo estas massas (Schilling, 1948).

Inúmeros trabalhos de desenvolvimento de engenharia estão sendo feitos para que a realidade seja de uma adição menor, mesmo que inevitável. Estes trabalhos contemplam motores com torques maiores que trabalham sem a necessidade de reduções, sistemas de reduções mais compactos e eficientes, a utilização de materiais mais leves, a criação de conceitos de suspensão e pontas de eixo compactos integrados ao motor elétrico, capazes de reduzir a massa do conjunto, entre muitas outras iniciativas (Chen, et al., 2014).

Com a recente evolução tecnológica que foi capaz de trazer o incremento de massa não suspensa a níveis aceitáveis, começou-se a avaliar como o incremento de massa não suspensa pode afetar o desempenho do automóvel e como controlar os seus níveis de degradação.

Muitos destes estudos foram realizados através do modelo de um quarto de veículo, sendo que esta formulação pode ser exposta a uma série de entradas que tentam representar o uso do automóvel, desde entradas padronizadas até sinais representando as irregularidades da pista em função da velocidade de deslocamento, apenas impondo o deslocamento da coordenada $Z_{2}$ (Barbosa, 2011), ilustrado na Figura 17. 


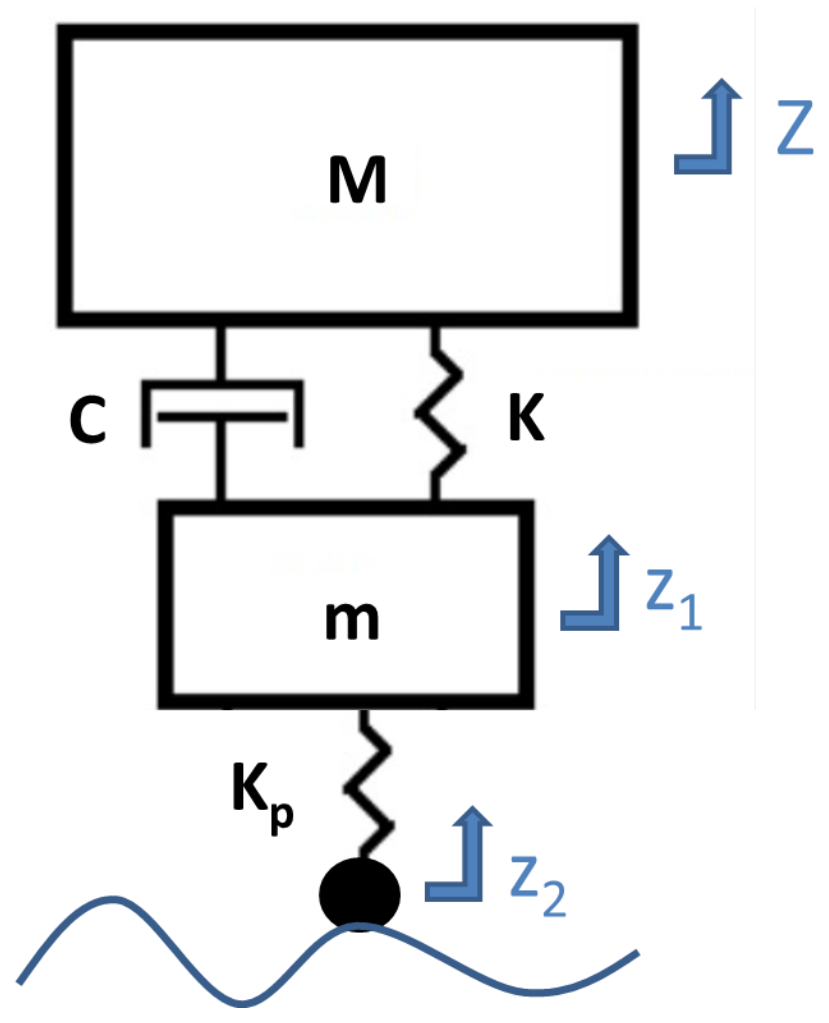

Figura 17 - Modelo de quarto de veículo

Onde:

$M=$ Massa suspensa

$\mathrm{m}=$ Massa não suspensa

$\mathrm{K}=$ Rigidez da suspensão

$\mathrm{K}_{\mathrm{p}}=$ Rigidez do Pneu

$\mathrm{C}=$ Amortecimento da suspensão

Com as equações de movimento do modelo de um quarto de veículo, já existem avaliações disponíveis realizando este tipo de comparação, com a massa costumeira e com a massa adicionada, indicando uma piora tolerável da aceleração da massa suspensa, quando excitada pela base (Rojas, et al., 2010). Além disso, tem-se a indicação que um retrabalho do coeficiente de amortecimento do veículo pode amenizar um pouco esta degradação (Bravo, et al., 2012).

Também com ajuda do modelo de um quarto de veículo, (Van Schalkwyk \& Kamper, 2006) observou que o acréscimo de massa transfere mais esforços à carroceria do automóvel e, consequentemente, impõe ao ocupante maiores acelerações. Entretanto, os níveis de degradação são aceitáveis quando se compara 
o acréscimo de massa utilizando valores compatíveis com os motores elétricos de última geração. Além disso, observou-se que o incremento da massa não suspensa reduz consideravelmente o modo ressonante de roda, o que a priori afetaria a capacidade do pneu em manter o contato com o solo.

Os dois modos naturais obtidos a partir do modelo de um quarto de veículo que podem ser associados aos modos de massa suspensa e de massa não suspensa estão presentes na literatura clássica e há as equações simplificadas para este sistema (Milliken \& Milliken, 1995), sendo a frequência natural não amortecida da massa suspensa mostrada equação $4.1\left(f_{n}\right)$ e o seu amortecimento critico em $4.2(\xi)$ e o modo natural de roda em $4.3\left(f_{r}\right)$.

$$
\begin{gathered}
f_{n}=\frac{1}{2 \pi} \sqrt{\frac{\left(\frac{K \cdot K_{p}}{K+K_{p}}\right)}{M}} \\
\xi=\frac{C}{\sqrt{4 \cdot K \cdot M}} \\
f_{r}=\frac{1}{2 \pi} \sqrt{\frac{K+K_{p}}{m}}
\end{gathered}
$$

Com uma simples observação das equações dos modos (4.1 e 4.3), pode-se facilmente inferir a conexão do valor da massa não suspensa com a frequência de roda, o que se torna objeto de interesse neste estudo de veículos elétricos com motores aplicados diretamente nas rodas. Este efeito da redução dos modos de massa não suspensa estão presentes em todos os modelos mais complexos. 
Para tentar ajustar o valor da frequência de roda (4.3), pode-se trabalhar alterando as rigidezes do pneu $\left(K_{p}\right)$ e da suspensão $(K)$. Entretanto, a alteração desses parâmetros afetará o modo de massa suspensa (4.1). Portanto, é necessário entender detalhadamente como o valor de cada frequência afeta o desempenho do veículo, para ser possível encontrar um ponto de balanço entre os dois valores, visto que ambas podem afetar a dirigibilidade do veículo de uma maneira indireta (Ganzarolli, 2012).

Outra observação para se dimensionar este balanço do sistema são as próprias frequências do corpo humano, que devem ser respeitadas (Figura 18), a fim de não se causar desconfortos localizados, deixando assim as frequências de massa suspensa restritas a certos intervalos.

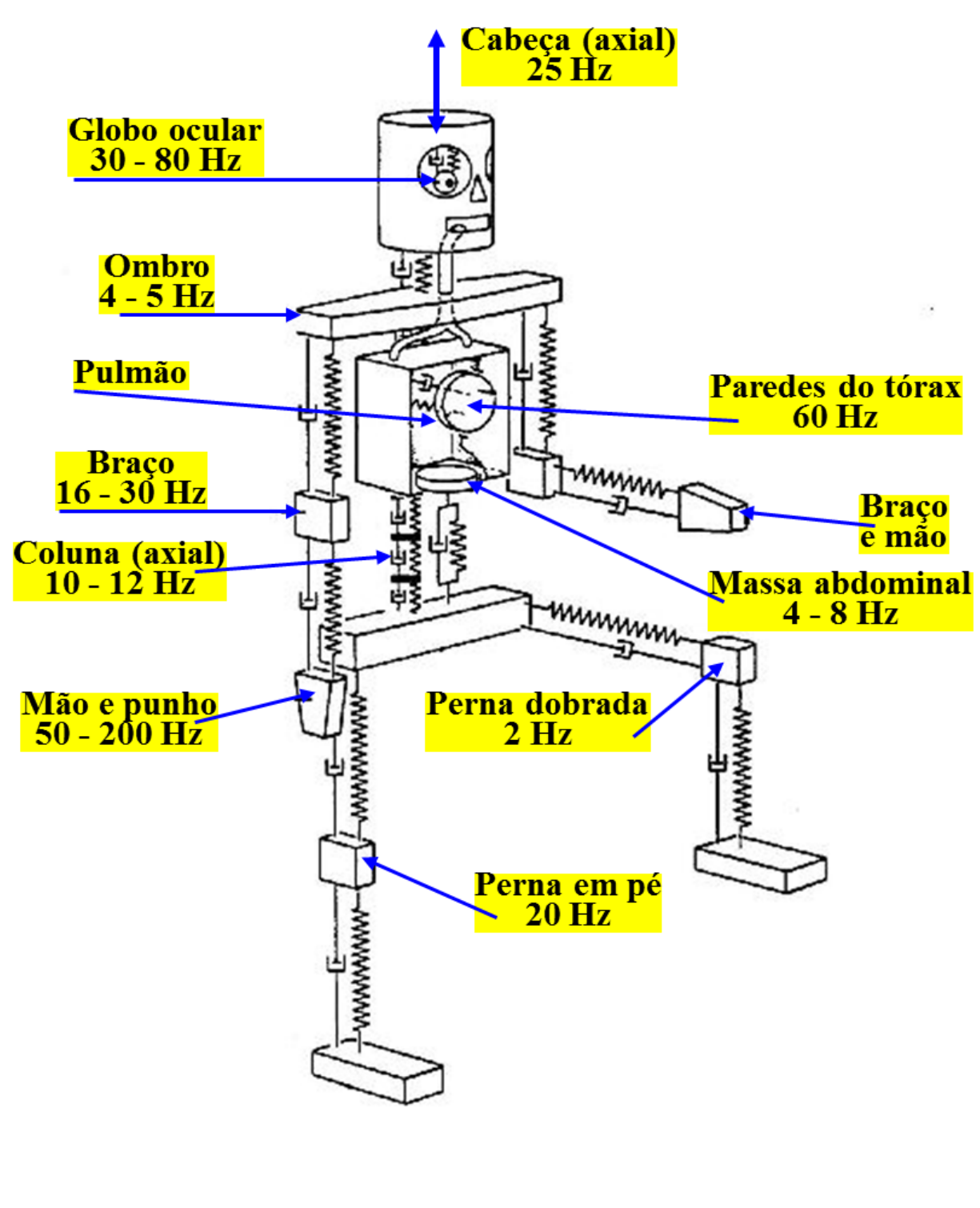

Figura 18 - Frequências naturais do corpo humano (Swedish Road Engineering Division, 2000) 
O segundo aspecto a se observar é o conceito de isolação. Neste lugar, desejase reduzir a transmissibilidade das excitações do sistema para a massa suspensa.

De maneira prática, quanto menor a frequência natural, melhor será a percepção do ocupante de estar isolado das irregularidades do solo, como exemplificado na Figura 19, que mostra o nível relativo da média quadrática da aceleração para um dado intervalo de frequência de excitação aplicado no modelo de um quarto de veículo (Gillespie, 1992).

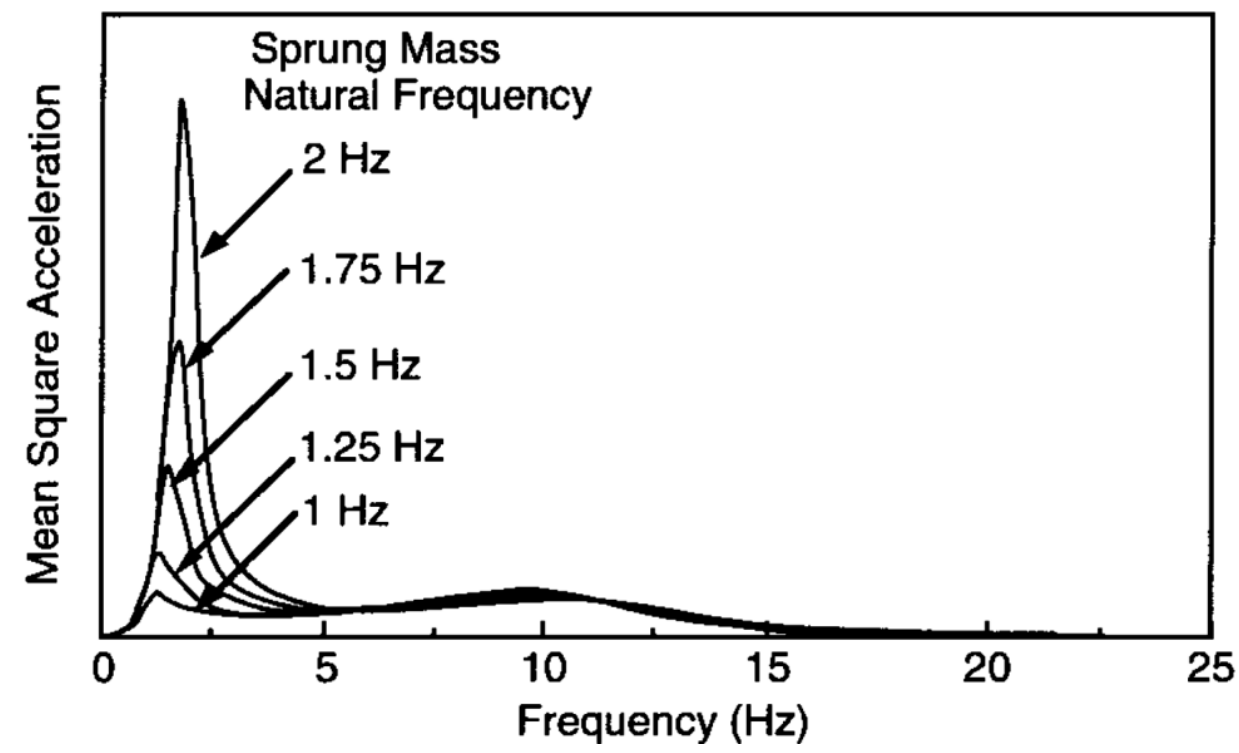

Figura 19 - Espectro das acelerações de pista para diferentes frequências naturais da massa suspensa (Gillespie, 1992)

Apesar de a isolação da vibração ser um aspecto muito importante no dimensionamento da mola, a sua rigidez afeta a dirigibilidade do veículo, e isto deve ser levado em conta.

Como guia, na literatura são apresentados valores típicos de "ride frequency" para cada conceito de carro (Tabela 1). Entretanto, os valores adotados para os carros atuais são ligeiramente superiores aos sugeridos na literatura tradicional, especialmente devido a dois fatores: a necessidade estética de se ter caixas de rodas mais compactas, o que restringe o curso da suspensão culminando em cursos menores, e também a utilização de pneus com uma menor resistência a rolagem, o que indiretamente pode aumentar a sua rigidez. 
Porém devido a melhora generalizada na condição das vias nos últimos 20 anos, esse aumento não representa uma deterioração para o conforto do passageiro, menos isolado das perturbações do solo.

Tabela 1 - 'Ride Frequency' recomendado para diversos tipos de carro (Milliken \& Milliken, 1995)

\begin{tabular}{l|l} 
Tipo de Veículo & Intervalo recomendado \\
\hline Carros de Passeio & $0.5 \mathrm{~Hz} \sim 1.5 \mathrm{~Hz}$ \\
\hline Carros Esportivos & $1.5 \mathrm{~Hz} \sim 2 \mathrm{~Hz}$ \\
\hline Carros de Corrida & $3 \mathrm{~Hz} \sim 5 \mathrm{~Hz}$
\end{tabular}

Já através do modelo mais detalhado (Figura 20), foi identificada uma degradação da força de contato do pneu com o solo, o que reduziria a sua capacidade de realizar forças tangencias decorrentes do atrito, degradando assim o seu desempenho de dirigibilidade. Entretanto uma readequação dos parâmetros da suspensão seria capaz de mitigar parcialmente estes efeitos (Terra \& Barbosa, 2016).

Com o auxílio deste, também já foi possível identificar que o aumento da massa suspensa altera o comportamento de arfagem (Figura 21) do carro de maneira prejudicial, gerando desconforto e alteração nos esforços do eixo dianteiro e traseiro (Momiyama, 2006). 


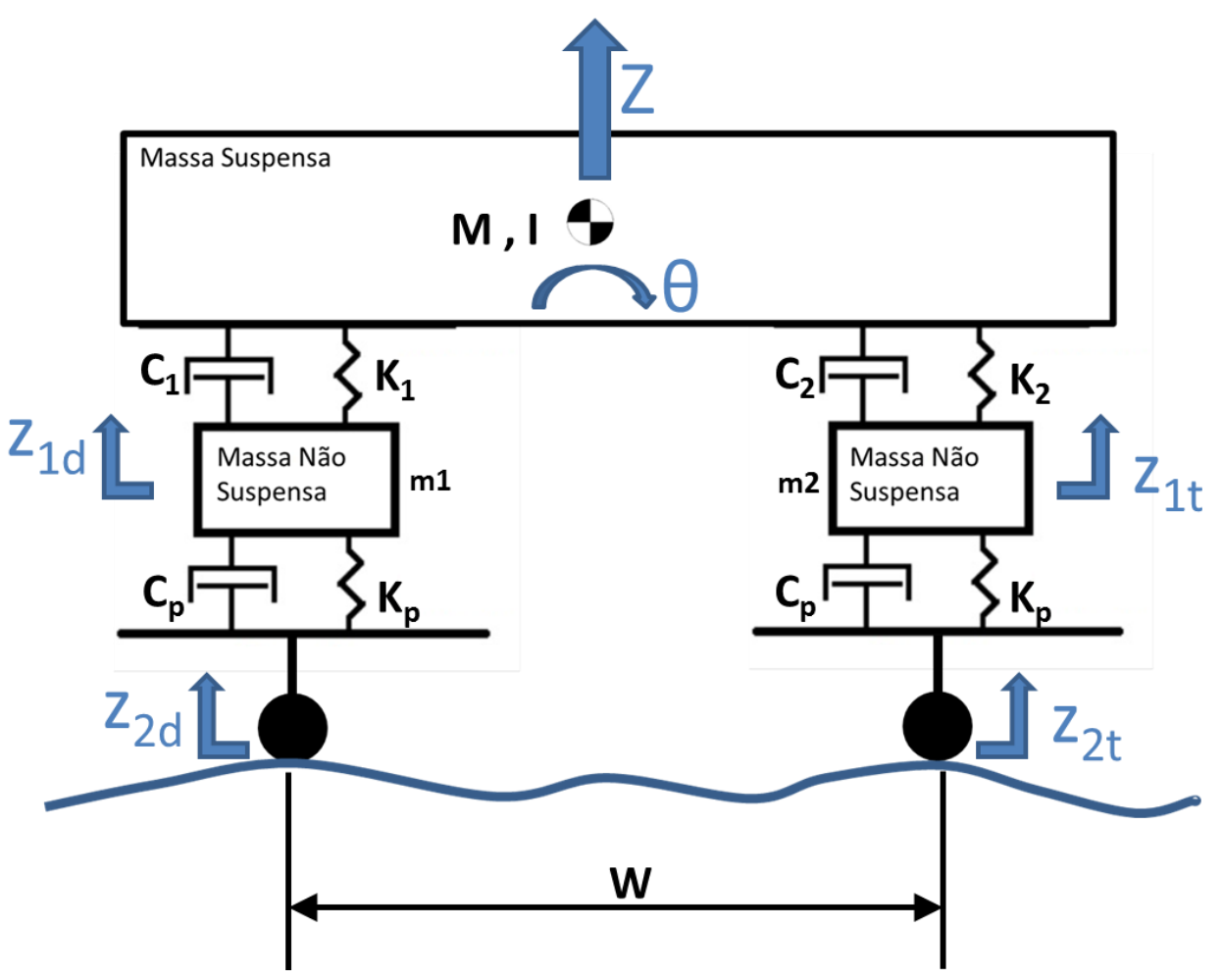

Figura 20 - Modelo de Meio Veículo

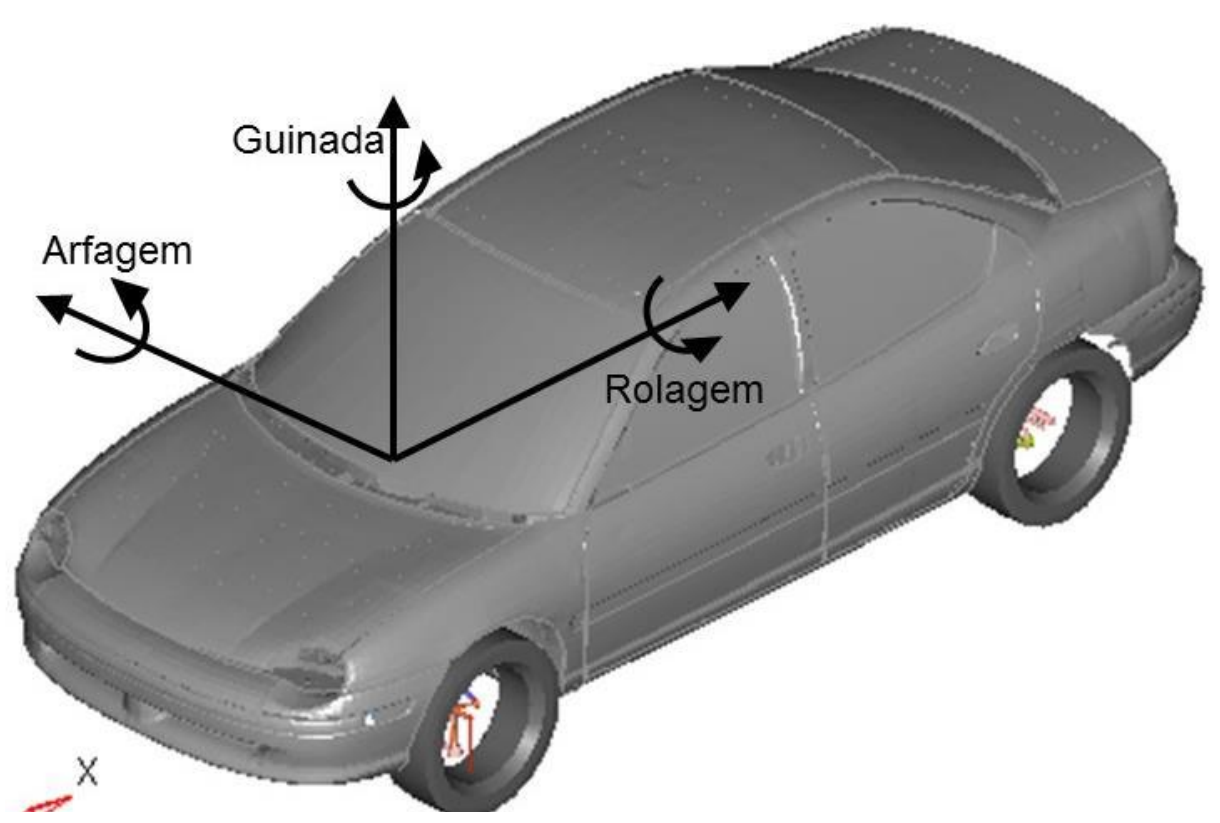

Figura 21 - Definição e nomenclatura das rotações do veiculo (Botosso, 2015)

Da mesma forma que no modelo de um quarto de veículo, a representação de meio carro tem modos conectados à massa não suspensa (também chamado de modo de cubo) e massa suspensa. De maneira semelhante ao que ocorre no modelo 
mais simples, os modos de cubos serão reduzidos e a ordem de grandeza de seus valores são semelhantes.

O modo de frequência de roda é um grande influenciador da resposta do automóvel. O exemplo, utilizando valores compatíveis de um veículo de carga, de Yang, et al., (2015), utilizando um modelo de veículo completo com 8 graus de liberdade (Figura 22), é um bom exemplificador de como este modo pode afetar os esforços no contato do pneu, afetando diretamente a dirigibilidade do veículo.

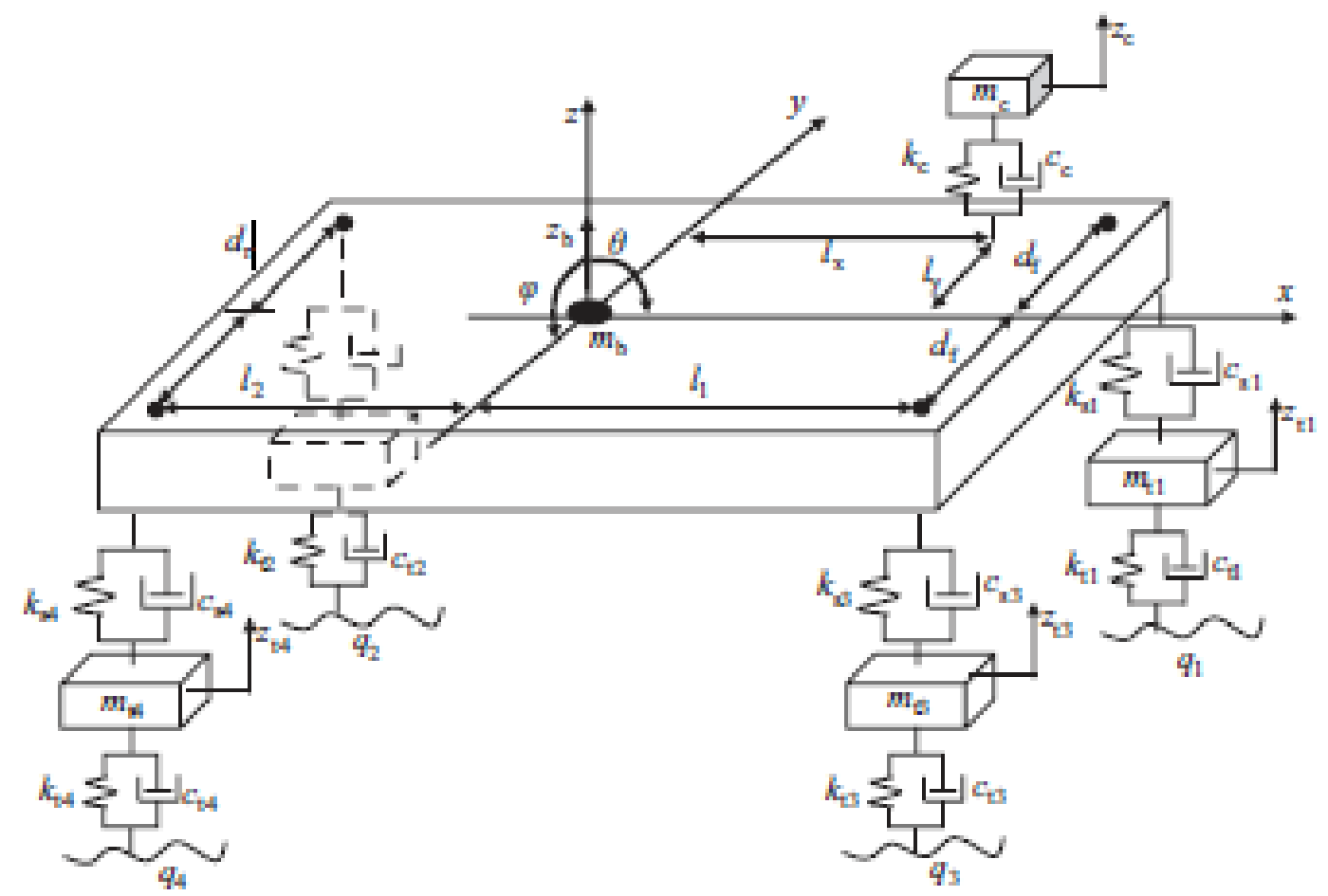

Figura 22 - Modelo de veículo completo (Yang, et al., 2015)

Pode-se observar de maneira direta, através de uma análise espectral dos esforços dos pneus, que a alteração da rigidez do pneu traseiro e a sua consequente alteração do modo ressonante de roda afeta os esforços de contato (Figura 23), e de maneira semelhante, nota-se o mesmo efeito quando se altera a rigidez da suspensão (Figura 24). 


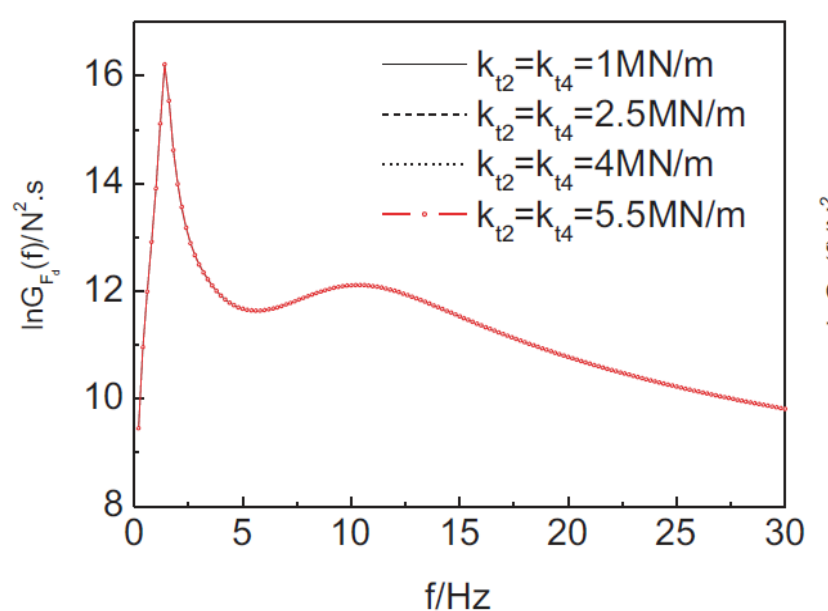

a

Front tire

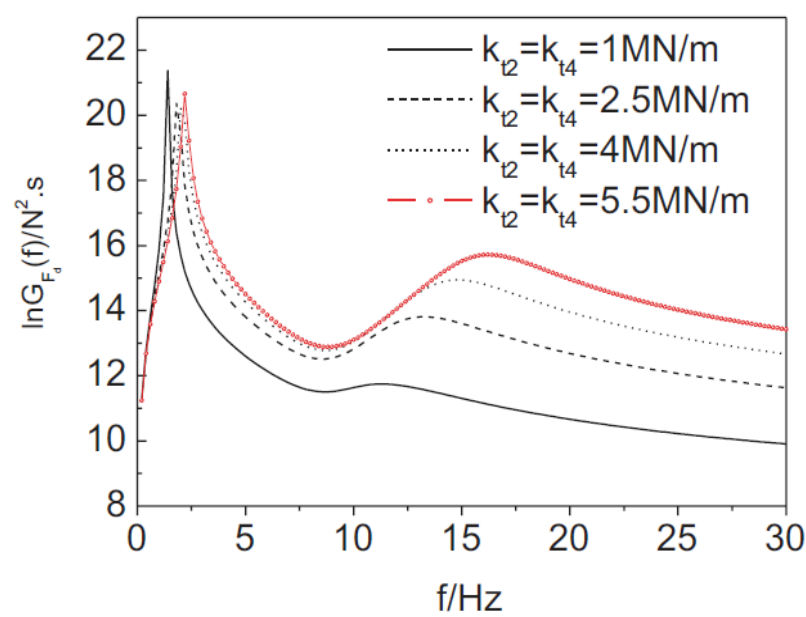

b

Rear tire

Figura 23 - Analise espectral (PSD) dos esforços do Pneu variando a frequência de roda através da alteração da rigidez do pneu traseiro (Yang, et al., 2015), sendo "a" referente ao eixo dianteiro e "b" referente ao eixo traseiro.

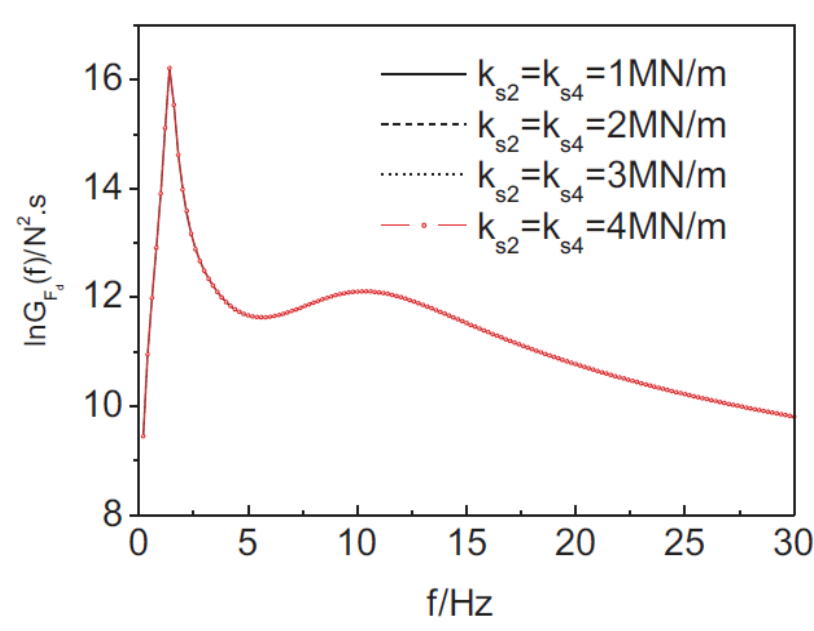

a

Front tire

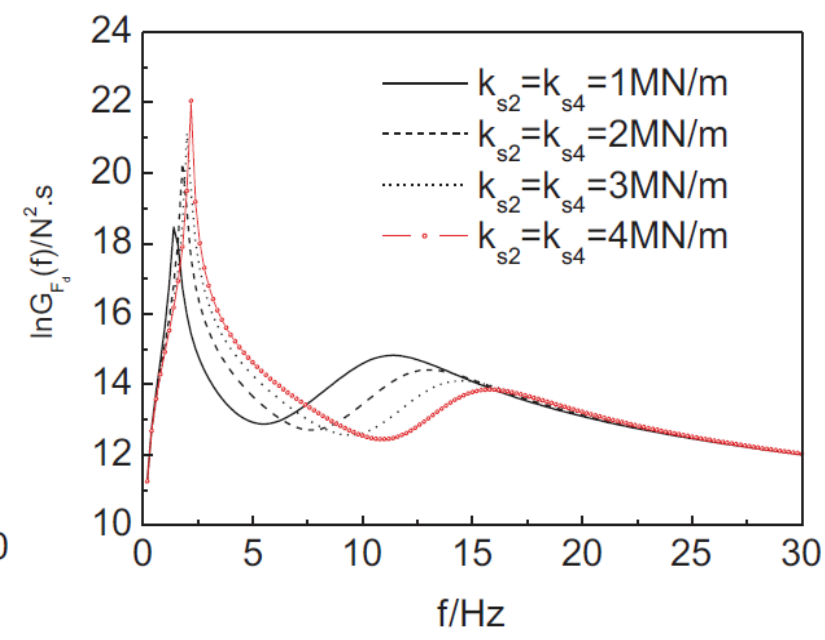

b

Rear tire

Figura 24 - Analise espectral (PSD) dos esforços do Pneu variando a frequência de roda através da alteração da rigidez da suspensão traseira (Yang, et al., 2015), sendo "a" referente ao eixo dianteiro e "b" referente ao eixo traseiro.

Levando-se em conta todas estas informações, é esperado que um acréscimo de massa não suspensa altere a frequência natural dos modos naturais de cubo, o que culminará em um diferente comportamento do contato entre o pneu e o solo, alterando inexoravelmente o desempenho de dirigibilidade do automóvel estudado. 


\section{Modelos}

Este trabalho avaliará o incremento da massa não suspensa através de duas formas de modelagem existentes: o modelo de meio veículo; o modelo completo feito através da técnica de multicorpos.

Adicionalmente neste trabalho todos os modelos foram feitos de maneira que acontecessem apenas o acrescimo de massa suspensa, sem alterações da posição do peso total e do centro de massa global do veículo.

\subsection{Modelo de meio veículo}

Um modelo muito conhecido na literatura, e apresentado no capítulo 4, é o modelo de meio veículo. Com este modelo é possível capturar detalhes do que ocorre com o veículo, como os movimentos de arfagem e rolagem, dependendo de como o modelo é montado. Então, é possível capturar como a massa adicional altera a resposta do carro, visto que ela causa uma assimetria entre as massas não suspensas do eixo dianteiro e traseiro.

Portanto, exemplificar-se-á com um modelo de meio veículo, mais representativo, cobrindo os movimentos verticais e de arfagem, com as suas coordenadas generalizadas apresentadas na Figura 25.

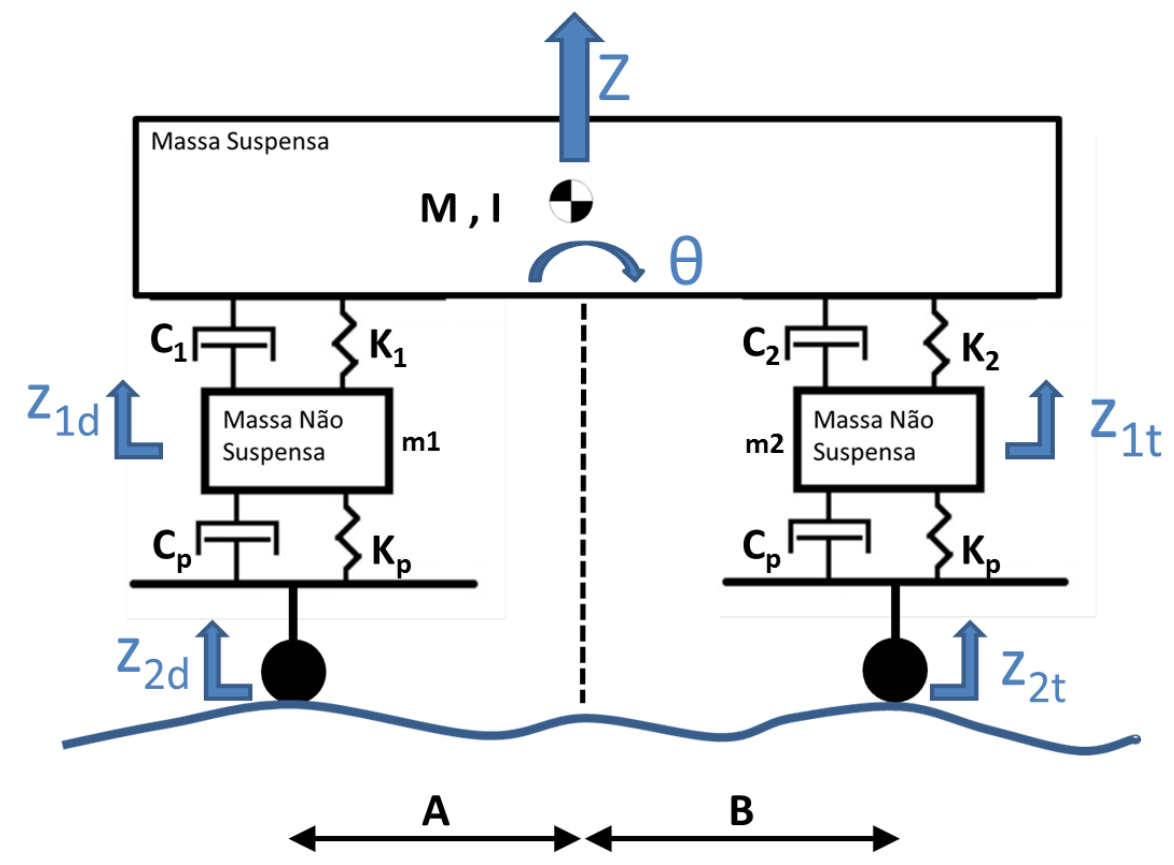

Figura 25 - Modelo de meio veículo e suas coordenadas generalizadas 
Onde:

$\mathrm{M}=$ Massa suspensa

I = Inércia da massa suspensa

$\mathrm{m}_{1}=$ Massa não suspensa dianteira

$\mathrm{k}_{1}=$ Rigidez da suspensão dianteira

$\mathrm{C}_{1}=$ Coeficiente de amortecimento da suspensão dianteira

$\mathrm{m}_{2}=$ Massa não suspensa traseira

$\mathrm{k}_{2}=$ Rigidez da suspensão traseira

$\mathrm{C}_{2}$ = Coeficiente de amortecimento da suspensão traseira

$\mathrm{k}_{\mathrm{p}}=$ Rigidez do pneu

$\mathrm{C}_{p}=$ Coeficiente de amortecimento do pneu

A = Distância do eixo dianteiro ao centro de gravidade da massa suspensa

$\mathrm{B}$ = Distância do eixo traseiro ao centro de gravidade da massa suspensa

Os movimentos nas coordenadas $Z_{2 d}$ e $Z_{2 t}$ são as entradas que representam o deslocamento imposto pelas irregularidades do solo. Desta forma estas entradas são excitadas de maneira a representar eventos como uma lombada, irregularidades ou mesmo uma excitação aleatória, lembrando que a frequência de excitação é dependente da velocidade linear com a qual o veículo está se movendo.

Com as devidas análises dos esforços e suas direções, e sabendo que a variação do ângulo $\theta$ esperada é inferior a dez graus, torna-se possível linearizar o sistema e obter as equações de movimento (5.1.1, 5.1.2, 5.1.3 e 5.1.4) do mesmo, através do método de Newton-Euler, realizando uma somatória de forças e momentos (Baruh, 1999).

$$
\begin{gathered}
m_{1} \ddot{z}_{1 d}=-\dot{z}_{1 d}\left(C_{p}+C_{1}\right)-z_{1 d}\left(k_{p}+k_{1}\right)+\dot{z}_{2 d} C_{p}+ \\
z_{2 d} k_{p}+\dot{Z} C_{1}+Z k_{1}+\theta A k_{1}+\dot{\theta} A C_{1} \\
m_{2} \ddot{z}_{1 t}=-\dot{z}_{1 t}\left(C_{p}+C_{2}\right)-z_{1 t}\left(k_{p}+k_{2}\right)+\dot{z}_{2 t} C_{p}+ \\
z_{2 t} k_{p}+\dot{Z} C_{2}+Z k_{2}-\theta B k_{2}-\dot{\theta} B C_{2}
\end{gathered}
$$




$$
\begin{gathered}
M \ddot{Z}=-\dot{Z}\left(C_{1}+C_{2}\right)-Z\left(k_{1}+k_{2}\right)+\dot{z}_{1 d} C_{1}+z_{1 d} k_{1}+\dot{z}_{1 t} C_{2}+ \\
z_{1 t} k_{2}-\dot{\theta}\left(A C_{1}-B C_{2}\right)-\theta\left(A k_{1}-B k_{2}\right) \\
\mathrm{I} \ddot{\theta}=-\dot{Z}\left(A C_{1}-B C_{2}\right)-Z\left(A k_{1}-B k_{2}\right)+\dot{z}_{1 d} A C_{1}+z_{1 d} A k_{1}-\dot{z}_{1 t} B C_{2} \\
-z_{1 t} B k_{2}-\dot{\theta}\left(A^{2} C_{1}+B^{2} C_{2}\right)-\theta\left(A^{2} k_{1}+B^{2} k_{2}\right)
\end{gathered}
$$

Sendo assim, é possível analisar uma série de efeitos dinâmicos. Adicionalmente, o modelo de meio veículo modelado parametricamente pode ser utilizado de forma a capturar os movimentos verticais e os movimentos de arfagem ("pitch") ou rolagem ("roll"), possibilitando uma análise mais completa do que aquela que seria possível com o modelo de quarto de veículo.

Sendo assim, utilizar-se-á o modelo na configuração que captura os movimentos verticais e de arfagem com valores de rigidezes e amortecimentos condizentes com os veículos compactos comercializados no Brasil, apresentados na Tabela 2.

Tabela 2 - Valores aplicados nos modelos de meio veículo

\begin{tabular}{c|c|c} 
Localização & Variável & Valor \\
\hline Eixo & $\mathrm{K}_{1}$ & $18.9 \mathrm{~N} / \mathrm{mm}$ \\
\cline { 2 - 3 } Dianteiro & $\mathrm{C}_{1}$ & $1200 \mathrm{~N} . \mathrm{s} / \mathrm{m}$ \\
\hline Eixo & $\mathrm{K}_{2}$ & $18.7 \mathrm{~N} / \mathrm{mm}$ \\
\cline { 2 - 3 } Traseiro & $\mathrm{C}_{2}$ & $1600 \mathrm{~N} . \mathrm{s} / \mathrm{m}$ \\
\hline \multirow{2}{*}{ Pneu } & $\mathrm{K}_{\mathrm{p}}$ & $190 \mathrm{~N} / \mathrm{mm}$ \\
\cline { 2 - 3 } & $\mathrm{C}_{\mathrm{p}}$ & $350 \mathrm{~N} . \mathrm{s} / \mathrm{m}$
\end{tabular}

Também serão avaliadas 3 configurações mássicas através do modelo: uma compatível com um carro tradicional, onde o trem de força vai dentro do carro; uma com os motores de cubo instalados no eixo dianteiro; e por final a configuração na qual o sistema de propulsão está instalado nas rodas traseiras. As variáveis relacionadas as estas condições são apresentados na Tabela 3, variando o centro de massa da porção suspensa de maneira que o centro de gravidade global do veículo esteja sempre na mesma localização. 
Tabela 3 - Massas e sua disposição no modelo de meio veículo

\begin{tabular}{c|c|c|c} 
Variável & Carro base & $\begin{array}{c}\text { Massa não } \\
\text { suspensa } \\
\text { acrescida na } \\
\text { dianteira }\end{array}$ & $\begin{array}{c}\text { Massa não } \\
\text { suspensa } \\
\text { acrescida na } \\
\text { traseira }\end{array}$ \\
\hline $\mathrm{M}$ & $700 \mathrm{~kg} \cdot \mathrm{m}^{2}$ & $625 \mathrm{~kg} \cdot \mathrm{m}^{2}$ & $625 \mathrm{~kg} \cdot \mathrm{m}^{2}$ \\
\hline $\mathrm{m}_{1}$ & $417.5 \mathrm{~kg}$ & $372.5 \mathrm{~kg}$ & $372.5 \mathrm{~kg}$ \\
\hline $\mathrm{m}_{2}$ & $40 \mathrm{~kg}$ & $87.5 \mathrm{~kg}$ & $42.5 \mathrm{~kg}$ \\
\hline $\mathrm{M}+\mathrm{m}_{1}+\mathrm{m}_{2}$ & $500 \mathrm{~kg}$ & $500 \mathrm{~kg}$ & $500 \mathrm{~kg}$ \\
\hline $\mathrm{A}$ & $1083 \mathrm{~mm}$ & 1213 & 911 \\
\hline $\mathrm{B}$ & $1417 \mathrm{~mm}$ & 1287 & 1589 \\
\hline $\mathrm{A}+\mathrm{B}$ & $2500 \mathrm{~mm}$ & $2500 \mathrm{~mm}$ & $2500 \mathrm{~mm}$
\end{tabular}

\subsection{Modelo de Carro Completo}

Como forma de capturar o desempenho em dirigibilidade do automóvel com massa acrescida na porção da massa não suspensa da maneira mais fiel possível, será utilizado o modelo mais completo, modelado através da técnica de multicorpos, com a ajuda dos "softwares" comerciais de engenharia assistida por computador (CAE) $\mathrm{ADAMS}^{\circledR}$ e Motion View ${ }^{\circledR}$.

Sabe-se que a modelagem em multicorpos é feita através do equacionamento dinâmico de diversos corpos dotados de massa, inércia e eventualmente rigidez, interconectados por juntas, buchas, molas e amortecedores.

Desta forma, é possível modelar um veículo completo considerando todos os componentes que influenciam no comportamento dinâmico deste (Figura 26). Com ajuda destes programas, será possível montar modelos extremamente fiéis a um automóvel de verdade, permitindo que se execute manobras tais quais seriam feitas no mundo físico, ou seja, solucionar numericamente as equações de movimento no domínio do tempo (Blundell \& Harty, 2004). 


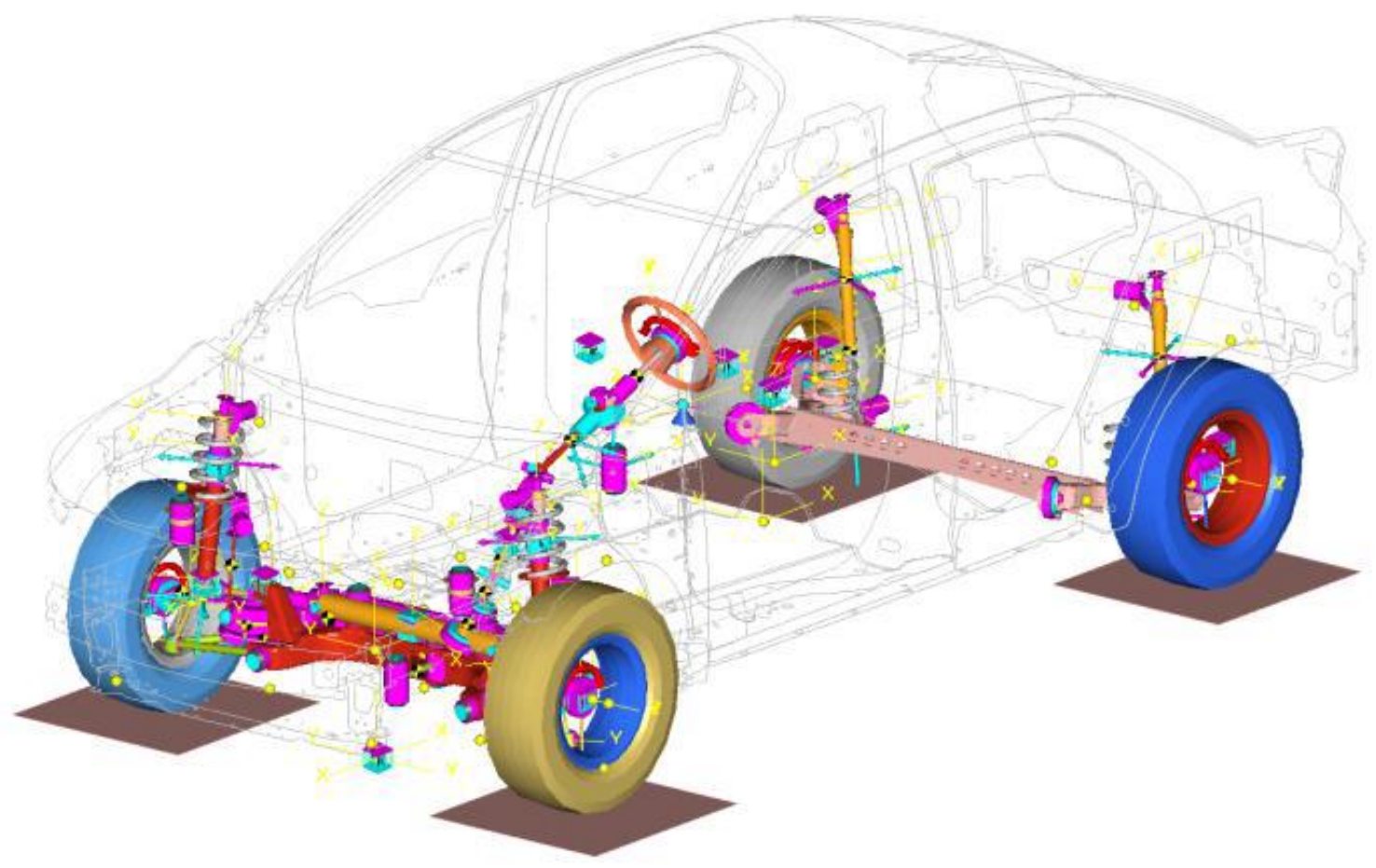

Figura 26 - Exemplo de modelo de veículo completo modelado através da técnica de multicorpos (Terra, et al., 2015).

Sendo assim, para avaliar como o incremento de massa não suspensa afeta a dirigibilidade de um veículo, foi criado um modelo com dimensões e propriedades dos componentes compatíveis com as de um automóvel compacto.

Este modelo foi dividido em três situações: o carro base, que tem as massas de um carro compacto convencional; o caso com massa acrescida na dianteira; e o caso com massa acrescida na traseira.

Para os cálculos, considerou-se que cada motor elétrico tem $45 \mathrm{~kg}$. No carro base, essa massa está na porção suspensa. Nos demais casos, tal massa encontrase em seus respectivos eixos, chegando na configuração apresentada na Tabela 4. Em todos os casos, a posição do centro de gravidade global do veículo permaneceu inalterada.

Para efeitos de comparação, a consideração da massa não suspensa, apresentada na Tabela 4, foi considerada a massa dos componentes não suspensa em sua totalidade e metade da massa dos elementos de conexão (Milliken \& Milliken, 1995). Foram considerados como elementos de conexão entre massa suspensa e não suspensa: eixos, braços de controle, molas, amortecedores e tirantes de direção. 
Porém, o modelo de multicorpos contempla a massa destas conexões, não sendo necessária esta simplificação no modelo de veículo completo.

Os valores de todas as propriedades foram impetrados de forma a serem similares ao estudo do modelo de meio veículo, respeitando as particularidades de cada modelo como, por exemplo, corrigindo a rigidez das molas pela relação de alavanca do mecanismo da suspensão.

Tabela 4 - Massas adotados para os três diferentes casos.

\begin{tabular}{c|c|c|c|c|c|c} 
& \multicolumn{2}{|c|}{ Carro base } & \multicolumn{2}{c|}{$\begin{array}{c}\text { Massa não } \\
\text { suspensa acrescida } \\
\text { na dianteira }\end{array}$} & \multicolumn{2}{c}{$\begin{array}{c}\text { Massa não } \\
\text { suspensa acrescida } \\
\text { na traseira }\end{array}$} \\
\hline & $\begin{array}{c}\text { Eixo } \\
\text { dianteiro }\end{array}$ & $\begin{array}{c}\text { Eixo } \\
\text { Traseiro }\end{array}$ & $\begin{array}{c}\text { Eixo } \\
\text { dianteiro }\end{array}$ & $\begin{array}{c}\text { Eixo } \\
\text { Traseiro }\end{array}$ & $\begin{array}{c}\text { Eixo } \\
\text { dianteiro }\end{array}$ & $\begin{array}{c}\text { Eixo } \\
\text { Traseiro }\end{array}$ \\
\hline $\begin{array}{c}\text { Massa } \\
\text { suspensa }\end{array}$ & $473.4 \mathrm{~kg}$ & $361.6 \mathrm{~kg}$ & $383.4 \mathrm{~kg}$ & $361.6 \mathrm{~kg}$ & $473.4 \mathrm{~kg}$ & $271.6 \mathrm{~kg}$ \\
\hline $\begin{array}{c}\text { Massa não } \\
\text { suspensa }\end{array}$ & $85 \mathrm{~kg}$ & $80 \mathrm{~kg}$ & $175 \mathrm{~kg}$ & $80 \mathrm{~kg}$ & $85 \mathrm{~kg}$ & $170 \mathrm{~kg}$ \\
\hline $\begin{array}{c}\text { Massa } \\
\text { total }\end{array}$ & $558.4 \mathrm{~kg}$ & $441.6 \mathrm{~kg}$ & $558.4 \mathrm{~kg}$ & $441.6 \mathrm{~kg}$ & $558.4 \mathrm{~kg}$ & $441.6 \mathrm{~kg}$
\end{tabular}

Também temos uma caracterização básica de algumas das propriedades mais relevantes do modelo de veículo completo, em multicorpos, na Tabela 5. Todas estas propriedades foram selecionadas para serem semelhantes ao caso de meio veiculo estudado anteriomente, por exemplo as molas possuem especificações diferentes ao caso anterior pois foi ajustado pela relação de alavanca imposta pelo mecanismo da suspensão.

Tabela 5 - Principais parâmetros físicos do carro

\begin{tabular}{c|c|c}
\multirow{2}{*}{ Dimensões Básicas } & Bitola & $1500 \mathrm{~mm}$ \\
\cline { 2 - 3 } & Entre eixos & $2500 \mathrm{~mm}$ \\
\hline \multirow{2}{*}{ Pneus } & Medidas & $185 / 70 \mathrm{R} 14$ \\
\cline { 2 - 3 } Molas & Rigidez Radial & $190 \mathrm{~N} / \mathrm{mm}$ \\
\hline \multirow{2}{*}{$\begin{array}{c}\text { Barra Estabilizadora } \\
\text { Dianteira }\end{array}$} & Rigidez Dianteira & $21 \mathrm{~N} / \mathrm{mm}$ \\
\cline { 2 - 3 } & Rigidez Traseira & $22 \mathrm{~N} / \mathrm{mm}$ \\
\hline Eixo Traseiro & Diâmetro & $18 \mathrm{~mm}$ \\
\hline & $\begin{array}{c}\text { Rigidez de } \\
\text { Rolagem }\end{array}$ & $75 \mathrm{~N} . \mathrm{m} / \mathbf{0}$
\end{tabular}


Além destes parâmetros, a força decorrente do amortecimento do sistema está modelada em função da velocidade (Terra, et al., 2015) e as suas curvas baseadas na de um carro real estão descritas na Figura 27.

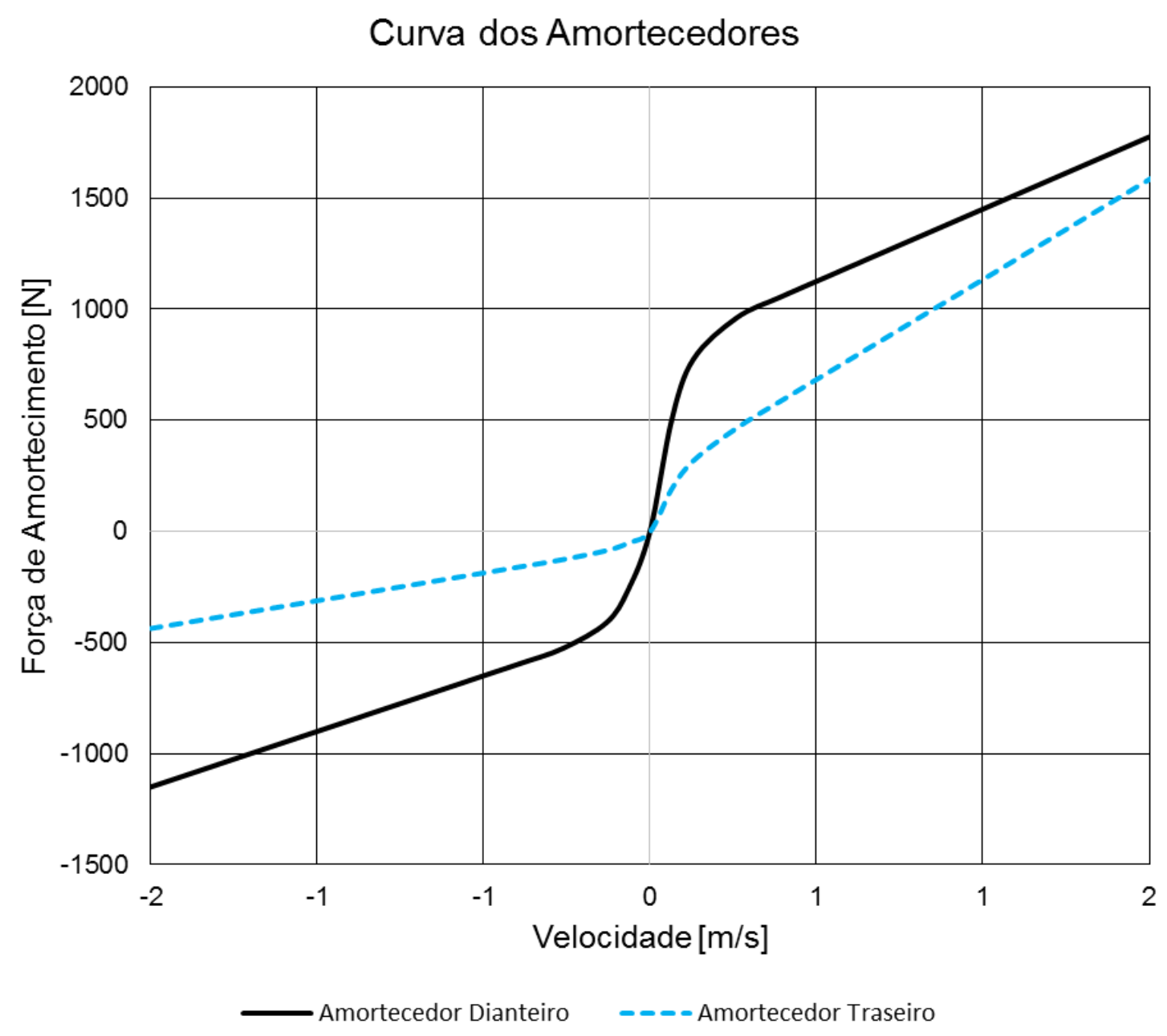

Figura 27 - Curva dos amortecedores 


\section{Resultados Numéricos}

Afim de se ter a real dimensão das particularidades causadas pelo incremento de massa, faz-se necessária a avaliação do veículo de diversas maneiras, desde o seu comportamento modal no mais simples dos modelos a até mesmo as suas reações quando da realização de uma manobra padrão.

\subsection{Análise modal através do modelo de um quarto de veículo}

A abordagem mais simples para se realizar o calculo das frequências naturais é a realizada através do modelo de um quarto de veículo, Figura 17, com ajuda da equação 4.1, que se refere ao modo de movimento predominante da carroceria, e da equação 4.3, que se refere ao modo de movimentação predominante da roda.

Assim, são obtidos os resultados mostrados na Tabela 6, com valores tendendo ao limite superior da recomendação de modos de carroceria sugeridos pela literatura (Tabela 1). Para o carro base, estes valores são compatíveis com os carros compactos de entrada comercializados atualmente no Brasil.

Tabela 6 - Frequências naturais não amortecidas, obtidas através do modelo de um quarto de veículo

\begin{tabular}{l|c|c|c}
\multicolumn{1}{c|}{ Descrição do Modo } & Carro base & $\begin{array}{c}\text { Massa não } \\
\text { suspensa } \\
\text { acrescida } \\
\text { na dianteira }\end{array}$ & $\begin{array}{c}\text { Massa não } \\
\text { suspensa } \\
\text { acrescida } \\
\text { na traseira }\end{array}$ \\
\cline { 2 - 4 } predominante da & 1.36 & 1.51 & 1.36 \\
\hline $\begin{array}{l}\text { Movimentação freq. [Hz] } \\
\text { carroceria no eixo dianteiro }\end{array}$ & Freq. [Hz] & Freq. [Hz] \\
\hline $\begin{array}{l}\text { Movimentação predominante da } \\
\text { carroceria no eixo traseiro }\end{array}$ & 1.54 & 1.54 & 1.78 \\
\hline $\begin{array}{l}\text { Massa não suspensa dianteira } \\
\text { movimentando-se predominatemente }\end{array}$ & 11.15 & 7.78 & 11.15 \\
\hline $\begin{array}{l}\text { Modo relacionado a uma maior } \\
\text { movimentação da massa não suspensa }\end{array}$ & 11.49 & 11.49 & 7.88 \\
traseira & & &
\end{tabular}


Para os cálculos através das equações 4.1 e 4.3, consideraram-se os mesmos valores de rigidezes já apresentados na Tabela 2.

De maneira geral pode-se observar uma mudança na frequência de carroceria (cerca de 15\%), devido à migração da massa do motor da parte suspensa para a não suspensa, do eixo afetado. Devido ao fato de este modelo desconectar a dianteira da traseira, esse incremento pode não representar uma mudança tão drástica do veículo, que teve sua massa reduzida na parte suspensa do eixo estudado, quando no carro de fato é reduzida da massa total, reduzindo o seu impacto como um todo.

Contudo, as maiores mudanças se dão nos modos de roda (por volta de 40\%) que têm os seus valores alterados pelo incremento de massa não suspensa.

\subsection{Resposta em frequência através do modelo de meio veículo}

Uma maneira mais detalhada de descrever como o carro se comporta com a adição de massa em um dos eixos é dada através do modelo de meio veículo e com auxílio do Software Matlab ${ }^{\circledR}$ Simulink $^{\circledR}$, para solucionar as equações 5.1.1, 5.1.2, 5.1.3 e 5.1.4. A analise foi feita através de uma varredura de 0 a $20 \mathrm{~Hz}$ com um deslocamento imposto pela base de $4 \mathrm{~mm}$ de intensidade.

Neste trabalho serão abordadas as situações onde a excitação está em fase e fora de fase, mas a defasagem que ocorreria na excitação em uma situação real é aleatória.

Assim, identificaram-se as amplitudes possibilitando a construção do envelope das grandezas a serem estudadas, sendo os seus valores máximos ou mínimos obtidos de acordo com a frequência de excitação.

Sabe-se que a força normal gerada pelos pneus tem grande influência na capacidade do veículo conseguir realizar os esforços tangenciais para se inscrever em uma curva e, por isso, o estudo monitorou principalmente esta grandeza. Foram observadas alterações consideráveis nas acelerações verticais e de arfagem que envolve a massa suspensa.

Também pode-se observar vales e picos no envelope construído que indicam as frequências naturais amortecidas do sistema. 


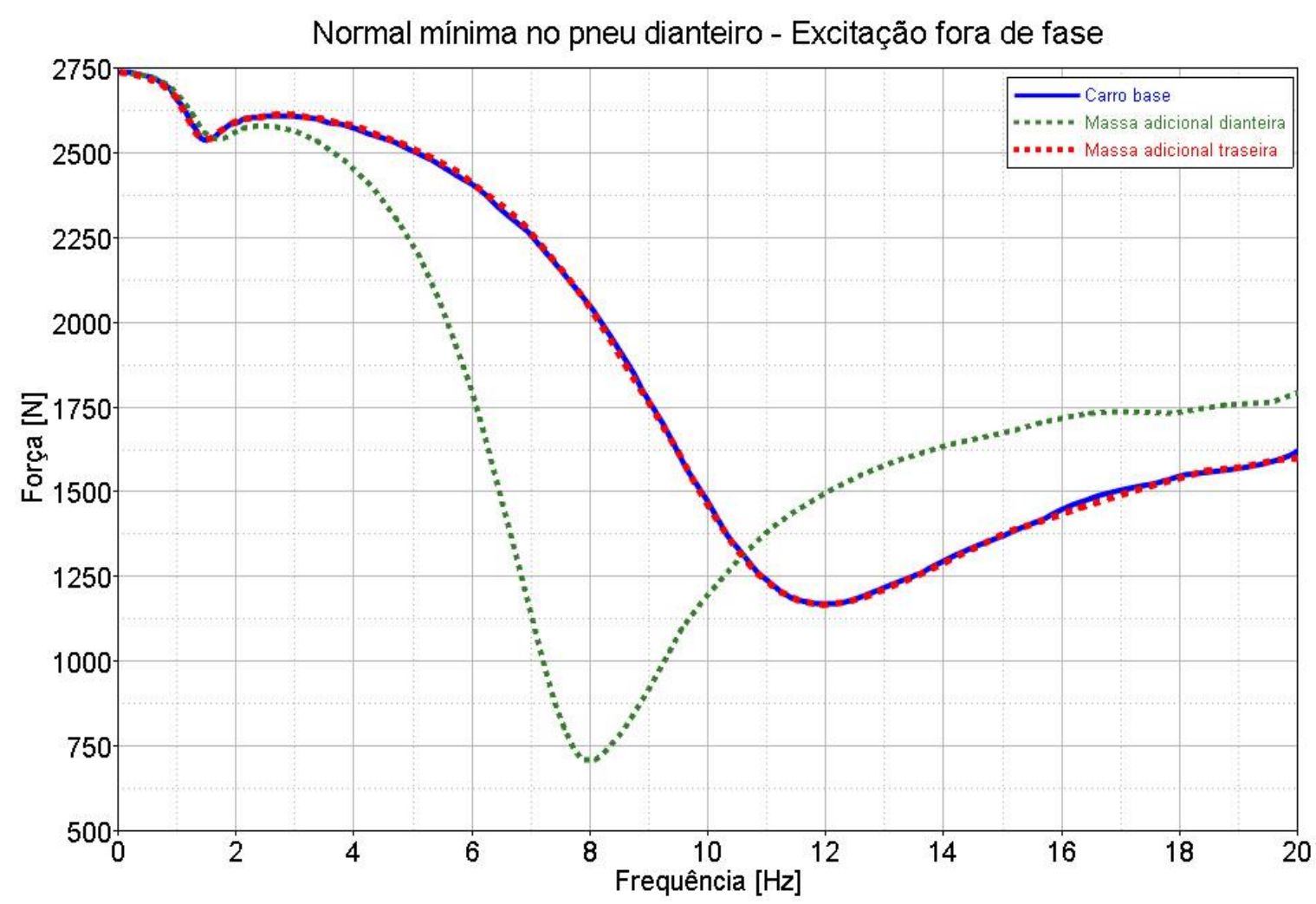

Figura 28 - Normal mínima dianteira, observada quando do modelo excitado fora de fase entre dianteira e traseira

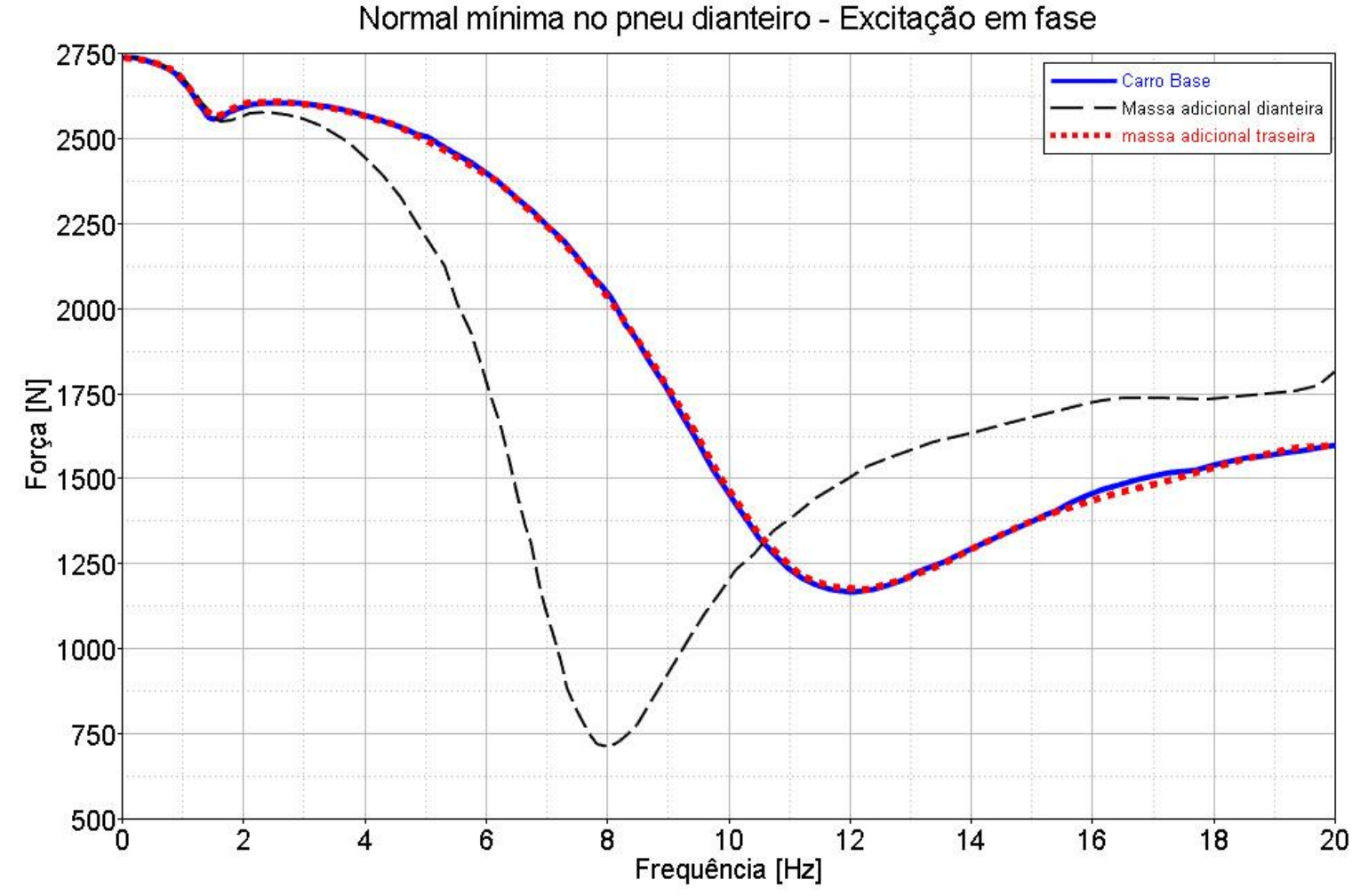

Figura 29 - Normal mínima dianteira, observada quando do modelo excitado em fase entre dianteira e traseira 


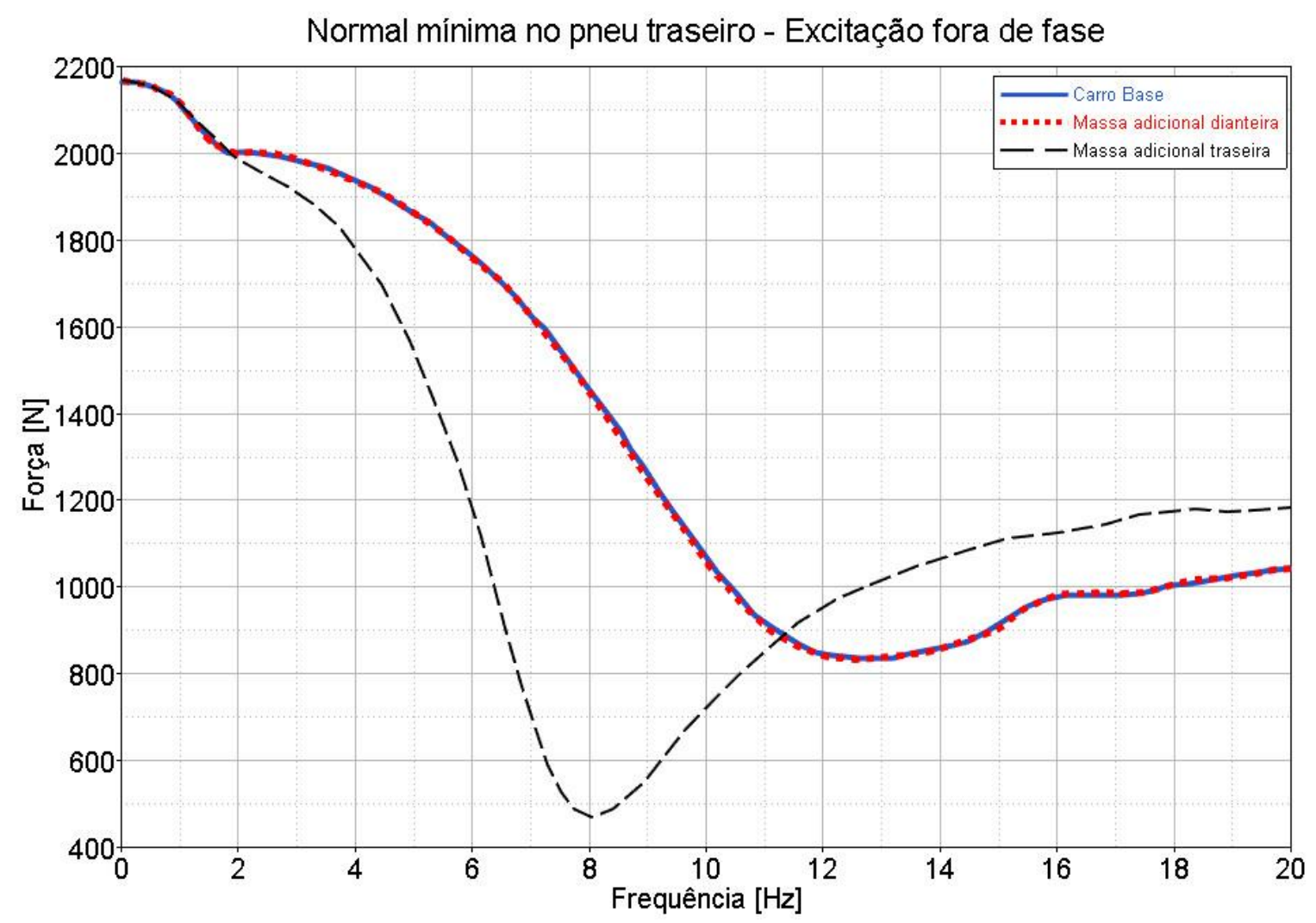

Figura 30 - Normal mínima traseira, observada quando do modelo excitado fora de fase entre dianteira e traseira

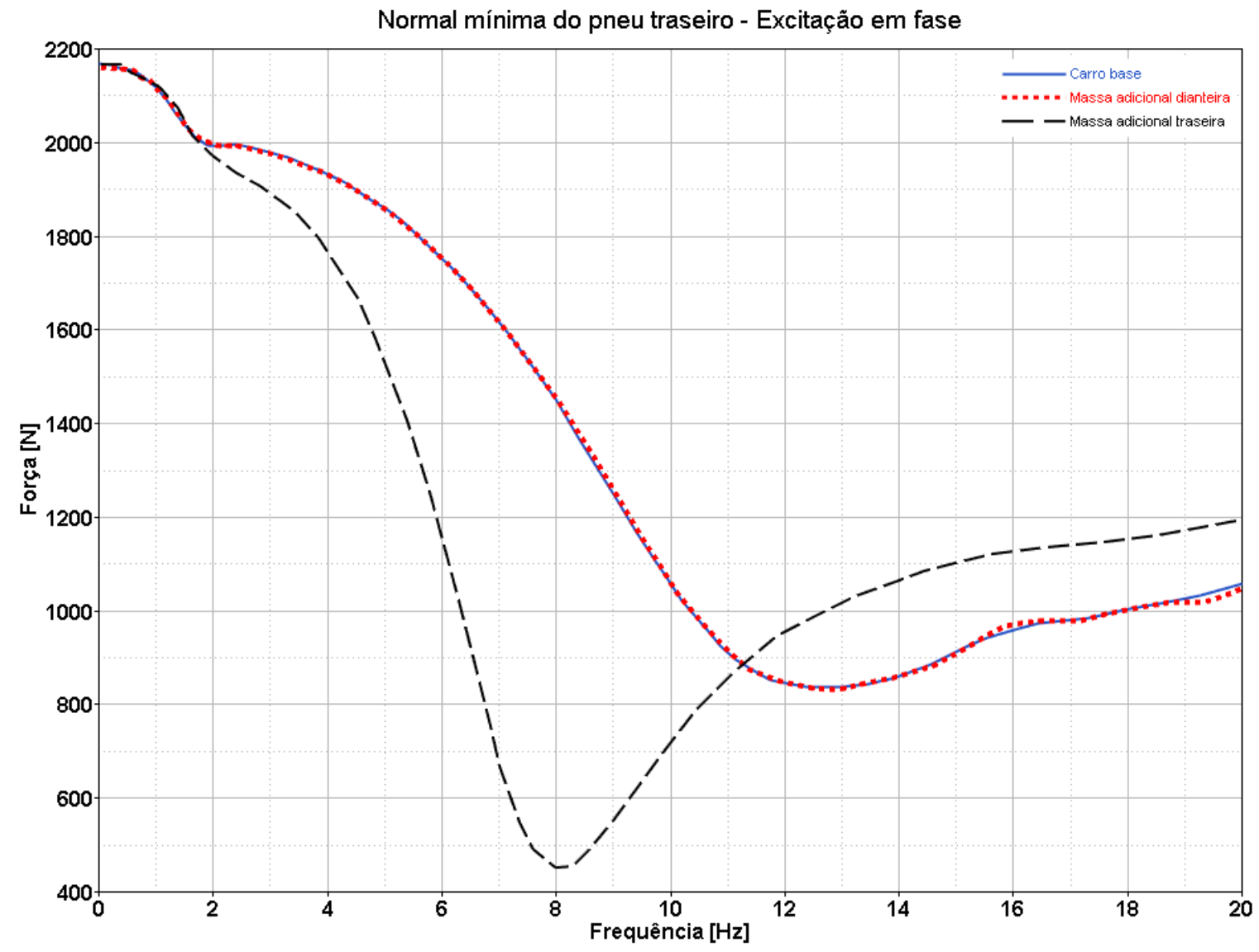

Figura 31 - Normal mínima traseira, observada quando do modelo excitado em fase entre dianteira e traseira 
Analisando os gráficos de força normal mínima (Figura 28, Figura 29, Figura 30 e Figura 31) é possível observar que houve uma redução da força normal mínima do eixo com massa acrescida, o que reduziria a sua capacidade trativa e afetaria o equilíbrio entre o eixo traseiro e dianteiro, visto que a massa somente foi acrescida em um deles. Como já se sabe, os modos de cubo afetam a reação dos pneus e a alteração ocorrida foi suficiente para influenciar nesta reação, obtendo-se resultado semelhante a (Yang, et al., 2015), como visto no capítulo 3.

Também foi identificada degradação nas acelerações verticais e de arfagem da massa suspensa (Figura 32, Figura 33, Figura 34 e Figura 35). Todos os resultados obtidos através do modelo de meio veículo foram similares ao estudo publicado por (Terra \& Barbosa, 2016) .

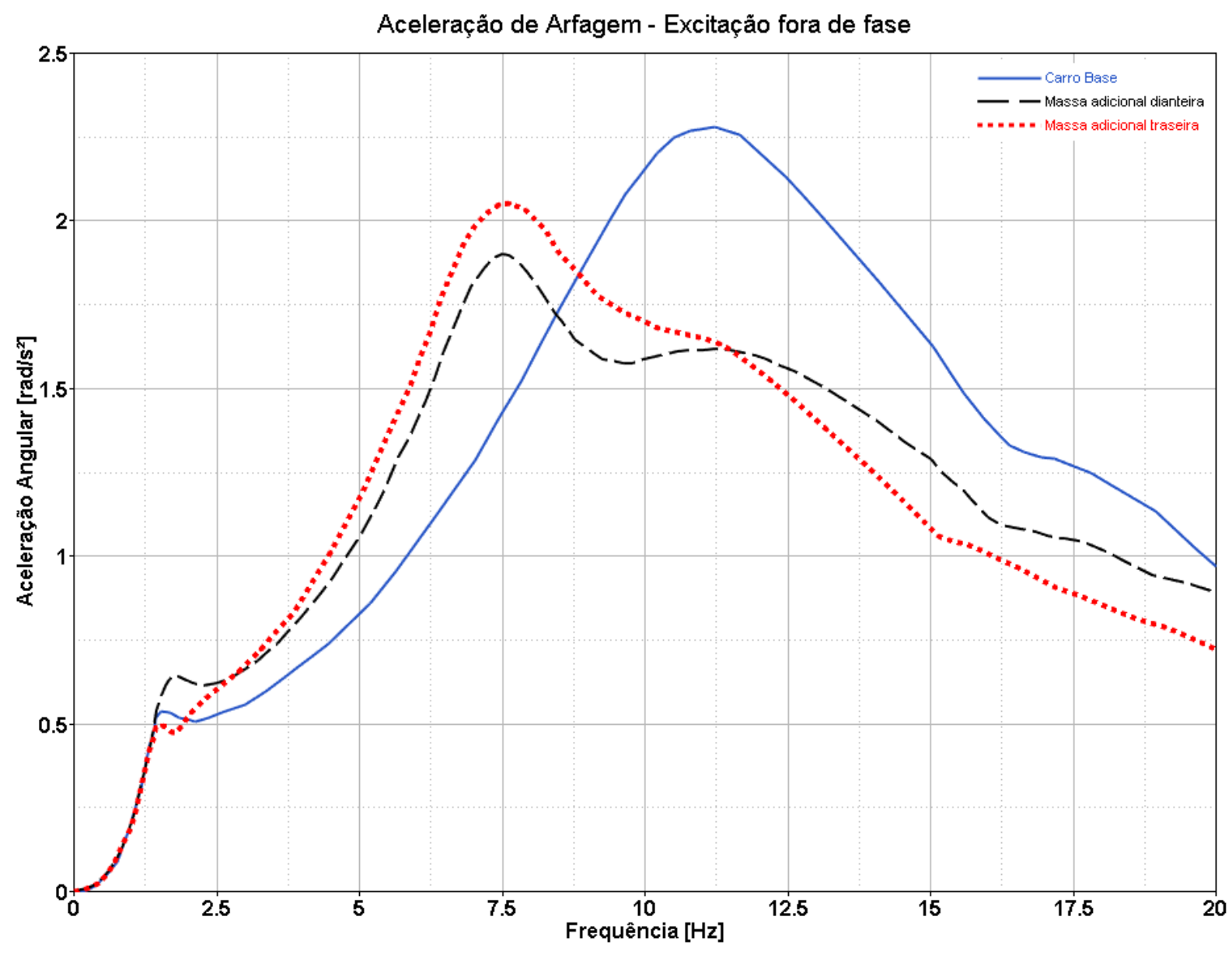

Figura 32 - Aceleração de arfagem, observada quando do modelo excitado fora de fase entre dianteira e traseira 


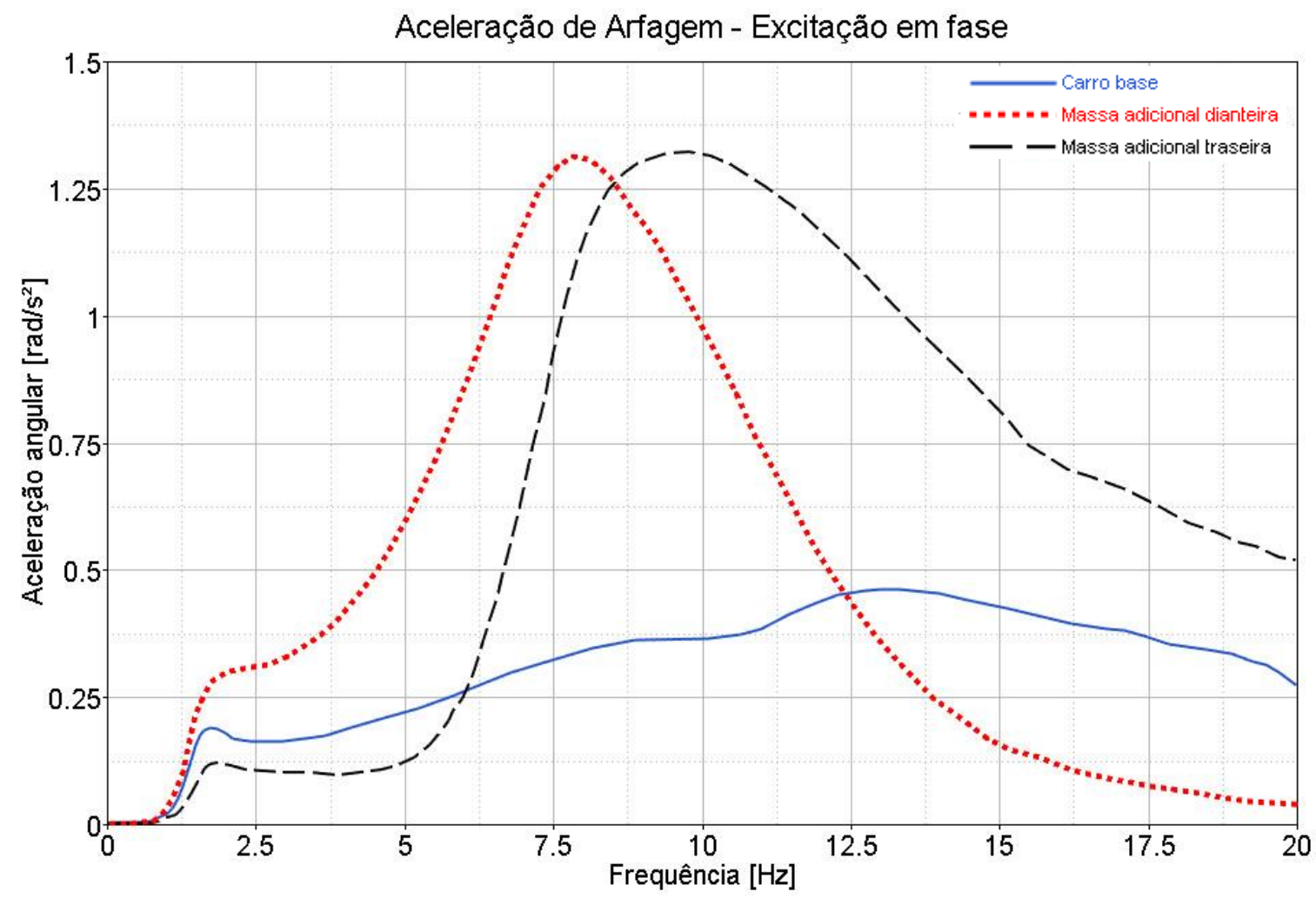

Figura 33 - Aceleração de arfagem, observada quando do modelo excitado em fase entre dianteira e traseira

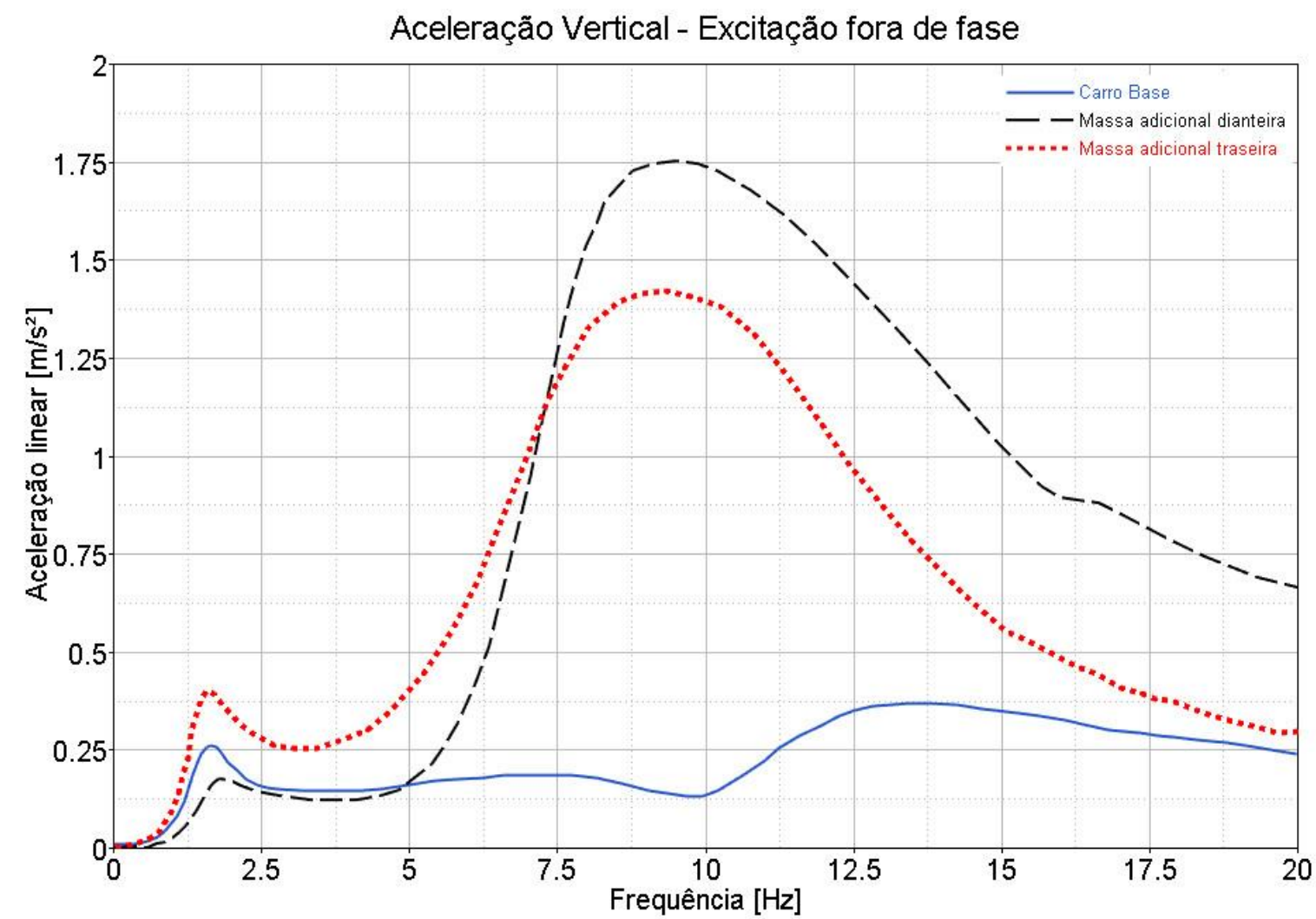

Figura 34 - Aceleração vertical, observada quando do modelo excitado fora de fase entre dianteira e traseira 


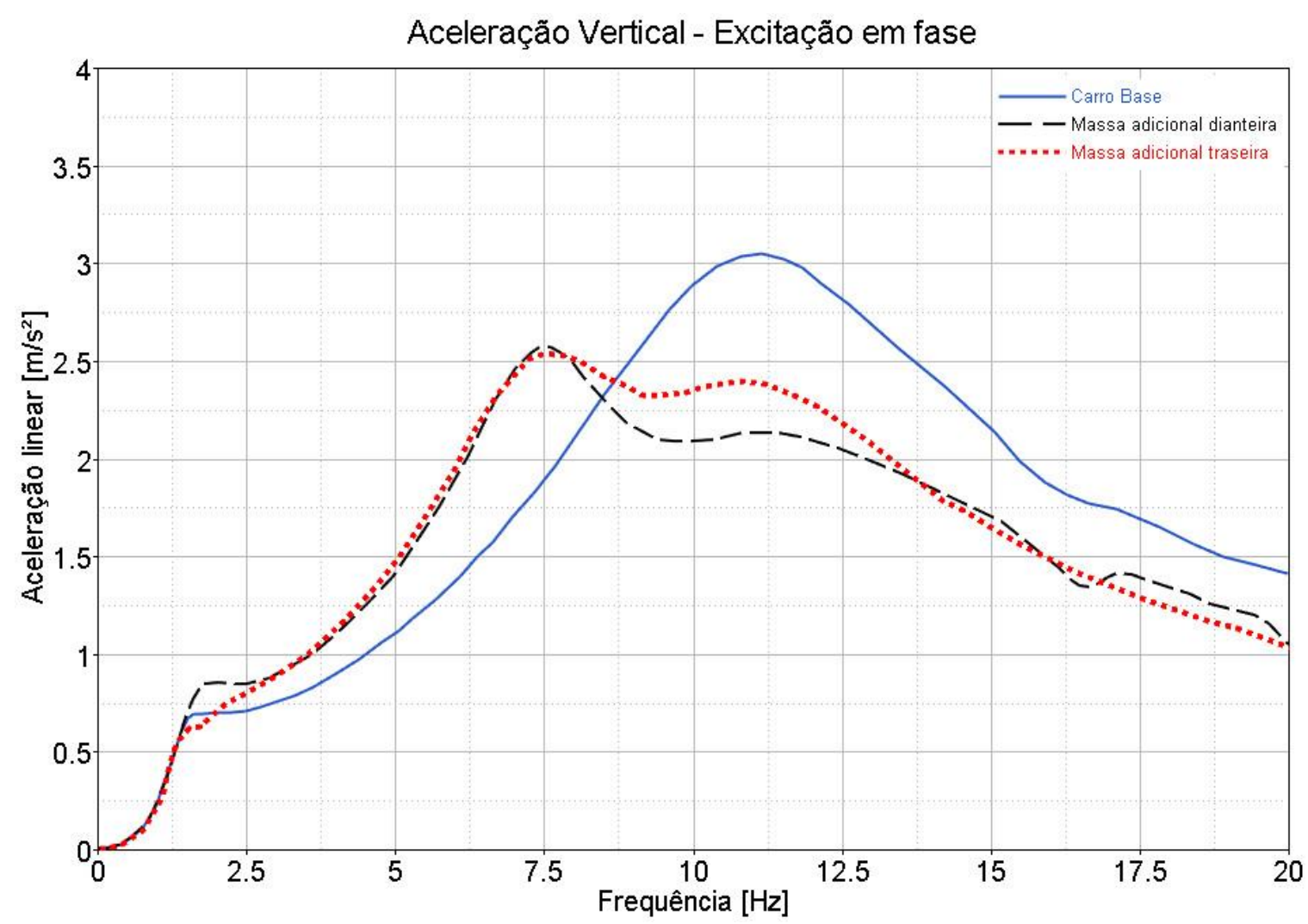

Figura 35 - - Aceleração vertical, observada quando do modelo excitado em fase entre dianteira e traseira

\subsection{Análise modal através do modelo completo}

Como uma forma mais completa de se identificar o que ocorre pelo acréscimo de massa não suspensa no veículo, uma análise modal através do modelo completo em multicorpos, detalhado na seção 5.2, será realizada.

Para tal análise, foi utilizado o comando "LINEAR/EIG" do pacote ADAMS ${ }^{\circledR}$ que captura os modos amortecidos através de uma linearização do sistema. Os resultados estão apresentados na Tabela 7. 
Tabela 7 - Resultado comparativo das análises modais

\begin{tabular}{|c|c|c|c|c|c|c|}
\hline \multirow[t]{2}{*}{ Descrição do Modo } & \multicolumn{2}{|c|}{ Carro base } & \multicolumn{2}{|c|}{$\begin{array}{l}\text { Massa não } \\
\text { suspensa } \\
\text { acrescida na } \\
\text { dianteira }\end{array}$} & \multicolumn{2}{|c|}{$\begin{array}{l}\text { Massa não } \\
\text { suspensa } \\
\text { acrescida na } \\
\text { traseira }\end{array}$} \\
\hline & $\begin{array}{l}\text { Freq. } \\
{[\mathrm{Hz}]}\end{array}$ & $\begin{array}{l}\mathrm{Am} . \\
{[\xi]}\end{array}$ & $\begin{array}{l}\text { Freq. } \\
{[\mathrm{Hz}]}\end{array}$ & $\begin{array}{l}\text { Am. } \\
{[\xi]}\end{array}$ & $\begin{array}{l}\text { Freq. } \\
{[\mathrm{Hz}]}\end{array}$ & $\begin{array}{l}\mathrm{Am} . \\
{[\xi]}\end{array}$ \\
\hline $\begin{array}{l}\text { Rolagem com pivotamento inferior } \\
\text { "Lower Sway" }\end{array}$ & 1.04 & 0.119 & 1.04 & 0.102 & 1.02 & 0.115 \\
\hline $\begin{array}{l}\text { Combinação entre movimentos de } \\
\text { arfagem e vertical com } \\
\text { pivotamento traseiro "Rear end } \\
\text { bounce" }\end{array}$ & 1.28 & 0.139 & 1.27 & 0.137 & 1.27 & 0.142 \\
\hline $\begin{array}{l}\text { Combinação entre movimentos de } \\
\text { arfagem e vertical com } \\
\text { pivotamento dianteiro "Front end } \\
\text { bounce" }\end{array}$ & 1.52 & 0.116 & 1.47 & 0.117 & 1.52 & 0.099 \\
\hline $\begin{array}{l}\text { Rolagem com pivotamento } \\
\text { superior "Upper Sway" }\end{array}$ & 2.67 & 0.072 & 2.65 & 0.072 & 2.64 & 0.069 \\
\hline $\begin{array}{l}\text { Movimento vertical da massa não } \\
\text { suspensa traseira fora de fase }\end{array}$ & 10.41 & 0.231 & 10.51 & 0.232 & 7.59 & 0.247 \\
\hline $\begin{array}{l}\text { Movimento vertical da massa não } \\
\text { suspensa traseira em fase }\end{array}$ & 12.33 & 0.182 & 12.31 & 0.183 & 9.93 & 0.197 \\
\hline $\begin{array}{l}\text { Movimento vertical da massa não } \\
\text { suspensa dianteira fora de fase }\end{array}$ & 11.66 & 0.413 & 8.69 & 0.416 & 11.64 & 0.419 \\
\hline $\begin{array}{l}\text { Movimento vertical da massa não } \\
\text { suspensa dianteira em fase }\end{array}$ & 11.99 & 0.433 & 10.04 & 0.430 & 11.94 & 0.419 \\
\hline
\end{tabular}




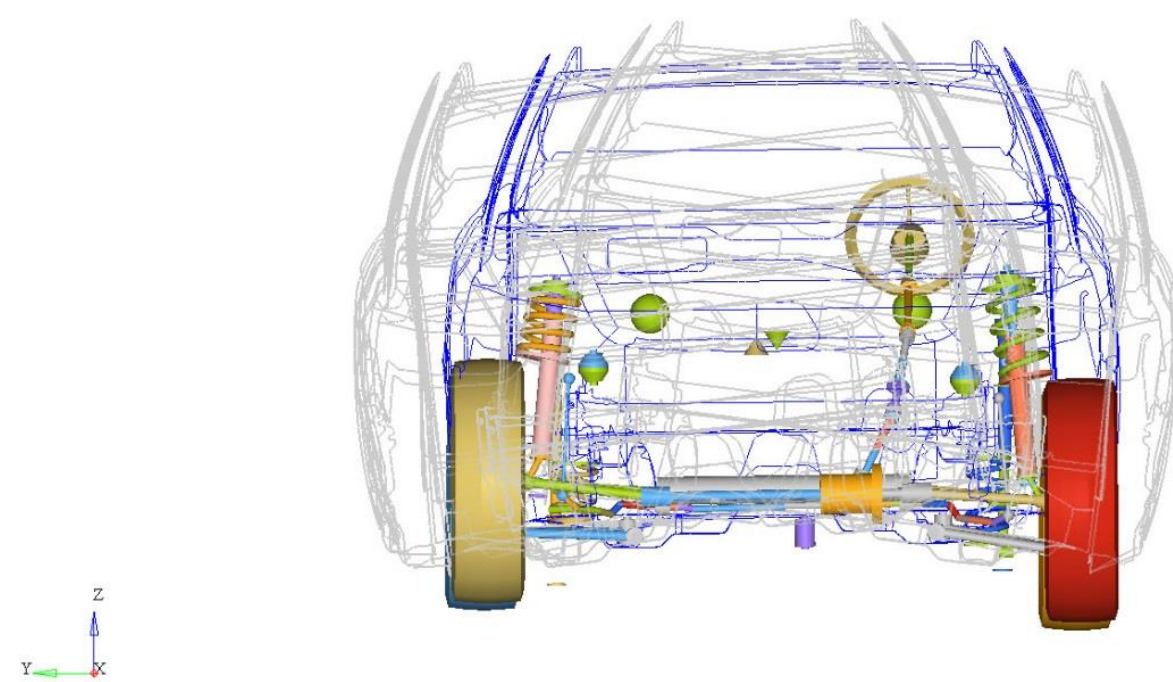

Figura 36 - Rolagem com pivotamento inferior "Lower Sway"

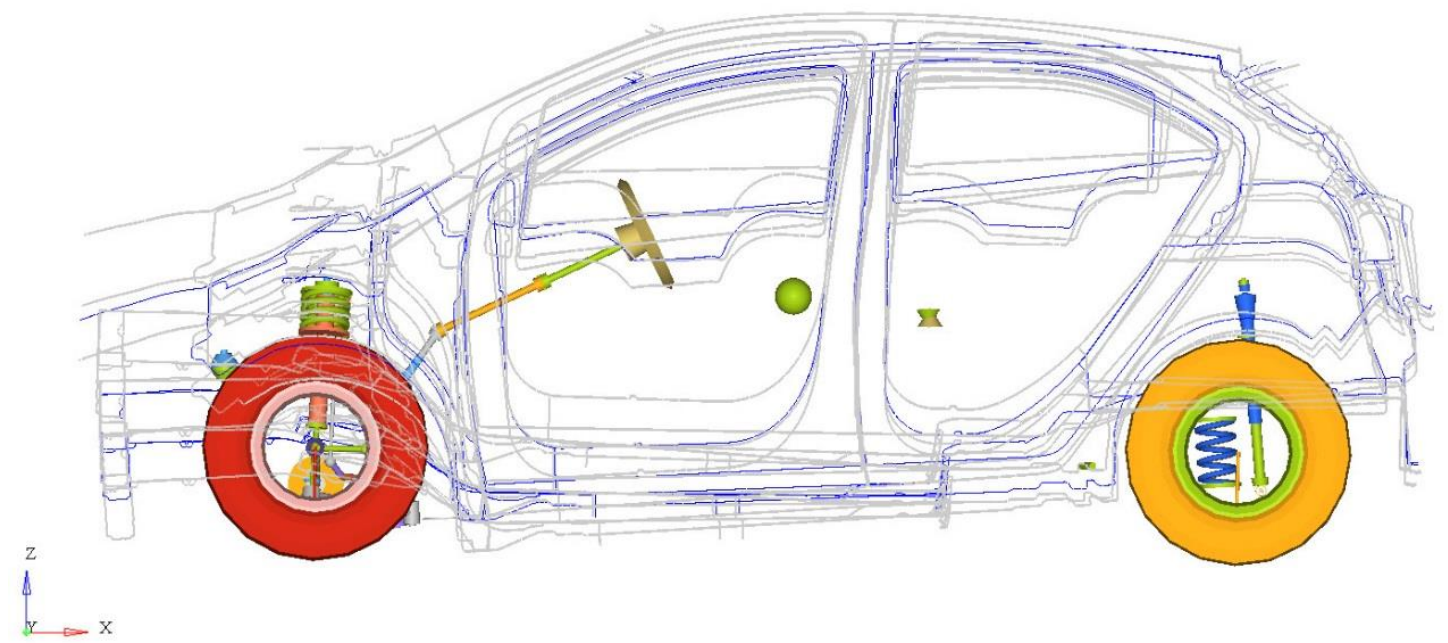

Figura 37 - Combinação entre movimentos de arfagem e vertical com pivotamento traseiro "Rear end bounce"

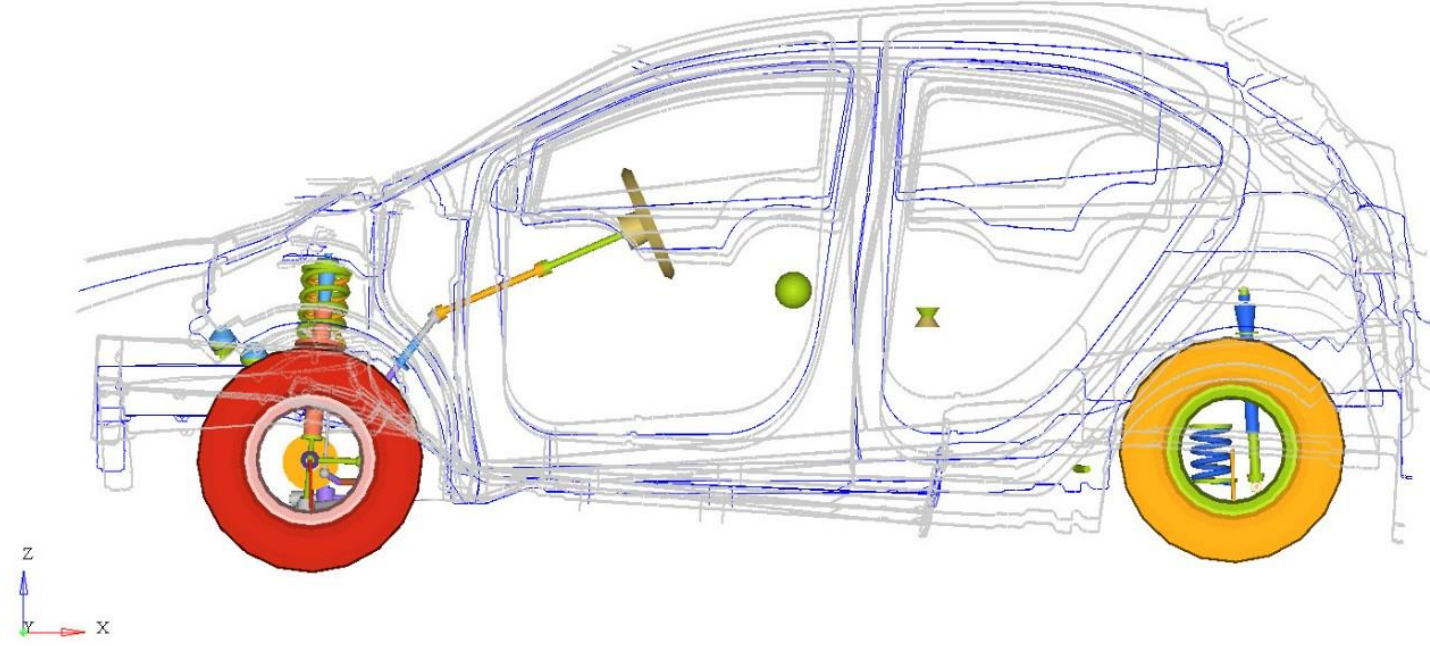

Figura 38 - Combinação entre movimentos de arfagem e vertical com pivotamento dianteiro "Front end bounce" 


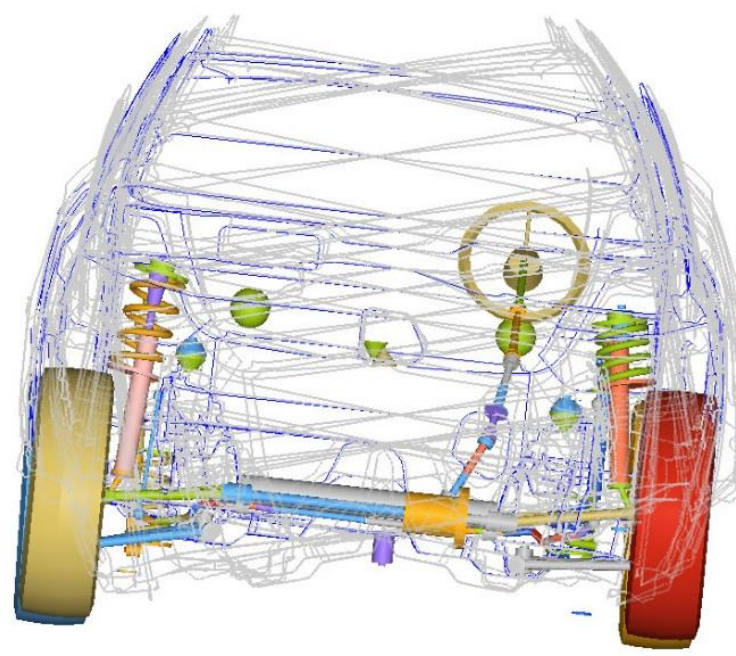

Figura 39 - Rolagem com pivotamento superior "Upper Sway"

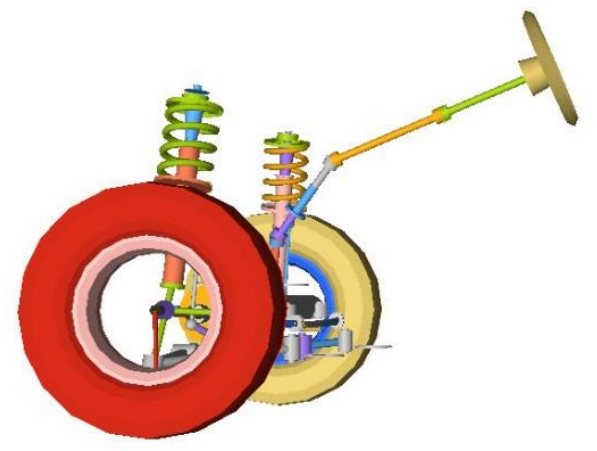

$\theta$

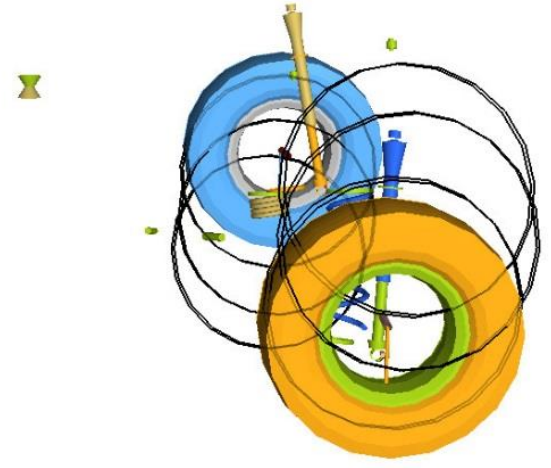

Figura 40 - Movimento vertical da massa não suspensa traseira fora de fase
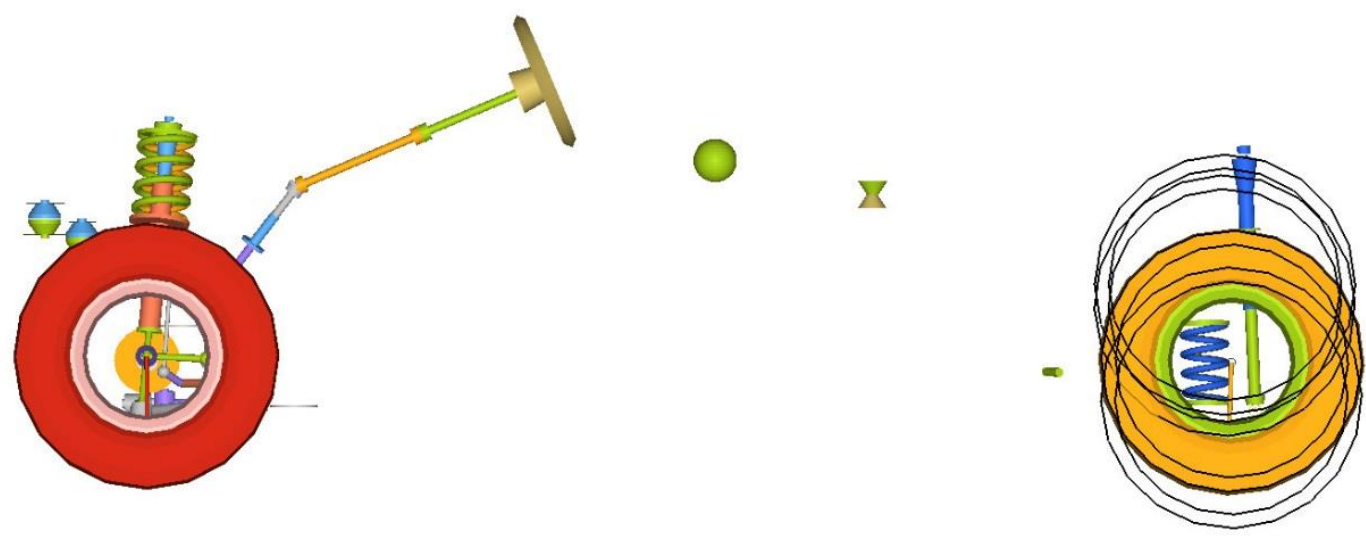

Figura 41 - Movimento vertical da massa não suspensa traseira em fase 

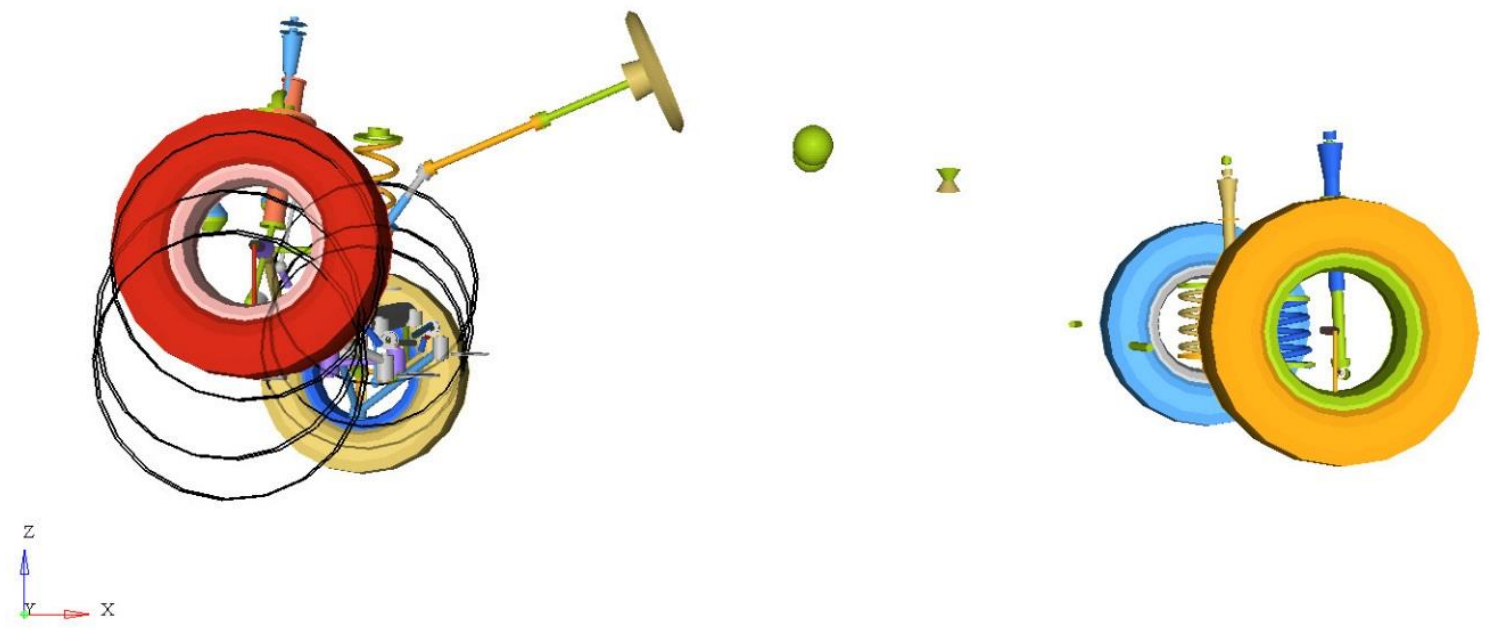

Figura 42 - Movimento vertical da massa não suspensa dianteira fora de fase
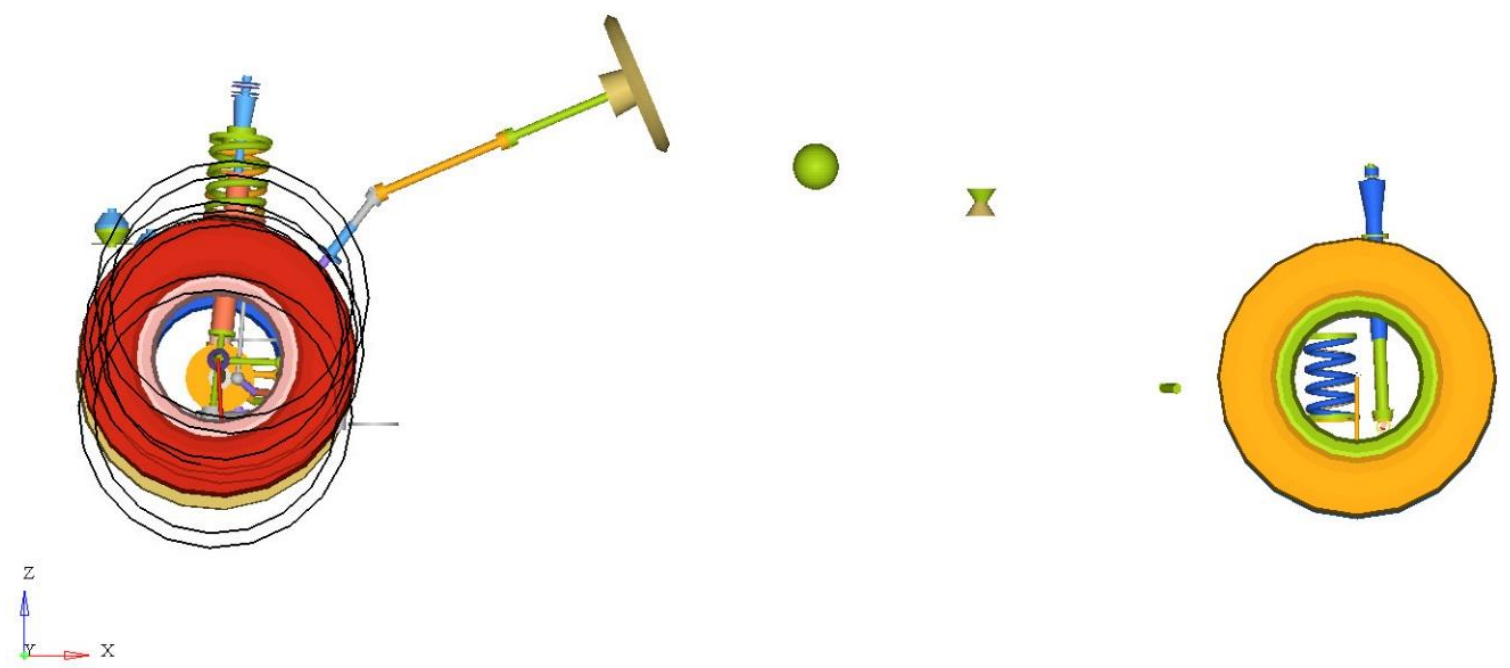

Figura 43 - Movimento vertical da massa não suspensa dianteira em fase

Através das análises dos modos, é possível observar uma redução de cerca de $30 \%$ da frequência dos modos de massa não suspensa no eixo que teve a massa acrescida, concordando com o identificado com o modelo mais simples. Sabe-se que estes modos estão extremamente conectados à capacidade de o pneu manter contato com o solo (Barbosa, 2012) e, desta forma, são esperadas mudanças indesejavéis no comportamento de dirigibilidade do veículo.

Já nos demais modos, as mudanças foram menos perceptíveis, especialmente nos modos de carroceria. 


\subsection{Dirigibilidade}

Para se avaliar de maneira direta como a massa não suspensa afeta a dirigibilidade do veículo, faz-se necessária a execução de manobras padronizadas através do modelo completo de multicorpos.

Desta maneira, consegue-se avaliar todos os deslocamentos, velocidades, acelerações e esforços ocorridos no automóvel como um todo e também nos mecanismos internos da suspensão e direção. Assim, é possível avaliar inúmeras métricas conhecidas de dirigibilidade pela análise direta dos dados, ou em combinações estratégicas destes.

\subsubsection{Manobras em regime permanente}

A manobra mais simples de ser executada é aquela em que se faz uma curva de raio constante, a uma velocidade constante, definida na norma ISO 4138 e também apresentada na norma SAE J266. Através desta manobra, consegue-se identificar algumas propriedades do veículo em regime permanente para diferentes acelerações laterais.

Com ajuda desta manobra, é possível medir o gradiente de rolagem, que nada mais é do que a derivada do ângulo de rolagem do automóvel em função de sua aceleração lateral medida no centro de gravidade.

Também é possível medir o coeficiente de subesterço que é definido como a derivada do ângulo médio de esterçamento também em função da aceleração lateral (alterada mudando-se a velocidade do carro). Assim, podemos observar estas medidas na Tabela 8. 
Tabela 8 - Resultados da Manobra de raio constante e velocidade constante para diferentes acelerações laterais.

\begin{tabular}{|c|c|c|c|c|c|c|}
\hline \multirow[b]{2}{*}{$\begin{array}{l}\text { Aceleração } \\
\text { lateral } \\
{\left[\mathrm{m} / \mathrm{s}^{2}\right]}\end{array}$} & \multicolumn{2}{|c|}{ Carro base } & \multicolumn{2}{|c|}{$\begin{array}{c}\text { Massa não suspensa } \\
\text { acrescida na } \\
\text { dianteira }\end{array}$} & \multicolumn{2}{|c|}{$\begin{array}{l}\text { Massa não suspensa } \\
\text { acrescida na traseira }\end{array}$} \\
\hline & $\begin{array}{c}\text { Gradiente } \\
\text { de } \\
\text { Rolagem } \\
{[\because / g]}\end{array}$ & $\begin{array}{c}\text { Coeficiente } \\
\text { de } \\
\text { subesterço } \\
{[\because / g]}\end{array}$ & $\begin{array}{c}\text { Gradiente } \\
\text { de } \\
\text { Rolagem } \\
{[\because / g]}\end{array}$ & $\begin{array}{c}\text { Coeficiente } \\
\text { de } \\
\text { subesterço } \\
{[\because / g]}\end{array}$ & $\begin{array}{l}\text { Gradiente } \\
\text { de } \\
\text { Rolagem } \\
{[\because / g]}\end{array}$ & $\begin{array}{l}\text { Coeficiente } \\
\text { de } \\
\text { subesterço } \\
{\left[{ }^{\circ} / \mathrm{g}\right]}\end{array}$ \\
\hline 1.5 & 4.23 & 1.33 & 4.17 & 1.38 & 4.27 & 1.36 \\
\hline 3 & 4.26 & 1.51 & 4.33 & 1.62 & 4.29 & 1.54 \\
\hline 5 & 4.37 & 2.13 & 4.57 & 2.32 & 4.39 & 2.19 \\
\hline 7 & 4.64 & 3.58 & 4.57 & 3.72 & 4.66 & 3.68 \\
\hline
\end{tabular}

Outra manobra, ainda em regime permanente, que pode ser executada é a manobra de busca do centro: o carro anda em uma velocidade compatível com uma rodovia e uma entrada senoidal é dada no volante de maneira bem suave, buscando simular uma situação de correção de trajetória em uma rodovia.

Através desta manobra, pode-se medir propriedades como a sensibilidade da direção, que é definida como a derivada da aceleração lateral em relação ao seu centro de gravidade, em função do ângulo de volante imposto, a sua unidade é geralmente dada em g por $100^{\circ}$ de ângulo de esterçamento (Vilela \& Barbosa, 2011). Sendo assim, os resultados são mostrados na Tabela 9.

Tabela 9 - Medição da sensibilidade da direção com ajuda da manobra de busca do centro

\begin{tabular}{c|c|c|c} 
& Carro base & $\begin{array}{c}\text { Massa não suspensa } \\
\text { acrescida na } \\
\text { dianteira }\end{array}$ & $\begin{array}{c}\text { Massa não suspensa } \\
\text { acrescida na traseira }\end{array}$ \\
\hline $\begin{array}{c}\text { Velocidade } \\
{[\mathrm{km} / \mathrm{h}]}\end{array}$ & $\begin{array}{c}\text { Sensibilidade da } \\
\text { direção } \\
{\left[\mathrm{g} / 100^{\circ}\right]\left(\left[\mathrm{m} / \mathrm{s}^{2} / \stackrel{\circ}{ }\right]\right)}\end{array}$ & $\begin{array}{c}\text { Sensibilidade da } \\
\text { direção } \\
{\left[\mathrm{g} / 100^{\circ}\right]\left(\left[\mathrm{m} / \mathrm{s}^{2} / \stackrel{\circ}{\circ}\right)\right.}\end{array}$ & $\begin{array}{c}\text { Sensibilidade da } \\
\text { direção } \\
{\left[\mathrm{g} / 100^{\circ}\right]\left(\left[\mathrm{m} / \mathrm{s}^{2} / \stackrel{\circ}{ } \mathrm{o}\right]\right)}\end{array}$ \\
\hline 60 & $0.87(0.085)$ & $0.87(0.085)$ & $0.86(0.084)$ \\
\hline 80 & $1.30(0.128)$ & $1.29(0.127)$ & $1.29(0.127)$ \\
\hline 100 & $1.70(0.167)$ & $1.69(0.166)$ & $1.68(0.165)$ \\
\hline 120 & $2.06(0.202)$ & $2.04(0.200)$ & $2.03(0.199)$ \\
\hline 140 & $2.36(0.232)$ & $2.33(0.229)$ & $2.34(0.230)$
\end{tabular}

Também na norma SAE J266, tem-se a manobra na qual o veículo mantém a velocidade constante e vai aumentando o ângulo de esterço do volante de maneira gradativa, incrementando a aceleração lateral, até a perda de contato dos pneus, fazendo o trajeto de um espiral (Figura 44). 


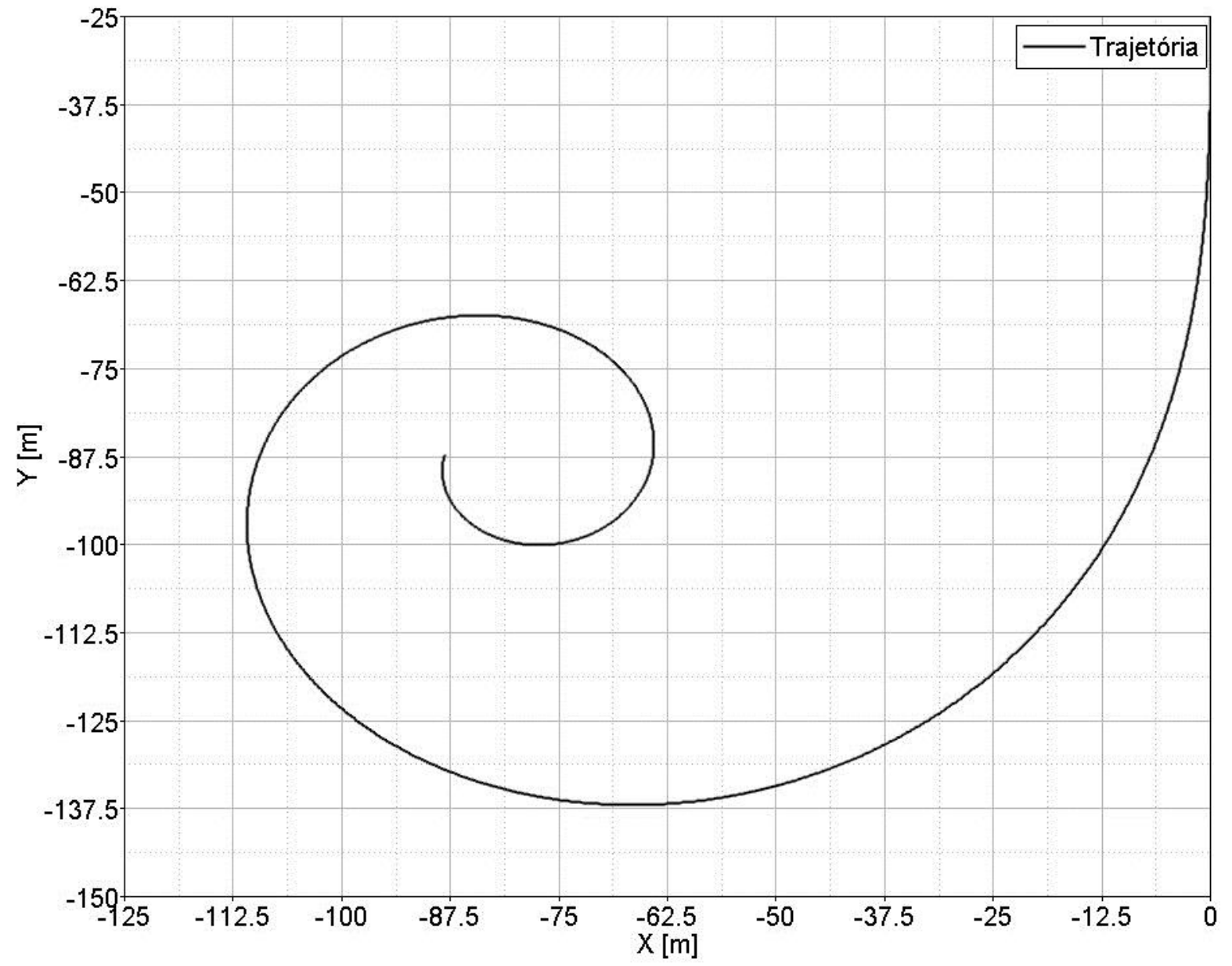

Figura 44 - Trajetória descrita do veículo durante a manobra de velocidade constante com esterço incremental.

Com esta manobra, consegue-se identificar a máxima aceleração lateral possível de se obter em regime permanente apresentado na Tabela 10 e observadas na saturação ao longo do incremento do ângulo de esterço (Figura 45). E novamente é possível notar uma diferença quase imperceptível entre as configurações utilizadas. 
Tabela 10 - Máxima aceleração lateral identificada durante a manobra de velocidade constante e incremento gradual de esterço.

\begin{tabular}{c|c|c} 
Carro base & $\begin{array}{c}\text { Massa não suspensa } \\
\text { acrescida na dianteira }\end{array}$ & $\begin{array}{c}\text { Massa não suspensa } \\
\text { acrescida na traseira }\end{array}$ \\
\hline $\begin{array}{c}\text { Aceleração lateral } \\
\text { máxima }\left[\mathrm{m} / \mathrm{s}^{2}\right]\end{array}$ & $\begin{array}{c}\text { Aceleração lateral } \\
\text { máxima }\left[\mathrm{m} / \mathrm{s}^{2}\right]\end{array}$ & $\begin{array}{c}\text { Aceleração lateral } \\
\text { máxima }\left[\mathrm{m} / \mathrm{s}^{2}\right]\end{array}$ \\
\hline 8.32 & 8.36 & 8.34
\end{tabular}

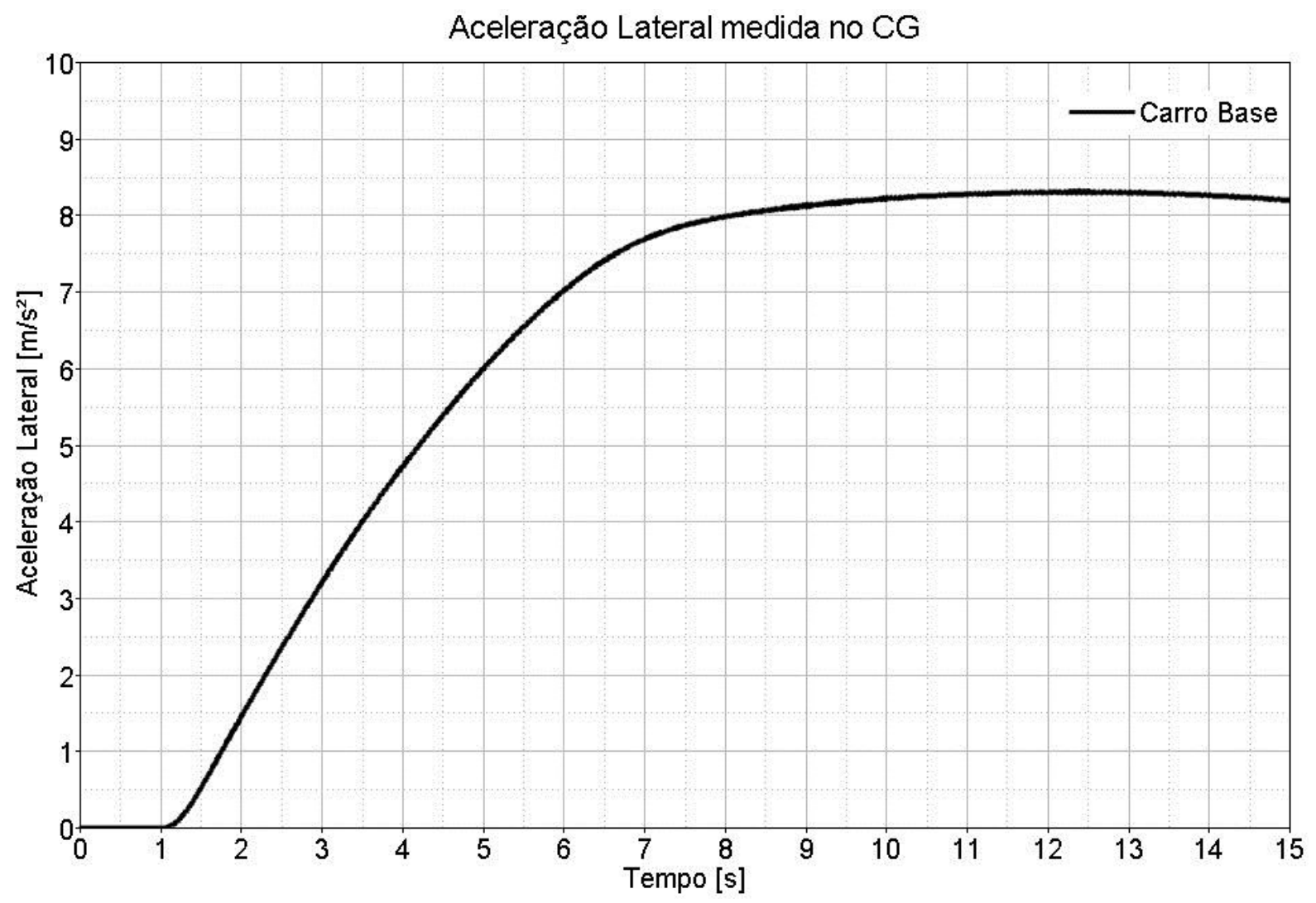

Figura 45 - Aceleração lateral medida ao longo da manobra de velocidade constante e incremento gradual de esterço

Da mesma maneira, na norma SAE J266 consta a manobra de raio constante com incremento de velocidade, mas neste caso o carro é conduzido de maneira que seu curso seja um círculo perfeito. Para realizar esta manobra, o veículo vai aumentando a sua velocidade gradualmente e o volante vai tendo seu ângulo alterado de maneira que o carro mantenha-se sempre no raio pré-determinado. Fisicamente, esta manobra exige grande perícia do piloto para garantir que o carro mantenha-se 
no mesmo raio. No ambiente multicorpos, entretanto, um controlador do tipo PID é o suficiente para executar a tarefa sem maiores dificuldades.

Tabela 11 Máxima aceleração lateral identificada durante a manobra raio constante com incremento de velocidade

\begin{tabular}{c|c|c} 
Carro base & $\begin{array}{c}\text { Massa não suspensa } \\
\text { acrescida na dianteira }\end{array}$ & $\begin{array}{c}\text { Massa não suspensa } \\
\text { acrescida na traseira }\end{array}$ \\
\hline $\begin{array}{c}\text { Aceleração lateral } \\
\text { máxima }\left[\mathrm{m} / \mathrm{s}^{2}\right]\end{array}$ & $\begin{array}{c}\text { Aceleração lateral } \\
\text { máxima }\left[\mathrm{m} / \mathrm{s}^{2}\right]\end{array}$ & $\begin{array}{c}\text { Aceleração lateral } \\
\text { máxima }\left[\mathrm{m} / \mathrm{s}^{2}\right]\end{array}$ \\
\hline 8.17 & 8.04 & 8.06
\end{tabular}

Já nesta manobra, observa-se uma ligeira diferença de cerca de $1.5 \%$ na máxima aceleração lateral atingida. Adicionalmente a manobra anterior não indicou nenhuma mudança neste sentido, o que indica que os três carros são capazes de obter acelerações laterais extremamente semelhantes em regime permanente.

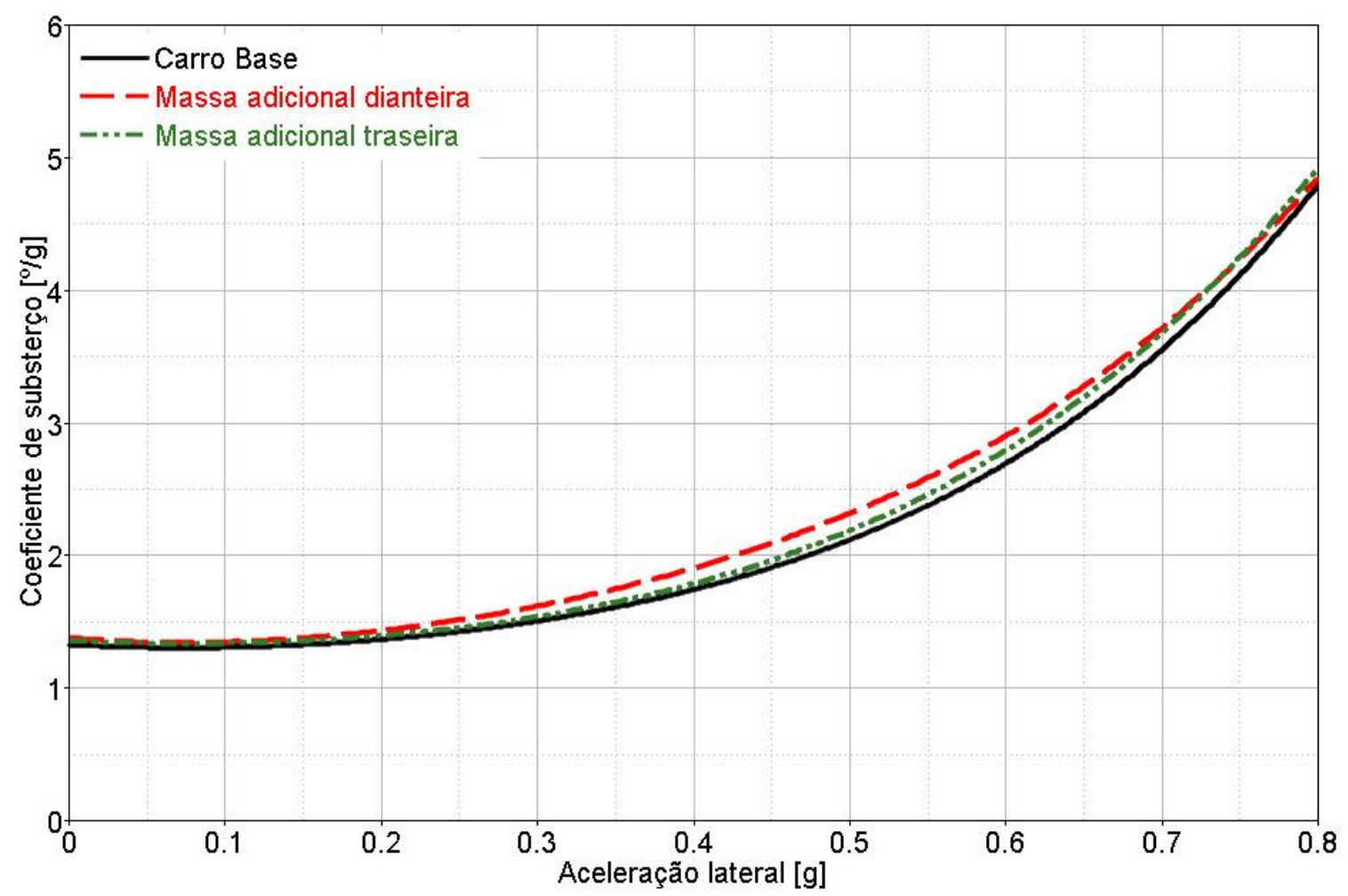

Figura 46 - Coeficiente de subesterço em função da aceleração lateral capturado durante a manobra de raio constante com incremento gradual de velocidade. 
Também ao se observar o coeficiente de subesterço durante o procedimento de raio constante com incremento gradual de velocidade (Figura 46), pode-se concluir que a diferença entre as configurações estudadas é mínima, e que todos têm comportamento substerçante que aumenta conforme o incremento da aceleração lateral ao longo da manobra.

Ao se analisar os resultados das manobras em regime permanente, não se notaram grandes degradações das métricas de dirigibilidade. Porém, como visto na revisão bibliográfica e na análise modal, são esperadas alterações no comportamento do veículo, então mais avaliações far-se-ão necessárias, na faixa não linear de dirigibilidade, para se ter real dimensão dos efeitos da adição de massa não suspensa.

\subsubsection{Manobras não lineares}

A manobra de mudança de faixa ("Single Lane Change"), é uma manobra que simula uma troca de faixa na condição de rodovia de maneira abrupta (Figura 47).

Esta manobra é realizada fisicamente por um piloto, em ambiente controlado para diversas velocidades, até a falha, ou seja, até o carro derrapar ou capotar. É esperado que todos os carros comerciais leves consigam executar esta manobra até velocidades superiores a $80 \mathrm{~km} / \mathrm{h}$.

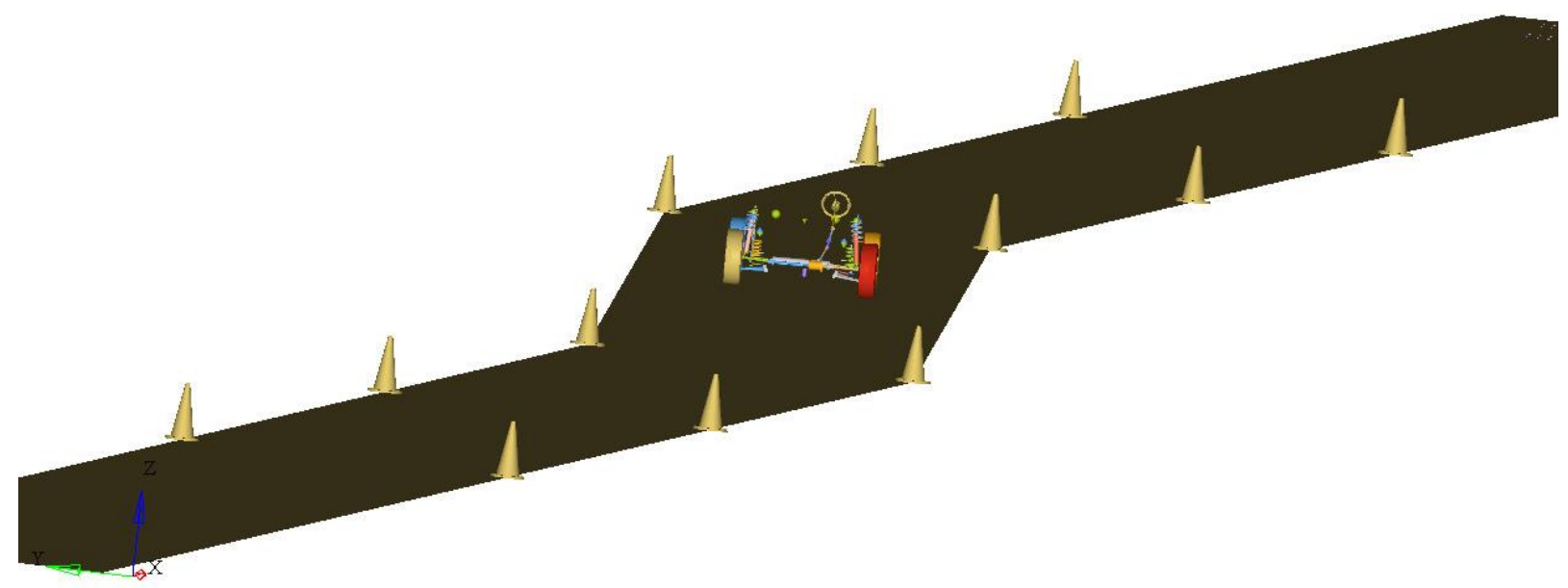

Figura 47 - Manobra de troca de faixa 
Para se comparar o resultado da manobra será monitorada a força normal dos pneus, que indicam o quão efetivo está sendo o contato do pneu com o solo, que está ligado à capacidade de gerar forças tangenciais e, consequentemente, são uma boa comparação para se avaliar a dirigibilidade de um automóvel (Barbosa, 2011).

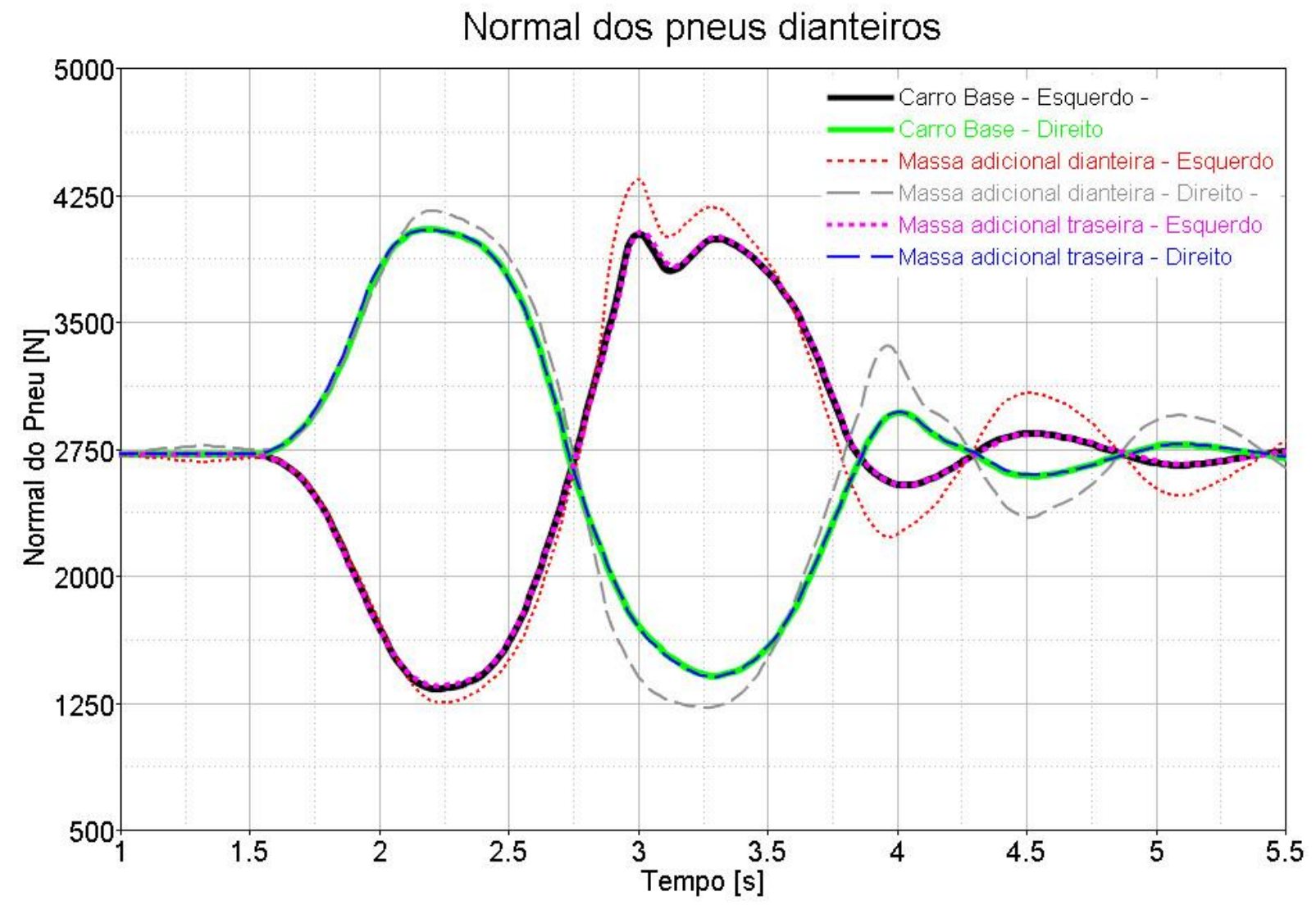

Figura 48 - Normal dos pneus dianteiros na manobra de troca de faixa feita a $100 \mathrm{~km} / \mathrm{h}$ 


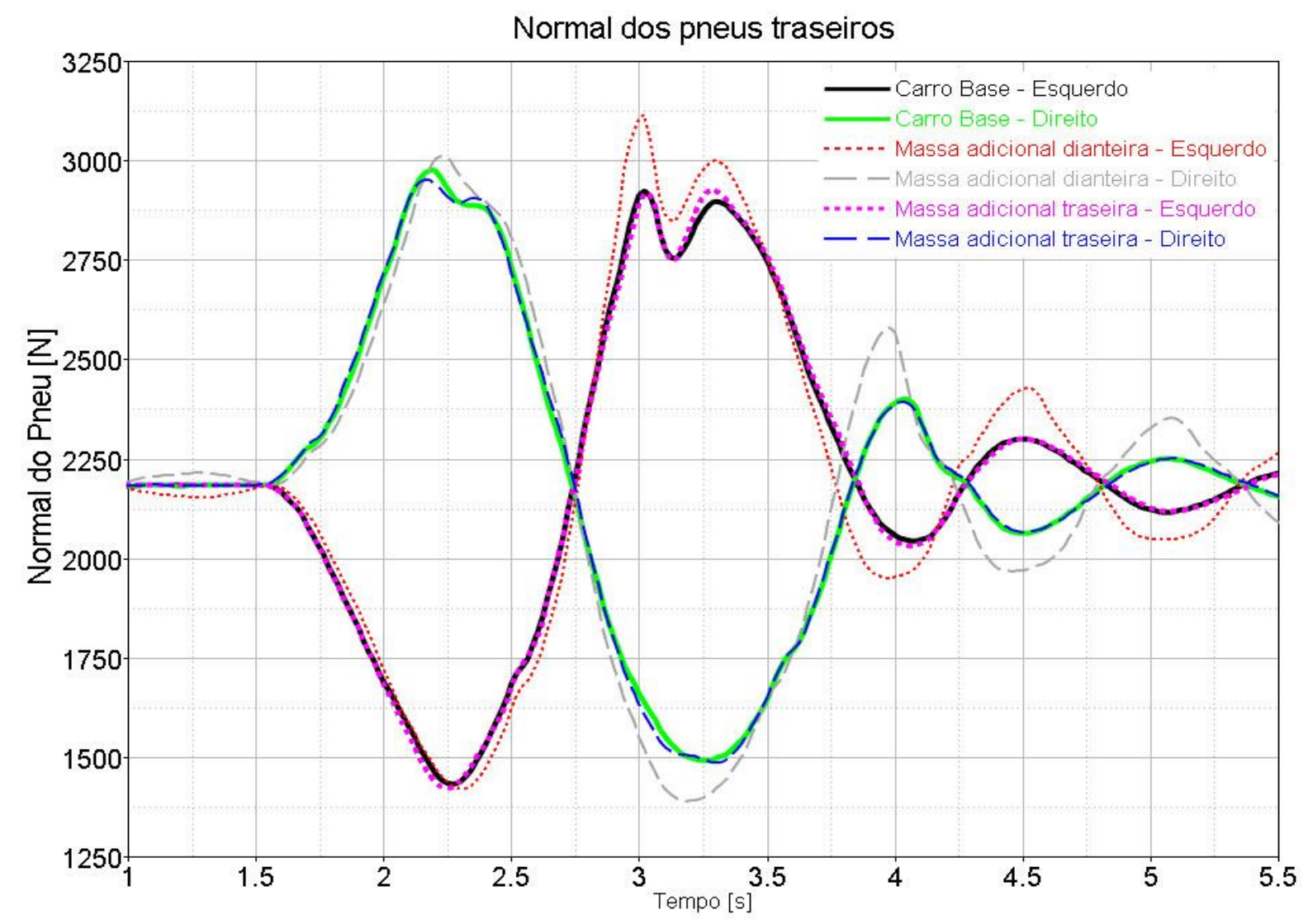

Figura 49 - Normal dos pneus traseiros na manobra de troca de faixa feita a $100 \mathrm{~km} / \mathrm{h}$

Comparando-se os resultados da manobra de troca de faixa, Figura 48 e Figura 49, é possível ver uma degradação da normal dos pneus, quando a massa não suspensa é acrescida no eixo dianteiro, o que é um indicativo de diferença de performance dependendo de onde a massa está alojada.

Outra análise transiente possível para se avaliar o veículo é a manobra do anzol, também conhecida por "Fish Hook maneuver". Esta manobra avalia o controle do veículo e a sua tendência de capotamento. Segundo o departamento nacional de trânsito norte-americano (NHTSA), um veículo para ser comercializado não pode erguer nenhuma de suas rodas por mais de duas polegadas quando esta manobra é realizada em um intervalo de 35 a 50 milhas por hora $(56 \mathrm{~km} / \mathrm{h}$ a $80 \mathrm{~km} / \mathrm{h})$.

Basicamente, a manobra consiste em virar o volante, com a ajuda de um robô, para a esquerda rapidamente, na posição na qual ele atingiria $0.3 \mathrm{~g}$ de aceleração lateral em uma situação de regime permanente e depois, da mesma forma, para o ângulo exatamente oposto. 
Esta manobra é execuada monitorando com rodas instrumentadas a normal dos pneus (Figura 50). Após a realização da manobra ele é repetido invertendo os sentidos de viragem do volante, pois um centro de gravidade deslocado do plano central do veículo pode gerar resultados diferentes entre um lado e o outro.

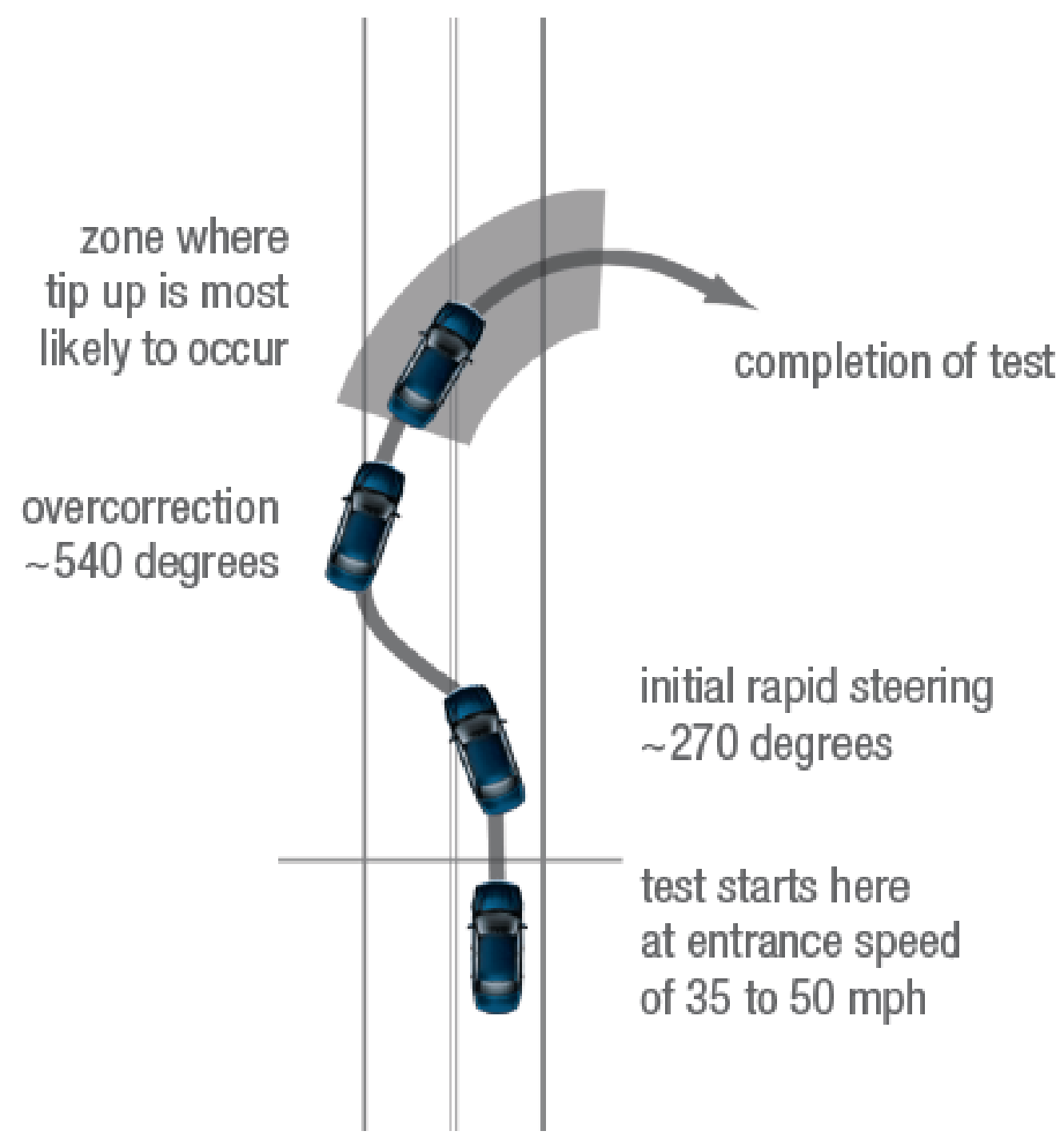

Figura 50 - Exemplificação da trajetória da manobra do anzol, para um veículo específico segundo HLDI, 2004

Porém o ângulo e velocidade de esterçamento exatos independentemente da velocidade e do modelo do carro são descritos pelo NHTSA como mostrado na Figura 51. 


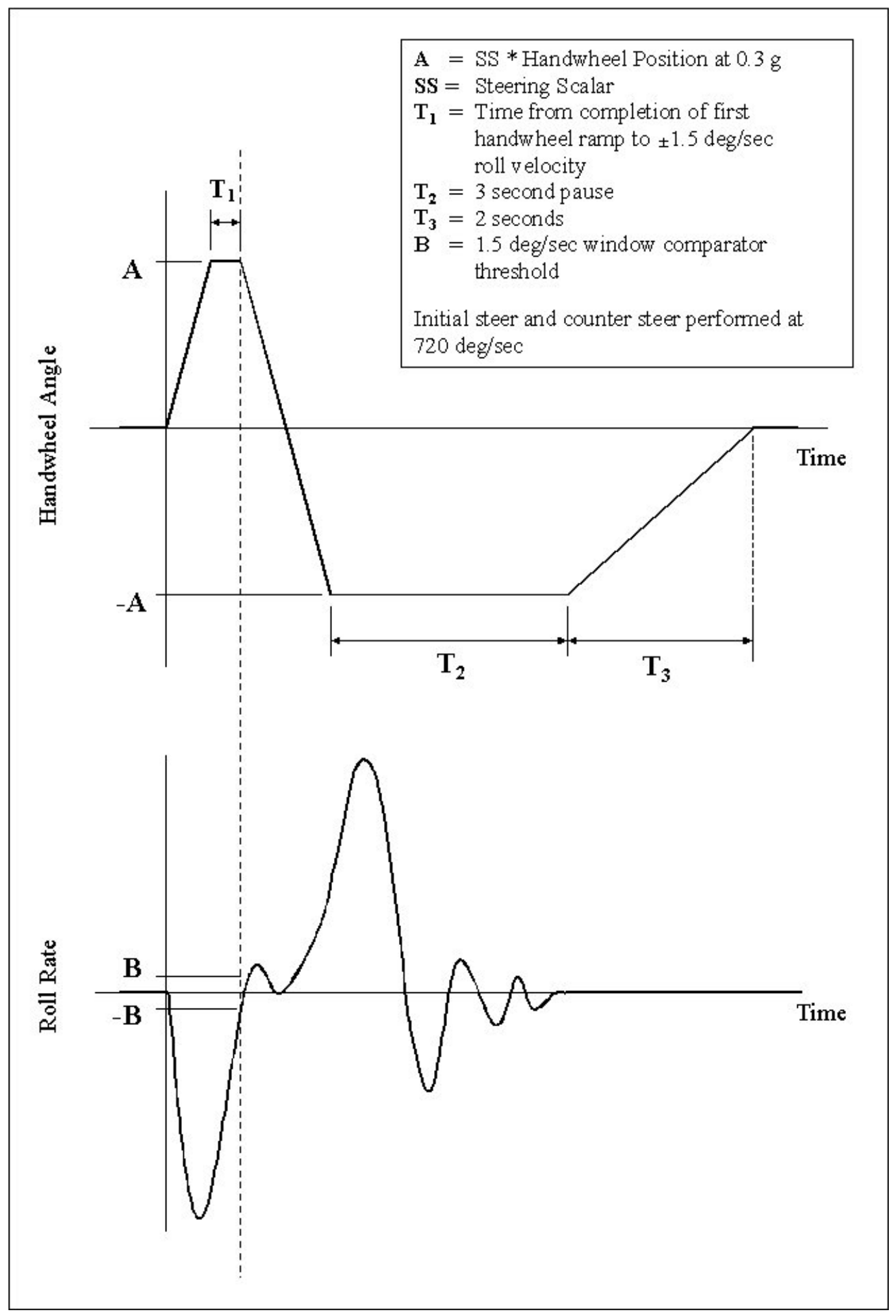

Figura 51 - Ângulo de esterçamento do volante e taxa de rolagem para a manobra do anzol (National Highway Traffic Safety Administration, 2004).

Adicionalmente, é atribuída uma nota de 0 a 5 estrelas, onde 5 é o carro que manteve todas as rodas no chão durante as manobras e 0 o carro que erguer uma das rodas mais de duas polegadas $(50,8 \mathrm{~mm})$ em algum caso. 
Esta manobra é extremamente indicada para fins de desenvolvimento de um veículo e analisar como a alteração de um componente pode afetar o desempenho de dirigibilidade do automóvel (Paldan \& Vantsevich, 2016). Esta manobra pode ser utilizada em diversas velocidades para se capturar a tendência do automóvel de perder o contato do pneu com o solo e o seu comportamento em regime transiente. Em uma situação física, devido a problemas de segurança e espaço, esta manobra não costuma ser realizadas em velocidades altas, porém em um ambiente virtual não há estas limitações.

Esta manobra também tem como vantagem poder ser utilizada no desenvolvimento virtual, especialmente pelo fato de ela ser executada fisicamente por um robô, garantindo a repetibilidade das medições, o que futuramente permite comparações entre carros físicos e virtuais e também cria a possibilidade de se comparar o resultado de automóveis diferentes, tirando qualquer influência do motorista.

A fim de se ter uma avaliação completa, realizar-se-á a manobra em velocidades que variam do uso cotidiano a um uso extremo de um carro de passeio, de $60 \mathrm{~km} / \mathrm{h}$ até $180 \mathrm{~km} / \mathrm{h}$. Vale salientar que o modelo matemático adotado é simétrico em relação ao lado direito e esquerdo do carro, tanto em sua geometria como em sua distribuição de massa, sendo desnecessária a avaliação para ambos os lados. Assim, será realizada a análise com a primeira curva à esquerda e consequentemente a segunda à direita, fechando o anzol. 
Taxa de Rolagem

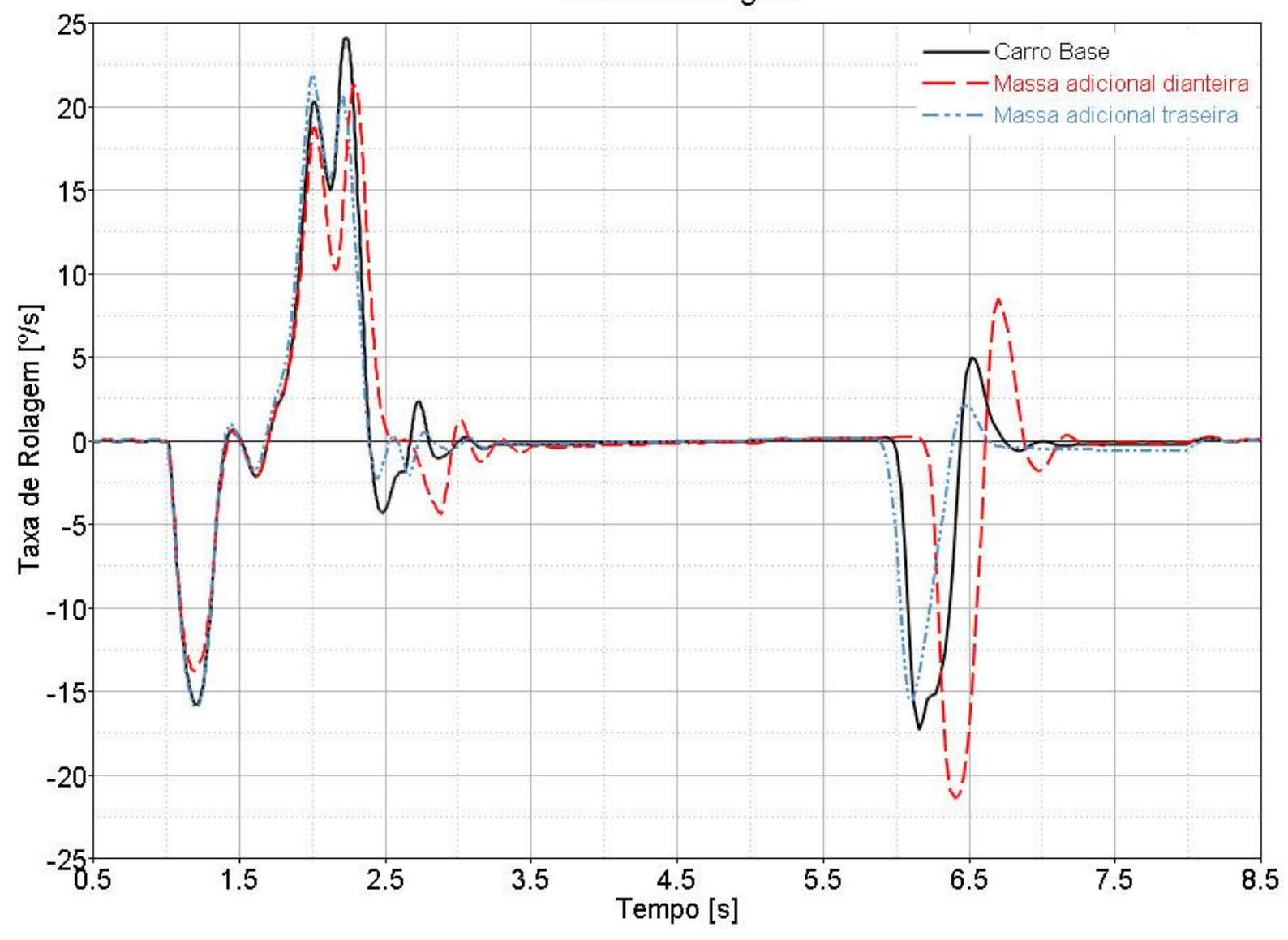

Figura 52 - Taxa de rolagem, para os três casos estudados, na manobra do anzol a $120 \mathrm{~km} / \mathrm{h}$.

Ao se comparar a taxa de rolagem durante a manobra (Figura 52), é possível notar diferenças consideráveis entre os modelos comparados, o que indica uma alteração de como a carga está se transferindo durante as curvas.

Mesmo com a norma estipulando as notas do veículo pela altura de levantamento de roda, este trabalho utilizará uma proposta alternativa de analise de resultados, através na analise das normais dos pneus e do tempo de levantamento de roda.

Assim, pode-se observar os resultados da normal do pneu, para cada um dos três casos avaliados, nos gráficos mostrados nas Figuras 53, 54, 55 e 56. 


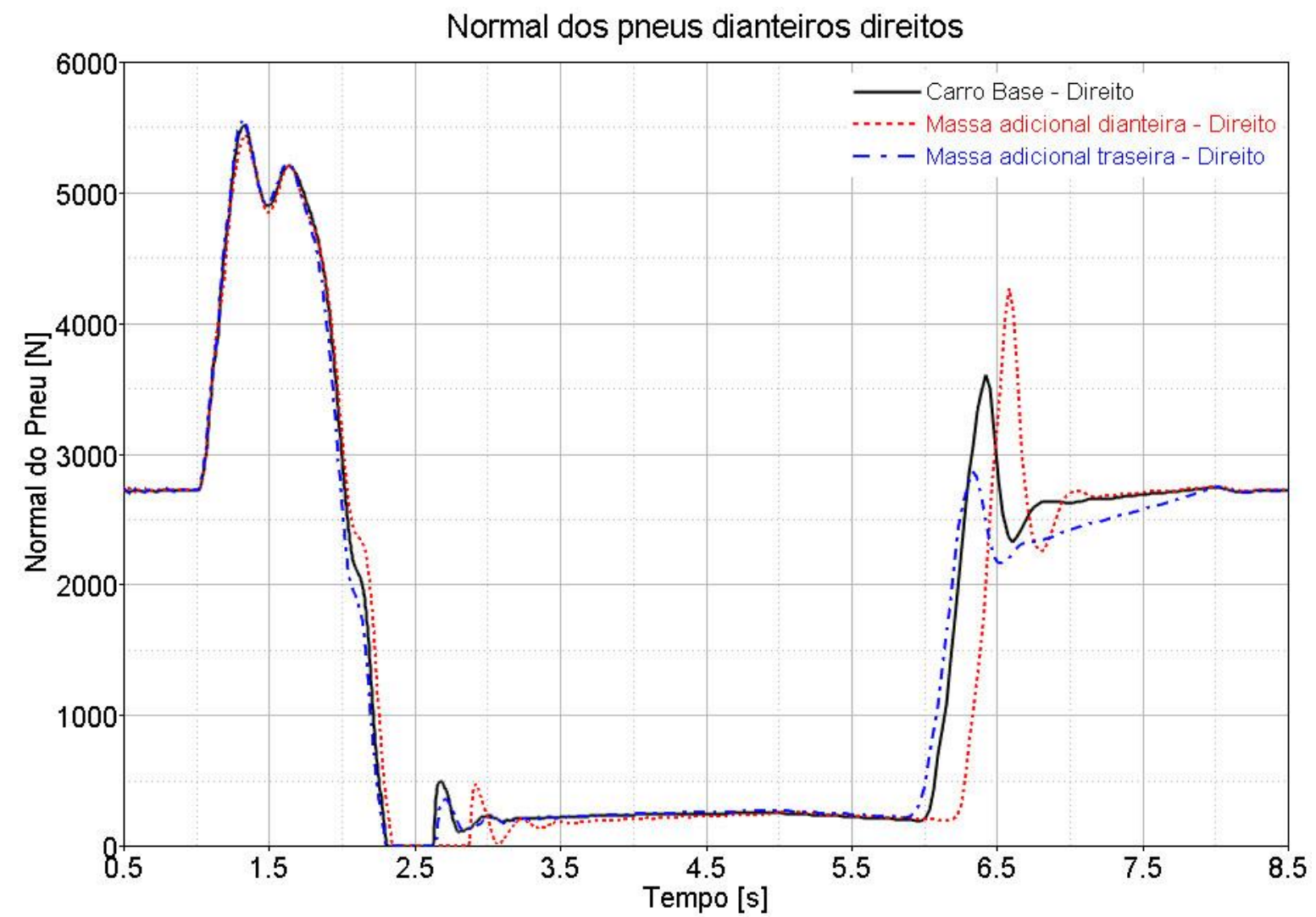

Figura 53 - Normal dos pneus dianteiros direitos, para os três casos estudados, na manobra do anzol a $120 \mathrm{~km} / \mathrm{h}$.

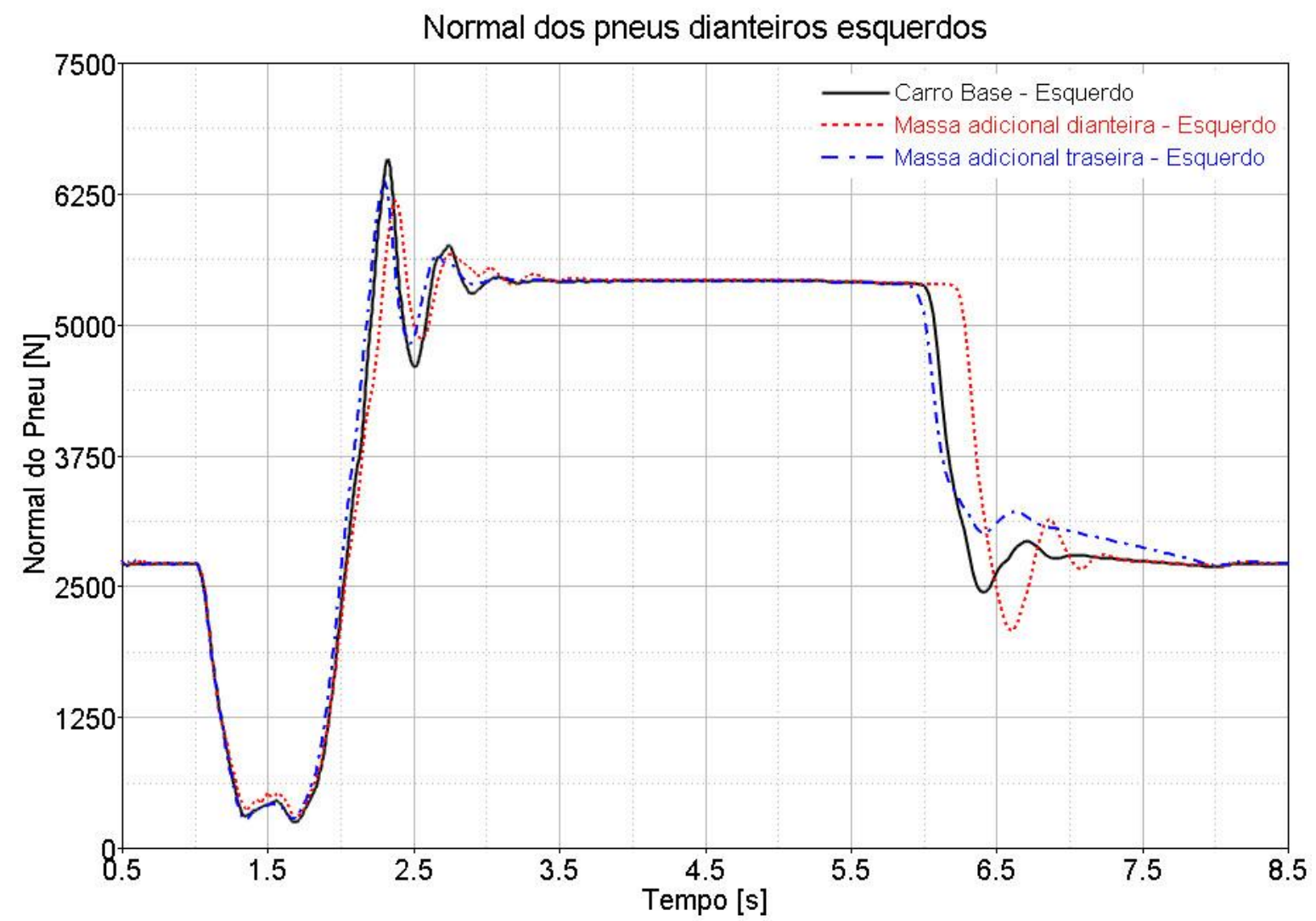

Figura 54 - Normal dos pneus dianteiros esquerdos, para os três casos estudados, na manobra do anzol a $120 \mathrm{~km} / \mathrm{h}$. 
Normal dos pneus traseiros direitos

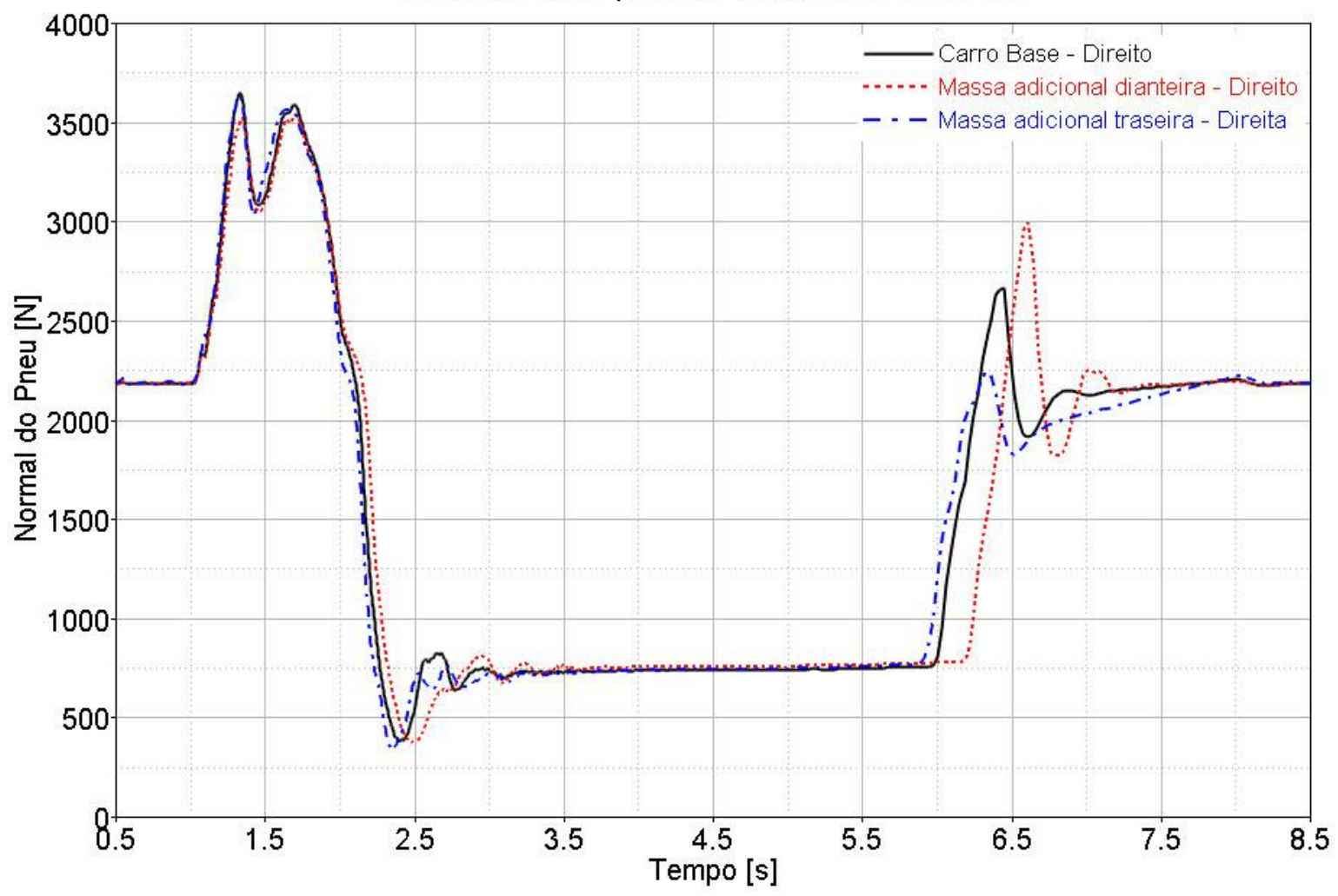

Figura 55 - Normal dos pneus traseiros direitos, para os três casos estudados, na manobra do anzol a $120 \mathrm{~km} / \mathrm{h}$.

Normal dos pneus traseiros esquerdos

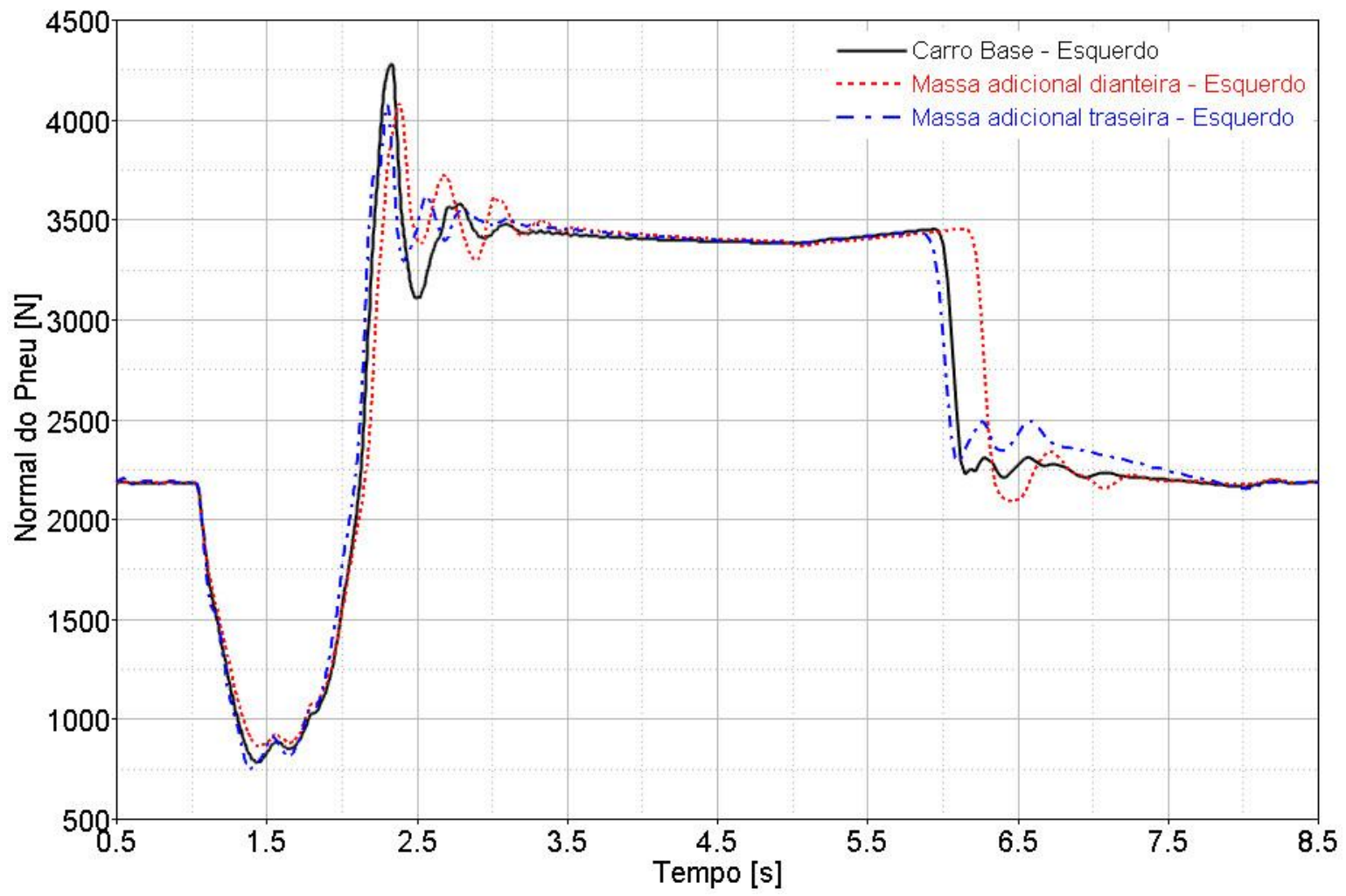

Figura 56 - Normal dos pneus traseiros esquerdos, para os três casos estudados, na manobra do anzol a $120 \mathrm{~km} / \mathrm{h}$. 
Analisando-se os gráficos, pode-se observar uma redução considerável do contato do pneu com o solo em determinados momentos, especialmente no lado direito. Do lado esquerdo, há o efeito contrário causando uma sobrecarga do pneu e aumentando a possibilidade de saturar o máximo ângulo de deriva suportado pelo pneu.

Este comportamento de transferência de carga excessiva é indesejável e, afim de se facilitar a comparação, será medida a normal mínima do lado direito apresentada durante a manobra, para assim realizar a comparação com os três tipos estudados (Tabela 12), para diferentes velocidades de deslocamento.

Tabela 12 - Força normal mínima identificada nos eixos através da manobra do anzol

\begin{tabular}{|c|c|c|c|c|c|c|}
\hline \multirow[b]{3}{*}{$\begin{array}{c}\text { Velocidade } \\
{[\mathrm{km} / \mathrm{h}]}\end{array}$} & \multicolumn{6}{|c|}{ Força Normal Mínima [N] } \\
\hline & \multicolumn{2}{|c|}{ Carro base } & \multicolumn{2}{|c|}{$\begin{array}{l}\text { Massa não } \\
\text { suspensa } \\
\text { acrescida na } \\
\text { dianteira }\end{array}$} & \multicolumn{2}{|c|}{$\begin{array}{l}\text { Massa não } \\
\text { suspensa } \\
\text { acrescida na } \\
\text { traseira }\end{array}$} \\
\hline & $\begin{array}{c}\text { Eixo } \\
\text { Dianteiro }\end{array}$ & $\begin{array}{c}\text { Eixo } \\
\text { Traseiro }\end{array}$ & $\begin{array}{c}\text { Eixo } \\
\text { Dianteiro }\end{array}$ & $\begin{array}{c}\text { Eixo } \\
\text { Traseiro }\end{array}$ & $\begin{array}{c}\text { Eixo } \\
\text { Dianteiro }\end{array}$ & $\begin{array}{c}\text { Eixo } \\
\text { Traseiro }\end{array}$ \\
\hline 40 & 668.8 & 1005.7 & 671.9 & 1038.8 & 665.7 & 979.6 \\
\hline 60 & 225.8 & 710.0 & 212.4 & 721.5 & 246.1 & 669.5 \\
\hline 80 & 0 & 575.0 & 0 & 616.7 & 0 & 497.3 \\
\hline 100 & 0 & 468.9 & 0 & 470.7 & 0 & 420.6 \\
\hline 120 & 0 & 381.6 & 0 & 374.9 & 0 & 334.4 \\
\hline 140 & 0 & 308.9 & 0 & 291.8 & 0 & 250.4 \\
\hline 160 & 0 & 261.1 & 0 & 208.2 & 0 & 220.3 \\
\hline 180 & 0 & 201.9 & 0 & 144.5 & 0 & 154.7 \\
\hline
\end{tabular}

Porém, em alguns casos durante a manobra do anzol há o descolamento do pneu com o solo (acontecendo a partir de uma velocidade entre $60 \mathrm{~km} / \mathrm{h}$ e $80 \mathrm{~km} / \mathrm{h}$ ), ou seja, a força normal é nula, como pode-se observar na Figura 57, o que é altamente indesejável (Shim \& Velusamy, 2006). 


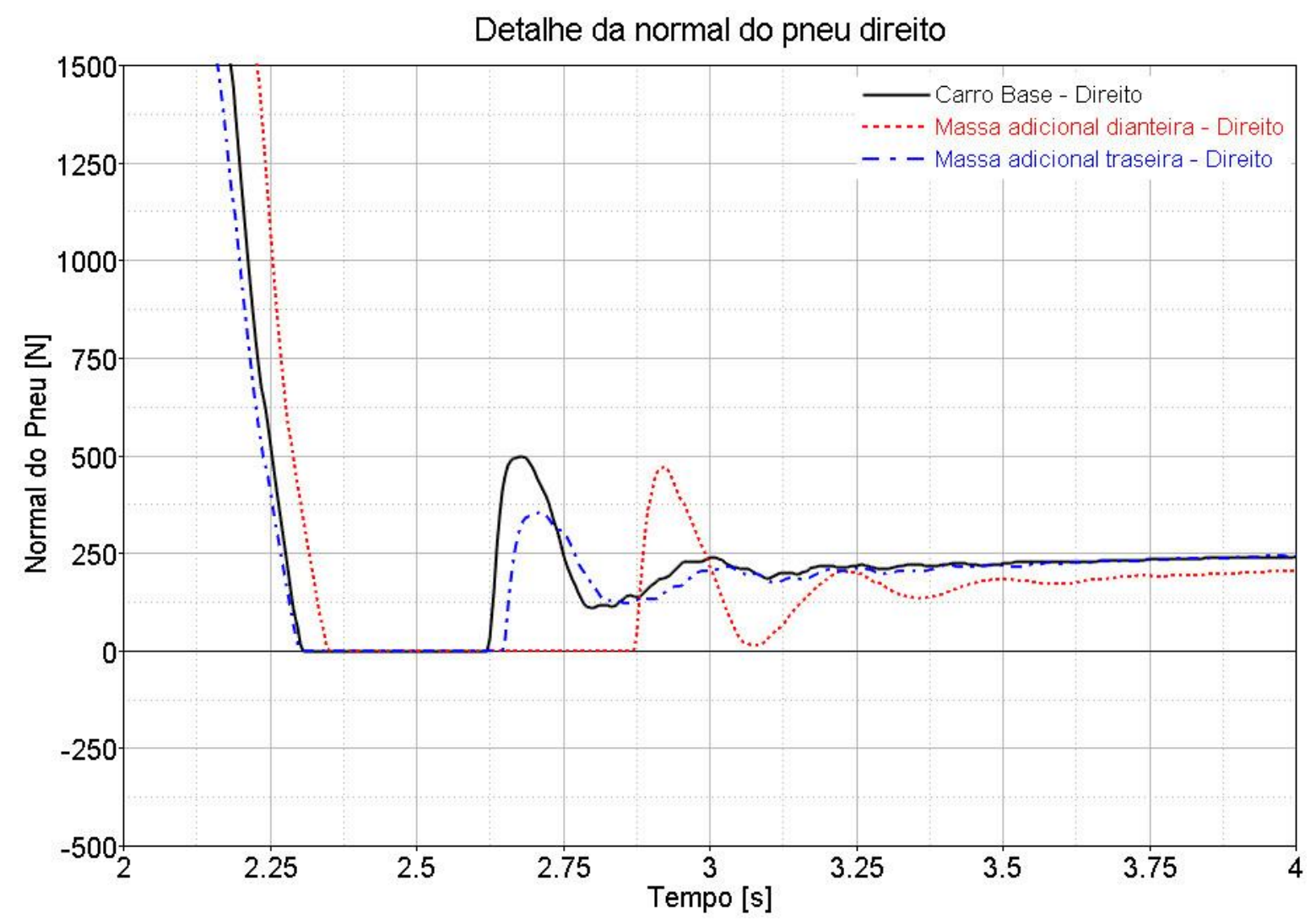

Figura 57 - Detalhe da força normal do pneu, quando do descolamento do solo, para a roda dianteira direita na manobra do anzol a $120 \mathrm{~km} / \mathrm{h}$.

Tendo a ciência do descolamento do pneu com o solo, comparar apenas força normal mínima do pneu pode ser deficiente para mensurar o tamanho da degradação. Então, para efeitos comparativos, quando não houver contato do pneu com o solo será medido o tempo deste evento, e assim mensurado objetivamente o que está acontecendo (Tabela 13). 
Tabela 13 - Tempo de levantamento de roda identificado pela manobra do anzol

\begin{tabular}{c|c|c|c|c|c|c} 
& \multicolumn{2}{c}{} & \multicolumn{2}{c}{ Tempo de perda de contato [s] } \\
\cline { 2 - 7 } & \multicolumn{2}{c}{ Carsa não } & \multicolumn{2}{|c}{$\begin{array}{c}\text { Massa não } \\
\text { suspensa } \\
\text { suspensa } \\
\text { acrescida na } \\
\text { dianteira } \\
\text { traseira }\end{array}$} \\
\cline { 2 - 7 } $\begin{array}{c}\text { Velocidade } \\
{[\mathrm{km} / \mathrm{h}]}\end{array}$ & $\begin{array}{c}\text { Eixo } \\
\text { Dianteiro }\end{array}$ & $\begin{array}{c}\text { Eixo } \\
\text { Traseiro }\end{array}$ & $\begin{array}{c}\text { Eixo } \\
\text { Dianteiro }\end{array}$ & $\begin{array}{c}\text { Eixo } \\
\text { Traseiro }\end{array}$ & $\begin{array}{c}\text { Eixo } \\
\text { Dianteiro }\end{array}$ & $\begin{array}{c}\text { Eixo } \\
\text { Traseiro }\end{array}$ \\
\hline 40 & 0 & 0 & 0 & 0 & 0 & 0 \\
\hline 60 & 0 & 0 & 0 & 0 & 0 & 0 \\
\hline 80 & 0.09 & 0 & 0.15 & 0 & 0.06 & 0 \\
\hline 100 & 0.22 & 0 & 0.35 & 0 & 0.22 & 0 \\
\hline 120 & 0.32 & 0 & 0.52 & 0 & 0.34 & 0 \\
\hline 140 & 0.40 & 0 & 0.70 & 0 & 0.46 & 0 \\
\hline 160 & 0.46 & 0 & 0.80 & 0 & 0.54 & 0 \\
\hline 180 & 0.51 & 0 & 0.91 & 0 & 0.62 & 0
\end{tabular}

Por fim, comparando ambas as tabelas (Tabela 12 e Tabela 13), é possível observar uma degradação de desempenho para ambos os casos. Porém, quando a massa é acrescida na dianteira a degradação se mostra bem maior e, desta maneira, pode-se deduzir que, no caso estudado, é preferível instalar o motor elétrico no eixo traseiro.

\subsection{Otimização através de análise de sensibilidade}

Como identificado, a influência no desempenho em dirigibilidade dos veículos com massa não suspensa acrescida na traseira é menor do que em relação àqueles com massa acrescida na dianteira, porém com um desempenho ainda inferior quando comparado ao carro base. Portanto, foi escolhido o caso da massa acrescida na traseira para se prosseguir o estudo e tentar chegar o mais próximo possível do desempenho de um automóvel na configuração tradicional.

Assim, como forma de amenizar o problema causado pelo incremento de massa e chegar mais perto do desempenho inicial, é preciso reduzir o tempo de levantamento de roda na dianteira e aumentar a normal mínima do pneu na traseira, 
para uma certa condição, como forma de se melhorar o desempenho da inâmico veicular.

Como identificado, foi na manobra do Anzol onde ocorreu a degradação mais perceptível e, ainda, quanto maior a velocidade maior a degradação observada. Desta maneira, será feita a readequação dos componentes da suspensão para melhorar o desempenho a $120 \mathrm{~km} / \mathrm{h}$, que é a maior velocidade permitida nas rodovias brasileiras.

Para isto, podem-se alterar diversos parâmetros da suspensão do automóvel. Entretanto, a alteração de vários parâmetros em diversos níveis culminaria em um número altíssimo de combinações, impossibilitando a realização de todas as variações possíveis.

Assim, é necessário entender a influência de cada variável no comportamento do sistema e, assim, determinar a melhor combinação possível. Para tanto, se utilizará a análise de sensibilidade para buscar a melhor configuração possível dentro de um intervalo determinado.

\subsubsection{Análise de sensibilidade (DOE)}

Uma técnica possível de se utilizar neste tipo de problema de dinâmica veicular é o método de engenharia robusta, ou método de Taguchi. Esta técnica estatística de tratamento de dados foi desenvolvida primeiramente para abordar problemas de qualidade em manufatura industrial. O método de Taguchi pode ser utilizado em inúmeros tipos de problemas de engenharia, a fim de se obter o seu ótimo, reduzindo substancialmente o número de combinações a serem executadas (Vilela, 2010).

Para se utilizar este método, faz-se necessário seguir as seguintes etapas (Taguchi, et al., 2005):

- Definição dos parâmetros de controle e o seu nível de discretização

- Definição dos parâmetros de ruído e dos níveis nos quais estes podem atuar no sistema

- Definição da matriz de experimentos (matriz ortogonal) adequada ao número de dimensões a serem estudados

- Análise do resultado sinal/ruído

- Aferição da sensibilidade de cada variável 
- Definição da configuração ótima dentro do intervalo estudado.

Uma das vantagens desse método é que ele se utiliza de medidas discretas, fazendo com que se possa trabalhar com valores factíveis. Adicionalmente, a possibilidade de se trabalhar com ruídos faz com que o resultado seja robusto dentro de um intervalo de uso do produto.

Para realizar a análise, será feita a avaliação de 5 variáveis em três níveis, em função percentual do valor utilizado inicialmente (Tabela 14), para o caso com a massa acrescida na traseira.

\begin{tabular}{c|c|c|c}
$\begin{array}{c}\text { Tabela 14 - Parâmetros de controle e seus níveis } \\
\text { Variável }\end{array}$ & Nível 1 & Nível 2 & Nível 3 \\
\hline $\mathrm{K}_{\mathrm{d}}$ & $90 \%$ & $100 \%$ & $110 \%$ \\
\hline $\mathrm{K}_{\mathrm{t}}$ & $90 \%$ & $100 \%$ & $110 \%$ \\
\hline $\mathrm{C}_{\mathrm{d}}$ & $90 \%$ & $100 \%$ & $110 \%$ \\
\hline $\mathrm{C}_{\mathrm{t}}$ & $90 \%$ & $100 \%$ & $110 \%$ \\
\hline $\mathrm{DB}_{\mathrm{d}}$ & $90 \%$ & $100 \%$ & $110 \%$
\end{tabular}

Os parâmetros, e os seus intervalos de variação de $10 \%$, foram escolhidos baseados em sua facilidade de alteração em um veículo físico.

Os coeficientes de amortecimento $\mathrm{C}_{\mathrm{d}}$ e $\mathrm{C}_{\mathrm{t}}$, tiveram um fator de escala de $10 \%$ aplicados em relação à curva inicial e podem ser fisicamente alterados apenas variando-se as válvulas internas do amortecedor, sem necessidade da introdução de um conceito diferenciado.

As rigidezes das molas, com as suas mudanças de $10 \%$ de rigidez para cada nível, teve o devido ajuste em sua pré carga a fim de não se alterar altura do automóvel, e podem ser fisicamente alteradas com mudanças no diâmetro do fio e nos tamanhos e quantidades de espiras.

Por fim, a barra estabilizadora teve uma variação de $10 \%$ no diâmetro de sua seção, alterando, consequentemente, o seu momento de inércia. Este, por sua vez, altera a rigidez de rolagem da suspensão.

Desta forma, com a ajuda da matriz ortogonal L18 (Tabela 15) e a técnica estatística "Design of experiments" ou DOE, propostas por Taguchi (Taguchi, et al., 
2005), é possível observar as tendências de cada variável e determinar o valor ótimo para cada uma delas dentro do intervalo de estudo rodando apenas 18 combinações.

Originalmente, esta tabela combina variáveis de uma mesma grandeza, no caso estudado, a natureza do fenômeno pede que se trabalhe para reduzir o tempo de levantamento de roda na dianteira e aumentar a força normal mínima na traseira, fazendo-se necessária uma abordagem alternativa do método de Taguchi.

Para se encaixar na formulação do D.O.E. pode-se normalizar os resultados, levando em conta que se deseja minimizar um valor e maximizar o outro, da seguinte maneira: será adotado o número 1 para o menor tempo de queda de roda e 0 para 0 maior. Para a força normal mínima, a lógica se inverte e adotamos 1 para o maior valor e 0 para menor, e estes números chamaremos de coeficiente de desempenho.

Com isso, consegue-se transformar grandezas diferentes em valores compatíveis, que chamaremos de coeficientes de desempenho e que podem ser categorizados como uma grandeza "quanto maior melhor", ou seja, os coeficientes de desempenhos obtidos deveriam ser maximizados $e$, consequentemente, se enquadraria na formulação proposta por Genichi Taguchi, (Vilela, 2010).

Adicionalmente, cada valor será tratado como um ruído diferente do sistema, dando a capacidade de realizar a curva de tendência para as duas métricas ao mesmo tempo, com um fator de ponderação de $50 \%$ entre elas, e garantindo um resultado ótimo para ambas. Caso os resultados (Tabela 15) fossem analisados separadamente, haveria a possibilidade de se melhorar uma em detrimento da outra, o que não é a intenção. 
Tabela 15 - Matriz ortogonal L18 da formulação de D.O.E. com os seus resultados brutos e normalizados

\begin{tabular}{|c|c|c|c|c|c|c|c|c|c|c|}
\hline & \multirow{2}{*}{\multicolumn{2}{|c|}{ Valores Brutos }} & \multirow{2}{*}{\multicolumn{2}{|c|}{ Valores Normalizados }} \\
\hline & & & & \\
\hline & \# & Kd & $\mathbf{K t}$ & Cd & Ct & DBd & $\begin{array}{c}\text { Tempo de } \\
\text { levantamento } \\
\text { de roda no } \\
\text { eixo dianteiro } \\
{[\mathrm{s}]}\end{array}$ & $\begin{array}{c}\text { Força Normal } \\
\text { Mínima no } \\
\text { eixo traseiro } \\
{[\mathrm{N}]}\end{array}$ & $\begin{array}{c}\text { Coeficiente } \\
\text { de } \\
\text { desempenho } \\
\text { do eixo } \\
\text { dianteiro } \\
\text { [s/ unidade] }\end{array}$ & $\begin{array}{c}\text { Coeficiente } \\
\text { de } \\
\text { desempenho } \\
\text { do eixo } \\
\text { traseiro [s/ } \\
\text { unidade] }\end{array}$ \\
\hline \multirow{18}{*}{$\begin{array}{l}\stackrel{0}{2 \pi} \\
\underset{\pi}{\pi} \\
\frac{\pi}{ \pm} \\
\pm\end{array}$} & 1 & 19 & 20 & 0.9 & 0.9 & 16 & 0.48 & 169.3 & 0.41 & 0.17 \\
\hline & 2 & 19 & 22 & 1 & 1 & 18 & 0.34 & 300.6 & 0.82 & 0.43 \\
\hline & 3 & 19 & 24 & 1.1 & 1.1 & 20 & 0.31 & 440.1 & 0.90 & 0.70 \\
\hline & 4 & 21 & 20 & 0.9 & 1 & 18 & 0.43 & 356.7 & 0.56 & 0.53 \\
\hline & 5 & 21 & 22 & 1 & 1.1 & 20 & 0.40 & 489.2 & 0.65 & 0.79 \\
\hline & 6 & 21 & 24 & 1.1 & 0.9 & 16 & 0.28 & 165.2 & 0.99 & 0.16 \\
\hline & 7 & 23 & 20 & 1 & 0.9 & 20 & 0.62 & 582.3 & 0.00 & 0.98 \\
\hline & 8 & 23 & 22 & 1.1 & 1 & 16 & 0.31 & 237.5 & 0.91 & 0.30 \\
\hline & 9 & 23 & 24 & 0.9 & 1.1 & 18 & 0.28 & 319.7 & 1.00 & 0.46 \\
\hline & 10 & 19 & 20 & 1.1 & 1.1 & 18 & 0.34 & 353.9 & 0.82 & 0.53 \\
\hline & 11 & 19 & 22 & 0.9 & 0.9 & 20 & 0.46 & 499.3 & 0.47 & 0.81 \\
\hline & 12 & 19 & 24 & 1 & 1 & 16 & 0.30 & 83.3 & 0.94 & 0.00 \\
\hline & 13 & 21 & 20 & 1 & 1.1 & 16 & 0.36 & 209.6 & 0.76 & 0.25 \\
\hline & 14 & 21 & 22 & 1.1 & 0.9 & 18 & 0.36 & 370.7 & 0.75 & 0.56 \\
\hline & 15 & 21 & 24 & 0.9 & 1 & 20 & 0.36 & 472.8 & 0.76 & 0.76 \\
\hline & 16 & 23 & 20 & 1.1 & 1 & 20 & 0.53 & 594.4 & 0.26 & 1.00 \\
\hline & 17 & 23 & 22 & 0.9 & 1.1 & 16 & 0.31 & 180.5 & 0.90 & 0.19 \\
\hline & 18 & 23 & 24 & 1 & 0.9 & 18 & 0.32 & 358.1 & 0.88 & 0.54 \\
\hline
\end{tabular}

Com isso, obter-se-á o gráfico de sensibilidade do sistema através da técnica DOE (Figura 58). 


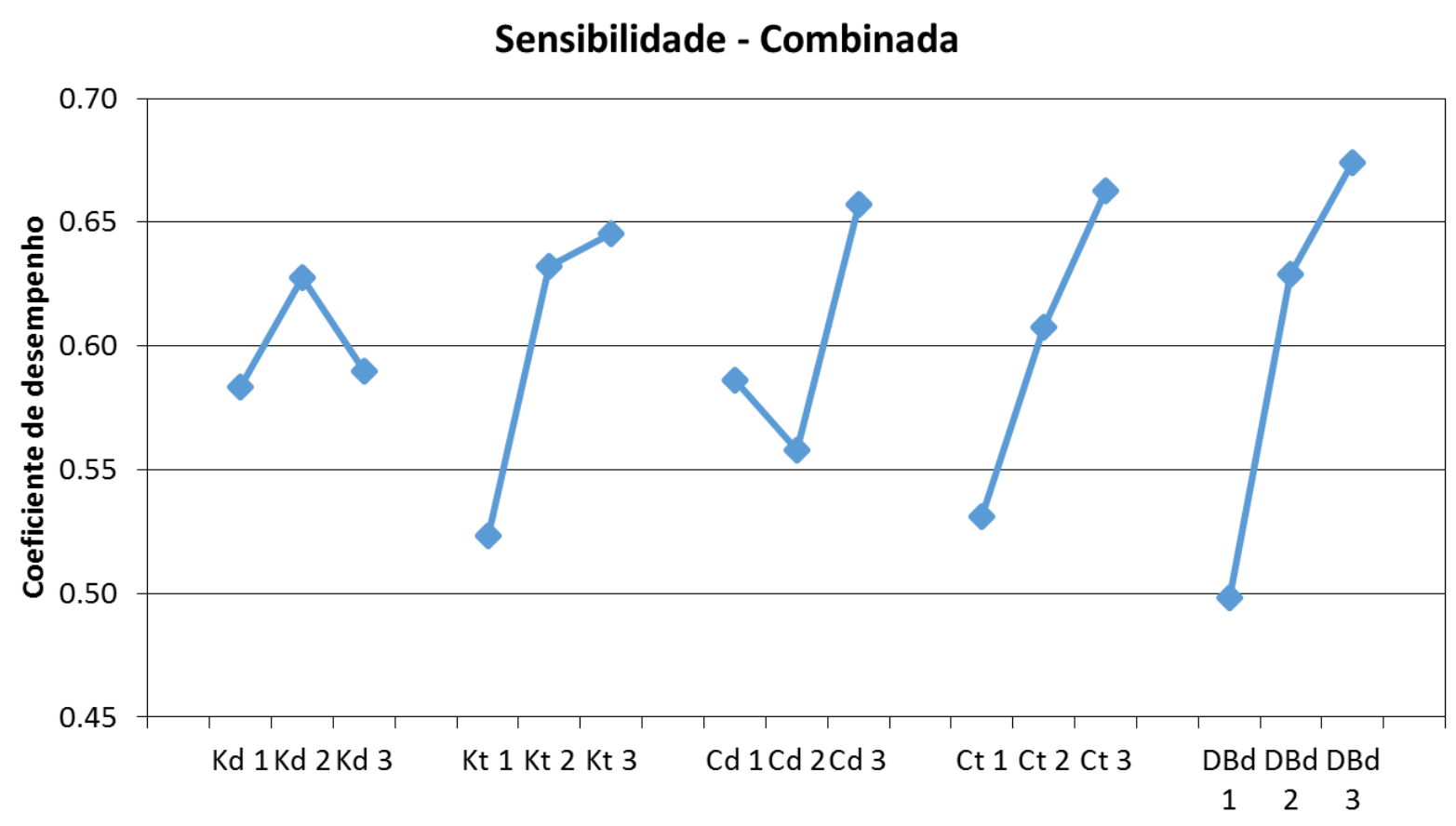

Figura 58 - Gráfico da sensibilidade das variáveis de controle em relação aos coeficientes de desempenhos combinados dos eixos dianteiros e traseiros

Porém, as tendências não estão exatamente claras ao se olhar as variáveis de rigidezes de molas e amortecimentos do eixo dianteiro. Afim de se obter um resultado mais completo, pode-se olhar separadamente a sensibilidade para cada grandeza estudada, mantendo todos os demais parâmetros constantes. Sendo assim, temos o gráfico de sensibilidade referente ao coeficiente de desempenho, oriundo do tempo de levantamento de roda dianteiro, e também ao coeficiente de desempenho calculado a partir da normal do pneu traseiro. 


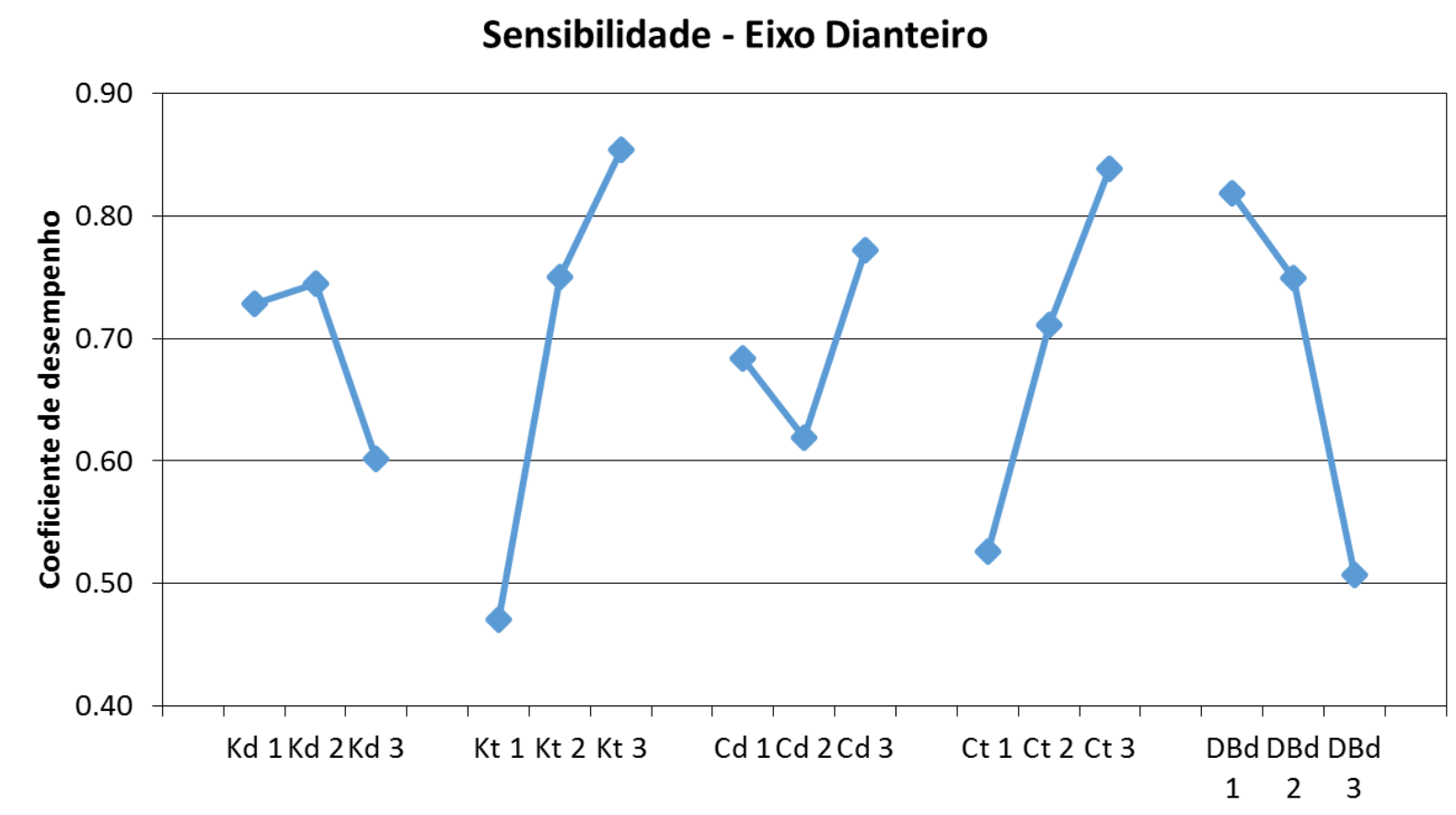

Figura 59 - Gráfico da sensibilidade das variáveis de controle em relação ao coeficiente de desempenho do eixo dianteiro

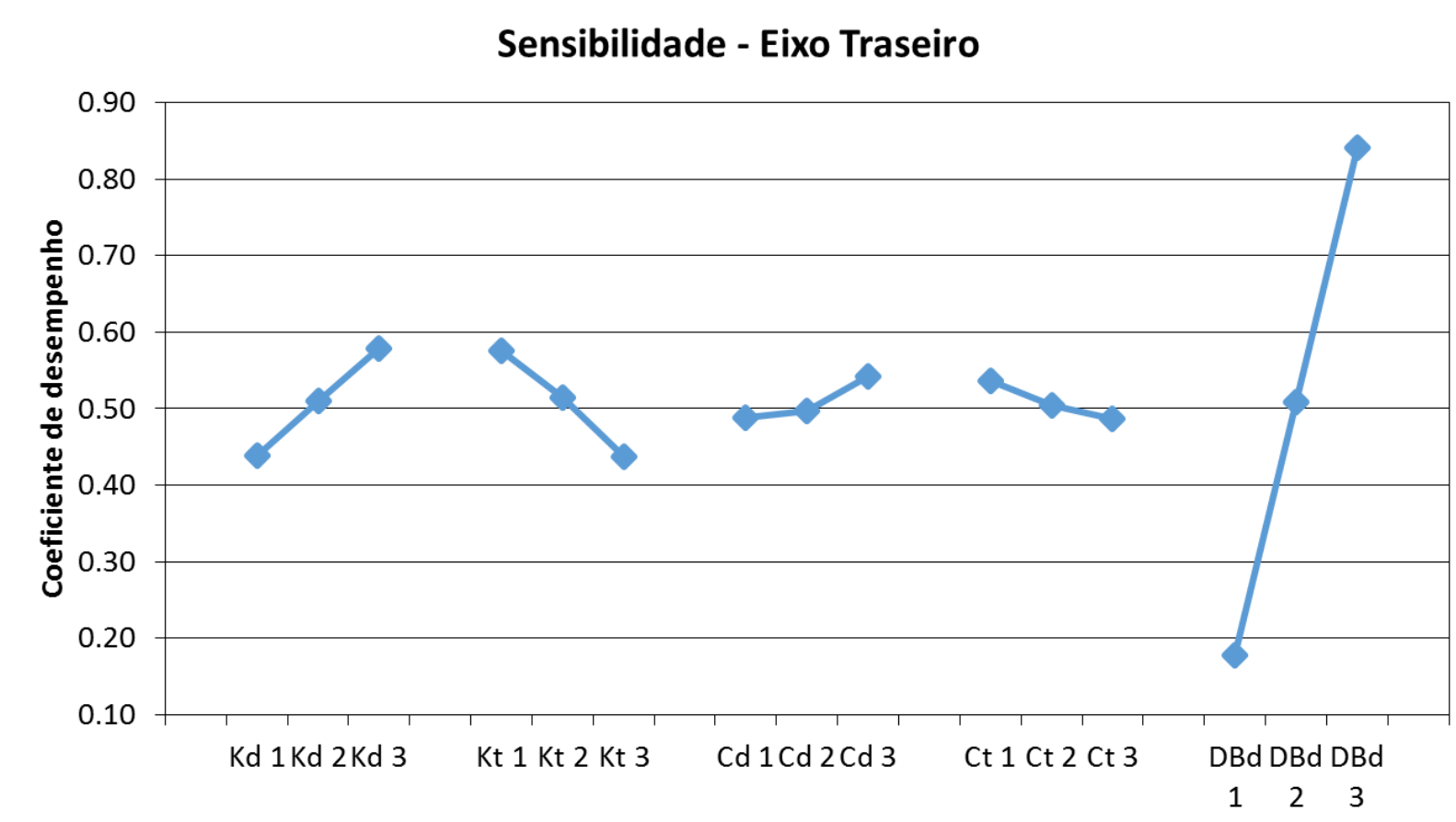

Figura 60 - Gráfico da sensibilidade das variáveis de controle em relação ao coeficiente de desempenho do eixo traseiro 
Comparando-se a Figura 59 com a Figura 60, conseguimos olhar que algumas grandezas influenciam mais que outras para ambos os casos, e até se comportam com tendências opostas, o que ratifica a necessidade de haver uma ponderação entre os dois casos, pois uma variável pode melhorar um resultado e piorar o outro.

As variáveis que mais contribuem com o comportamento do coeficiente de desempenho no eixo dianteiro são, de maneira equilibrada entre eles, o diâmetro da barra dianteira, a rigidez e o amortecimento do eixo traseiro. Já para o traseiro é o diâmetro da barra, inclusive com uma tendência contrária ao observado no eixo dianteiro, que ao se aplicar o coeficiente de ponderação de $50 \%$ se mostrou mais importante a tendência de aumentar o seu diâmetro, o que melhora o coeficiente de desempenho da traseira e piora na dianteira.

Também foi possível observar que o fenômeno do tempo de levantamento de roda na dianteira não mostra tendências comportadas para todas as variáveis, o que tornaria o ajuste dos parâmetros por tentativa e erro muito difícil. Isso reitera a necessidade do uso de uma técnica para nortear as tendências. Já o coeficiente de desempenho traseiro mostrou tendências mais lineares para os parâmetros estudados, tornando neste caso o fenômeno mais previsível.

Assim, os parâmetros de rigidez e amortecimento da suspensão dianteira, que se mostraram com uma tendência não linear na análise combinada, não se mostraram com uma grande sensibilidade para nenhum dos casos, o que nos dá segurança para escolher o resultado obtido através da análise combinada, com a segurança de não melhorar apenas um coeficiente de desempenho, mas ambos.

Desta forma, consegue-se avaliar de forma mais madura que a configuração de variáveis e os seus níveis que irão apresentar o melhor desempenho pela análise de sensibilidade, com os coeficientes de desempenhos combinados, são apresentados na Tabela 16:

Tabela 16 - Variáveis estudadas em seus níveis para o desempenho ótimo.

\begin{tabular}{c|c|c} 
Variável & Nível & \multicolumn{2}{|c}{ Valor } \\
\hline $\mathrm{K}_{\mathrm{d}}$ & 2 & $100 \%$ \\
\hline $\mathrm{K}_{\mathrm{t}}$ & 3 & $110 \%$ \\
\hline $\mathrm{C}_{\mathrm{d}}$ & 3 & $110 \%$ \\
\hline $\mathrm{C}_{\mathrm{t}}$ & 3 & $110 \%$ \\
\hline $\mathrm{DB}_{d}$ & 3 & $110 \%$
\end{tabular}


Partindo dos níveis apresentados na Tabela 16, que são os valores ótimos dentro do intervalo estudado foi reavaliado o modelo com os níveis indicados, conferindo o resultado final na Tabela 17. Também comparando-se os resultados com o carro base sem massa acrescida nenhuma, Tabela 18, é nitido de se observar a melhora desejada do veículo na configuração ótima com massa acrescida na traseira.

Tabela 17 - Resultado final da manobra do anzol a $120 \mathrm{~km} / \mathrm{h}$ do veículo com massa acrescida na traseira comparando com sua configuração inicial

\begin{tabular}{c|c|c}
\multicolumn{1}{c}{} & \multicolumn{2}{c}{ Manobra do Anzol a $120 \mathrm{~km} / \mathrm{h}$} \\
\cline { 2 - 3 } & $\begin{array}{c}\text { Tempo de } \\
\text { levantamento de } \\
\text { roda no eixo } \\
\text { dianteiro [s] }\end{array}$ & $\begin{array}{c}\text { Força normal } \\
\text { mínima no eixo } \\
\text { traseiro [N] }\end{array}$ \\
\hline $\begin{array}{c}\text { Configuração } \\
\text { inicial }\end{array}$ & 0.34 & 334.4 \\
\hline $\begin{array}{c}\text { Configuração } \\
\text { ótima }\end{array}$ & 0.31 & 482.7 \\
\hline Melhora & $-9.7 \%$ & $+30.7 \%$
\end{tabular}

Tabela 18 - Resultado final da manobra do anzol a $120 \mathrm{~km} / \mathrm{h}$ do veículo com massa acrescida na traseira comparando com a configuração sem massa acrescida

\begin{tabular}{c|c|c}
\multicolumn{1}{c}{} & \multicolumn{2}{c}{ Manobra do Anzol a $120 \mathrm{~km} / \mathrm{h}$} \\
\cline { 2 - 3 } & $\begin{array}{c}\text { Tempo de } \\
\text { levantamento de } \\
\text { roda no eixo } \\
\text { dianteiro [s] }\end{array}$ & $\begin{array}{c}\text { Força normal } \\
\text { mínima no eixo } \\
\text { traseiro [N] }\end{array}$ \\
\hline $\begin{array}{c}\text { Configuração s/ } \\
\text { massa acrescida }\end{array}$ & 0.32 & 381.6 \\
\hline $\begin{array}{c}\text { Configuração } \\
\text { ótima }\end{array}$ & 0.31 & 482.7 \\
\hline Melhora & $-3.2 \%$ & $+20.9 \%$
\end{tabular}

\subsubsection{Confirmação da Otimização}

Com o resultado alcançado através da análise de sensibilidade e a real confirmação que houve uma melhoria para a manobra realizada a $120 \mathrm{~km} / \mathrm{h}$, é necessário avaliar o veículo como um todo, e confirmar que a expectativa de melhora se estende para todas as velocidades. 
Assim, será repetida a rodagem da manobra do Anzol para várias velocidades, comparando-se com os resultados dos veículos base e com massa acrescida na traseira inicial (Tabela 19).

Tabela 19 - Comparação da Força normal mínima, em Newtons, entre o carro ótimo e os casos anteriores.

\begin{tabular}{c|c|c|c|c|c|c} 
& \multicolumn{6}{c}{ Força Normal Mínima [N] } \\
\cline { 2 - 7 } & \multicolumn{2}{c}{ Carro base } & \multicolumn{2}{c}{$\begin{array}{c}\text { Massa não } \\
\text { suspensa } \\
\text { acrescida na } \\
\text { traseira - Inicial }\end{array}$} & \multicolumn{2}{c}{$\begin{array}{c}\text { Massa não } \\
\text { suspensa } \\
\text { acrescida na } \\
\text { traseira - Ótimo }\end{array}$} \\
\cline { 2 - 7 } $\begin{array}{c}\text { Velocidade } \\
{[\mathrm{km} / \mathrm{h}]}\end{array}$ & $\begin{array}{c}\text { Eixo } \\
\text { Dianteiro }\end{array}$ & $\begin{array}{c}\text { Eixo } \\
\text { Traseiro }\end{array}$ & $\begin{array}{c}\text { Eixo } \\
\text { Dianteiro }\end{array}$ & $\begin{array}{c}\text { Eixo } \\
\text { Traseiro }\end{array}$ & $\begin{array}{c}\text { Eixo } \\
\text { Dianteiro }\end{array}$ & $\begin{array}{c}\text { Eixo } \\
\text { Traseiro }\end{array}$ \\
\hline 40 & 668.8 & 1005.7 & 665.7 & 979.6 & 626.5 & 1045.6 \\
\hline 60 & 225.8 & 710.0 & 246.1 & 669.5 & 262.4 & 763.3 \\
\hline 80 & 0 & 575.0 & 0 & 497.3 & 34.2 & 641 \\
\hline 100 & 0 & 468.9 & 0 & 420.6 & 0 & 567.8 \\
\hline 120 & 0 & 381.6 & 0 & 334.4 & 0 & 482.7 \\
\hline 140 & 0 & 308.9 & 0 & 250.4 & 0 & 415.9 \\
\hline 160 & 0 & 261.1 & 0 & 220.3 & 0 & 353.9 \\
\hline 180 & 0 & 201.9 & 0 & 154.7 & 0 & 293.3
\end{tabular}

Tabela 20 - Comparação do tempo de perda de contato, em segundos, entre o carro ótimo e os casos anteriores.

\begin{tabular}{c|c|c|c|c|c|c} 
& \multicolumn{6}{c}{ Tempo de perda de contato [s] } \\
\cline { 2 - 7 } & \multicolumn{2}{c}{ Carro base } & \multicolumn{2}{c}{$\begin{array}{c}\text { Massa não } \\
\text { suspensa } \\
\text { acrescida na } \\
\text { traseira - Inicial }\end{array}$} & \multicolumn{2}{|c}{$\begin{array}{c}\text { Massa não } \\
\text { suspensa } \\
\text { acrescida na } \\
\text { traseira - Ótimo }\end{array}$} \\
\cline { 2 - 7 } $\begin{array}{c}\text { Velocidade } \\
{[\mathrm{km} / \mathrm{h}]}\end{array}$ & $\begin{array}{c}\text { Eixo } \\
\text { Dianteiro }\end{array}$ & $\begin{array}{c}\text { Eixo } \\
\text { Traseiro }\end{array}$ & $\begin{array}{c}\text { Eixo } \\
\text { Dianteiro }\end{array}$ & $\begin{array}{c}\text { Eixo } \\
\text { Traseiro }\end{array}$ & $\begin{array}{c}\text { Eixo } \\
\text { Dianteiro }\end{array}$ & $\begin{array}{c}\text { Eixo } \\
\text { Traseiro }\end{array}$ \\
\hline 40 & 0 & 0 & 0 & 0 & 0 & 0 \\
\hline 60 & 0 & 0 & 0 & 0 & 0 & 0 \\
\hline 80 & 0.09 & 0 & 0.06 & 0 & 0 & 0 \\
\hline 100 & 0.22 & 0 & 0.22 & 0 & 0.16 & 0 \\
\hline 120 & 0.32 & 0 & 0.34 & 0 & 0.31 & 0 \\
\hline 140 & 0.40 & 0 & 0.46 & 0 & 0.43 & 0 \\
\hline 160 & 0.46 & 0 & 0.54 & 0 & 0.54 & 0 \\
\hline 180 & 0.51 & 0 & 0.62 & 0 & 0.66 & 0
\end{tabular}




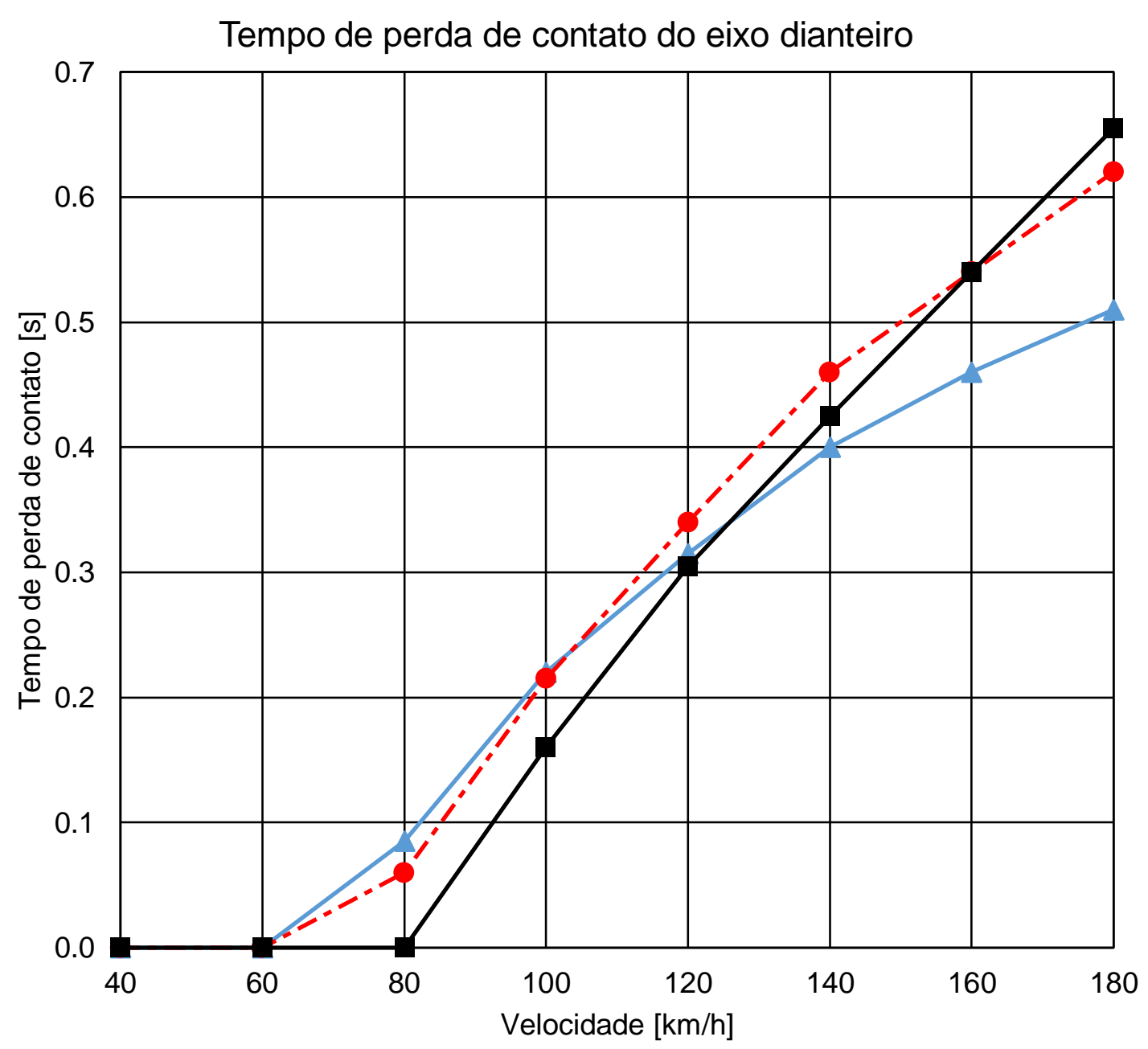

$\leftarrow$ Carro base

- @- Massa não suspensa acrescida na traseira - Inicial

$\rightarrow$ - Massa não suspensa acrescida na traseira - Ótimo

Figura 61 - Comparação do tempo de perda de contato para várias velocidades 
Força normal mínima no eixo traseiro

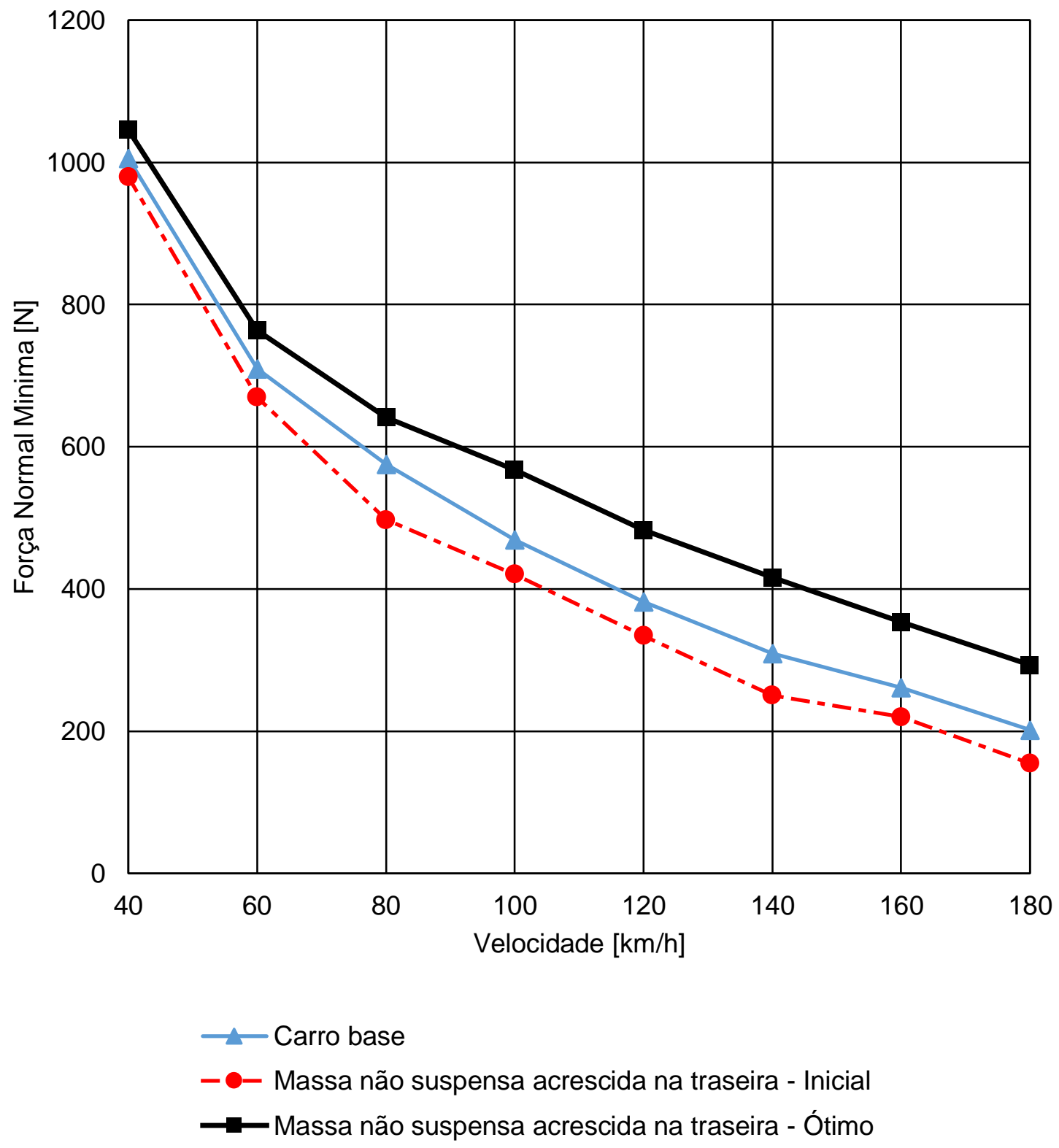

Figura 62 - Comparação da força normal mínima para várias velocidades.

Com os gráficos apresentados na Figura 61 e na Figura 62, é possível comparar o desempenho do carro ótimo com os dois casos anteriores. O tempo de perda de contato do pneu dianteiro com o solo apresentou valores melhores que o carro inicial até $160 \mathrm{~km} / \mathrm{h}$ e até $120 \mathrm{~km} / \mathrm{h}$, que é a máxima velocidade permitida em rodovias brasileiras, quando comparado com o carro sem massa acrescida.

Já quando se compara a força normal mínima do pneu traseiro, obtivemos uma melhora em todo o intervalo estudado, o que é altamente desejado. Um contato maior do eixo traseiro do carro com o solo evita a situação de sobresterço, que é indesejável 
para carros de passeio, pois para se manter o controle do veículo nesses casos se exige uma grande perícia por parte do motorista.

Devido às alterações das rigidezes da suspensão, que alterou a maneira como a carga se transfere, também é esperado uma alteração em seu comportamento de rolagem (Figura 63). É possível observar que a configuração otimizada, por utilizar molas mais rígidas e uma barra estabilizadora de maior diâmetro, a inclinação da carroceria durante as curvas foi reduzida substancialmente, o que também é extremamente desejável para se melhorar o desempenho de dirigibilidade.

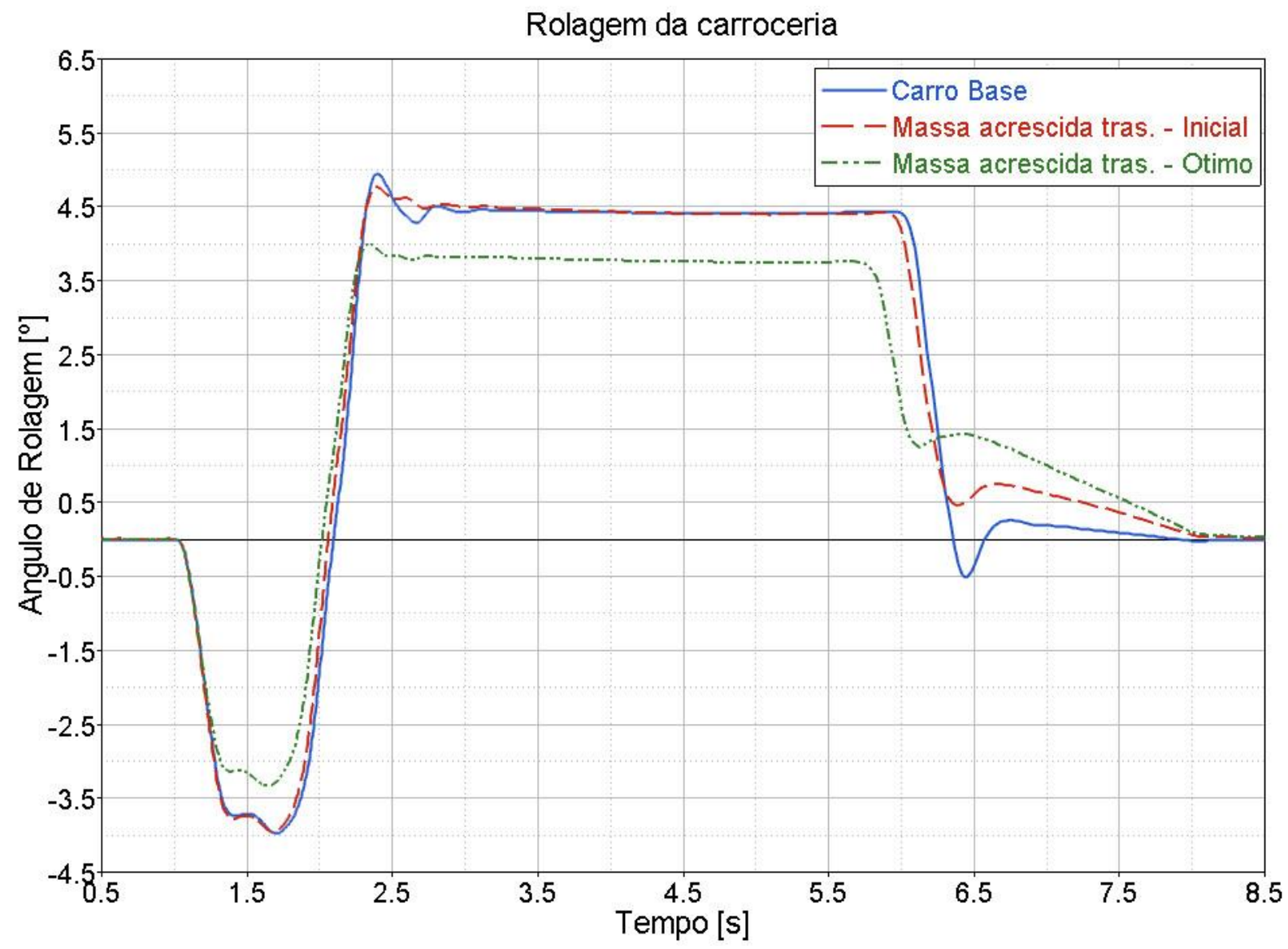

Figura 63 - Ângulo de Rolagem do veículo, em suas diversas configurações, durante a manobra do anzol a $120 \mathrm{~km} / \mathrm{h}$

De maneira geral, o processo de otimização através da análise de sensibilidade deu um resultado positivo, seja maximizando o contato do pneu com o solo de uma maneira geral, como também evitando que o carro tenha uma perda de contato do pneu traseiro, o que pode gerar comportamento sobresterçante. Indiretamente ele 
melhorou o comportamento de rolagem, como observado na Figura 63, o que é desejável, entretanto ao final da manobra, no intervalo entre $6 \mathrm{~s}$ e $8 \mathrm{~s}$ o retorno do veículo a posição de equilíbrio, se tornou mais lento, o que pode ser considerado um efeito colateral negativo do processo adotado.

Também foi possível perceber que o desempenho do carro é dependente, não somente da massa não suspensa, como da rigidez da suspensão. Através da técnica DOE, pode-se compreender que é possível compensar os efeitos causados pelo incremento da massa trabalhando na rigidez da suspensão, salientando que existe um compromisso dependente de ambos parâmetros. 


\section{Conclusão}

Foi elaborado um modelo matemático pela técnica de multicorpos de um veículo de passeio compacto com inclusão de motor elétrico instalado no cubo das rodas para o estudo de comportamento dinâmico e dirigibilidade. Foi avaliado como o incremento de massa afetaram a dirigibilidade, através de simulações numéricas e análises de resultados.

Utilizando a análise modal comparativa com um carro convencional (Tabela 7), foi identificado que a frequência dos modos de vibrar relacionados à massa não suspensa teve uma redução de cerca de $30 \%$, para o eixo ao qual o motor elétrico foi instalado, o que, inevitavelmente, acarretará em alterações no desempenho de dirigibilidade. Para os modos de vibrar associados a massa suspensa, as alterações de frequência foram deprezíveis.

Com a ajuda das manobras padrão, foi identificado que o incremento de massa não suspensa devido ao motor elétrico tem pouca influência nos resultados para as manobras de regime permanente, aquelas realizadas em aceleração lateral constante, ou com uma alteração gradual e lenta. Já para as manobras transientes, com mudanças expressivas na intensidade das acelerações durante a manobra, foram observadas grandes influências em dirigibilidade.

Desta forma, foi identificado que, quando o incremento de massa for realizado no eixo traseiro, existirá uma menor influência negativa sobre o desempenho de dirigibilidade, como visto, especialmente na manobra do anzol realizada em diversas velocidades, onde foi possível comparar a força normal mínima dos pneus, com uma redução média de $10 \%$ para o eixo traseiro e o tempo de levantamento de roda com um aumento médio de 50\% - resultados apresentados na Tabela 12 e na Tabela 13.

Adicionalmente, através de uma readequação dos parâmetros de suspensão, com a ajuda da análise de sensibilidade feita através da técnica de sensibilidades do sistema (D.O.E.), levando-se em conta o tempo de levantamento da roda dianteira e a normal mínima do pneu traseiro, demonstrou-se que é possível reverter a degradação em dirigibilidade causada pelo incremento da massa, como visto na Figura 61 e na Figura 62, chegando a desempenhos até superiores aos de um carro convencional para velocidade de até $120 \mathrm{~km} / \mathrm{h}$. 
Constatou-se, também, que a influência produzida por uma massa similar aos motores elétricos modernos pode ser mitigada através de um ajuste na elasticidade e no amortecimento dos componentes da suspensão do veículo.

Portanto, conclui-se que é possível utilizar motores elétricos instalados diretamento no cubo em carros compactos de passeio, sem perda de dirigibilidade, em velocidades compatíveis com o uso rodoviário, desde que a rigidez e o amortecimento da suspensão sejam adequados para isto. Finalmente, recomenda-se que o motor elétrico seja instalado no eixo traseiro, que possui uma menor sensibilidade de alteração para a dirigibilidade quanto ao incremento de massa não suspensa. 


\section{Recomendações}

Conforme identificado neste trabalho, existe um eixo, o qual a massa adicional instalada tem um menor prejuizo sobre o desempenho de dirigibilidade. É recomendado que, ao se iniciar o estudo conceitual de um veiculo avalie-se qual eixo traria um melhor resultado.

Neste estudo foi realizado um processo de otimização da suspensão do veículo alterando-se a elasticidade das molas e da barra estabilizadora dianteira além dos coeficientes de amortecimento. Entretanto, este universo pode englobar mais variáveis, desde as rigidezes de buchas dos braços de controle até os pontos de ancoragem da suspensão no veículo.

Também é indicado, em trabalhos futuros, estudar o quanto é possível alterar o posicionamento do centro de gravidade do automóvel, afim de se melhorar o desempenho de dirigibilidade por um simples reposicionamento das massas que compõem o mesmo. Como exemplo, os carros elétricos possuem um banco de baterias com massa considerável, com a possibilidade de alteração de sua localização espacial dentro do automóvel.

Por fim estudar sistemas de suspensão ativa e semi-ativa, que também são formas promissoras de melhorar a dirigibilidade de um veículo mesmo com o acrescimo de massa não suspensa. 


\section{Referências}

Abramovay, R., 2012. Muito Além da Economia Verde. São Paulo: Abril.

Anderson, C. D. \& Anderson, J., 2005. Electric and Hybrid Cars: A History. Londres: Mc Farland.

Azevedo, R. L. S. d. \& Goldenstein, M., 2006. Combustíveis alternativos e inovações no setor automotivo: Será o fim da "Era do Petróleo?". [Online] Disponível em:http://www.bndes.gov.br/SiteBNDES/export/sites/default/bndes pt/Galerias/Arqui vos/conhecimento/bnset/set2308.pdf [Acesso em Fevereiro 2016].

Barbosa, R. S., 2011. Vehicle dynamic safety in measured rough pavement. JOURNAL OF TRANSPORTATION ENGINEERING, Maio, pp. 305-310.

Barbosa, R. S., 2012. Vehicle Vibration Response Subjected to Longwave Measured Pavement Irregularity. Journal of Mechanical Engineering and Automation, pp. 17-24.

Baruh, H., 1999. Analytical Dynamics. Singapore: Mc Graw-Hill.

Benz, K., 1886. Benz Patent-Motorwagen. s.I. Patente № 37435.

Blundell, M. \& Harty, D., 2004. Multibody Systems Approach to Vehicle Dynamics. Oxford: Elsevier Butterworth-Heinemann.

Botosso, A. C., 2015. Avaliação do efeito da rigidez estrutural sobre a dinâmica veicular. São Paulo: Dissertação (Mestrado em Engenharia de Controle e Automação Mecânica) - Escola Politécnica, Universidade de São Paulo.

BP, 2015. BP STATISTICAL REVIEW OF WORLD ENERGY, 2015. [Online] Disponível em: http://www.bp.com [Acesso em Fevereiro 2016].

Bravo, D. M., 2016. Estudo sobre a Utilização de um Sistema Auxiliar Elétrico para a Propulsão de Veículos Leves de Baixa Cilindrada. Campinas: Dissertação 
(Mestrado em Engenharia Mecânica) - Faculdade de Engenharia Mecânica, Universidade de Campinas.

Bravo, D. M., Meirelles, P. S. \& Giallonardo, W., 2014. Análise dos desafios para a difusão dos veículos elétricos e híbridos no Brasil. Simpósio Internacional de Engenharia Automotiva, Agosto, pp. 1-22.

Bravo, D. M. et al., 2012. Estudo da influência do aumento da massa não suspensa em um veículo híbrido com motores elétricos nas rodas. CONEM, 2 de Agosto.

Car Blues print, s.d. Car Blues print. [Online] Disponível em: http://carblueprints.info [Acesso em Dezembro 2015].

Chen, X. et al., 2014. The Research and Development of Direct Wheel Drive System with reducer for suppressing unsprung Mass Negative effects. Transportation Electrification Asia Pacific, IEEE Conference and Expo, pp. 1-5.

Fischer, R., 2014. Schaeffler's wheel hub drives, Herzogenaurach: s.n.

Fórum do carro antigo, s.d. Fórum do Carro Antigo. [Online] Available at: http://www.carroantigo.com.br [Acesso em Dezembro 2015].

Fuhs, A. E., 2009. Hybrid Vehicles and the Future of Personal Transportation. Boca Raton: CRC Press.

Ganzarolli, F., 2012. Influência das frequências de ride no conforto e dirigibilidade veiculares na faixa linear de uso dos veiculos. São Carlos: Dissertação de mestrado em Engenharia Mecânica - Escola de Engenharia de São Carlos da Universidade de São Paulo.

Gillespie, T. D., 1992. Fundamentals of Vehicle Dynamics. Warrendale EUA: SAE - The Engineering Society For Advancing Mobility Land Sea Air and Space..

Gore, A., 2008. Uma Verdade Inconveniente. Emmaus: Manole. 
Gupte, S., 2015. Experimental Analysis and Feasibility Study of 1400 CC Dieselv Engine Car Converted Into Hybrid Electric Vehicle by Using BLDC Hub Motors. Energy Procedia , 25 Agosto, pp. 177-184.

Gurgel 800, s.d. Gurgel 800. [Online] Available at: httpllwww.gurgel800.com.br [Acesso em Dezembro 2015].

HLDI, I., 2004. Insurance Intitute for Highway Safety, Highway Loss Data Institute.[Online] Available at: http://www.iihs.org/iihs/sr/statusreport/article/39/3/3 [Acesso em 28 Fevereiro 2017].

ISO, 2002. ISO3888-2 - Passenger cars - Test track for a severe lane-change manoeuvre, Geneva: International Organization for Standardization.

ISO, 2012. ISO 4138 - Passenger cars - Steady-state circular driving behaviour - Open-loop test methods, Geneva: International Organization for Standardization.

Jalopnik, s.d. [Online] Available at: http://jalopnik.com [Acesso em Dezembro 2015].

Jedicke, P., 2001. Extreme Science: The Highway of Light and Other Man-Made Wonders. New York: St. Martin's Griffin.

Jin, B., Sun, C. \& Zhang, X., 2015. Research on lateral stability of four hubmotor-in-wheels drive electric vehicle. International Journal on Smart Sensing and Intelligent Systems, pp. 1855-1876.

Lovins, A., Lovins, H. \& Hawken, P., 1999. Natural Capitalism: Creating the next industrial revolution. Snowmass: Little, Brown \& Company.

Milliken, W. F. \& Milliken, D. L., 1995. Race Car Vehicle Dynamics. Warrendale EUA: SAE - The Engineering Society For Advancing Mobility Land Sea Air and Space.. 
Momiyama, F., 2006. Unsprung mass pitching action and its effects on riding comfort. SAE technical paper Series, 3-6 April.

Momoh, O. D. \& Omoigui, M. O., 2009. An Overview of Hybrid Electric Vehicle Technology. IEEE - Vehicle Power and Propulsion Conference, 7-10 Setembro, pp. 1286-1292.

NASA, 2011. NASA Research Finds 2010 Tied for Warmest Year on Record. [Online] Available at: http://www.giss.nasa.gov/research/news/20110112 [Acesso em Fevereiro 2016].

National Highway Traffic Safety Administration, 2004. A demonstration of the Dynamic teste developed for NHTSA's NCAP Rollover Rating System. Washington, D.C.: US Department of Transportation.

Omar, A. A. A. \& Ozkan, B., 2015. Analysis of effect of in-wheel electric motors mass on passive and active suspension systems. ARPN Journal of engineering and Applied Sciences, 14 Agosto, pp. 5924-5929.

Paldan, J. \& Vantsevich, V. V., 2016. 2016-01-8025 Stability of Motion and Mobility Analysis of a $4 \times 4$ Hybrid-electric Vehicle with Passive Drivelines. SAE technical series, 27 Setembro, pp. 1-9.

Porsche, 2016. http://www.porsche.com. [Online] Available at: http://www.porsche.com/usa/eventsandracing/motorsport/worksracing/racingcars/919 -hybrid/featuresandspecs/

Quatro Rodas, 2016. Quatro Rodas. [Online] Available at: http://quatrorodas.abril.com.br/noticias/alemanha-quer-proibir-carros-acombustao-ate-2030/

Rahman, K. M. et al., 2006. Application of Direct-Drive Wheel Motor for Fuel Cell Electric and Hybrid Electric Vehicle Propulsion System. IEEE Transactions on industry applications, Setembro, pp. 1185-1192. 
Rojas, A. E. R., Niederkofler, H. \& Willberger, J., 2010. Comfort and safety enhacement of passenger vehicles with in-wheel motors. SAE technical paper series, 04 Dezembro.

SAE, 1996. J266 - Steady-state directional control test procedures for passenger cars and light trucks, Warrendale: The Engineering Society For Advancing Mobility Land Sea Air and Space.

SAE, 2014. J1715 - (R) Hybrid Electric Vehicle (HEV) and Electric Vehicle (EV) Terminology, Warrendale: The Engineering Society for Advancing Mobility Land Sea Air and Space.

Schilling, R., 1948. Masses on ride. SAE quarterly transactions, abril, pp. 220226.

Shim, T. \& Velusamy, P. C., 2006. 2006-01-1950 Influence of Suspension Properties on Vehicle Roll Stability. SAE Techincal Paper Sries, 14-16 Fevereiro, pp. $1-15$.

Swedish Road Engineering Division, 2000. Whole-body vibration when riding on rough roads, Borlänge: s.n.

Taguchi, G., Chowdhury, S. \& Wu, Y., 2005. Taguchi's Quality Engineering Handbook. Hoboken: John Wiley \& Sons, Inc.

Terra, R. T. \& Barbosa, R. S., 2016. The Influence of hub driven motor on vehicle dynamics behavior. SAE technical Paper Series, Outubro, pp. 1-7.

Terra, R. T., Barbosa, R. S. \& Botosso, A. C., 2015. Inclusion of the displacement variable on the damper modeling in multibody environment. $S A E$ Technical Paper Series, Outubro, pp. 1-6. 
Toyota, 2016. http://www.toyota-global.com. [Online] Available at: http://www.toyotaglobal.com/company/toyota traditions/innovation/nov2008 feb2009 1.html

Van Schalkwyk, D. J. \& Kamper, M. J., 2006. Effect of hub motor mass on stability and comfort of electric vehicles. IEEE - Vehicle power and propulsion conference, 6-8 Setembro, pp. 1-6.

Vilela, D., 2010. Aplicação de métodos numéricos de otimização ao problema conjunto da dirigibilidade e conforto veicular.. São Paulo: Tese (Doutorado em Engenharia de Controle e Automação Mecânica) - Escola Politécnica, Universidade de São Paulo.

Vilela, D. \& Barbosa, R. S., 2011. Analytical Models Correlation for vehicle dynamic handling properties. Journal of the Brazilian Society of Mechanical Science \& Engineering, Outubro - Dezembro, pp. 437-44.

Wakefield, E. H., 1998. History of the electric automobile : hybrid electric vehicles. Warrendale: SAE - The Engineering Society For Advancing Mobility Land Sea Air and Space..

WEG, 2016. http//weg.com.br. [Online] Available at: http//weg.com.br

West Hills Collision Center, s.d. West Hills Collision Center. [Online] Available at: http://www.westhillscollision.com [Acesso em Dezembro 2015].

Yang, S., Chen, L. \& Li, S., 2015. Dynamics of Vehicle-Road Coupled System. Beijing: Science Press Beijing / Springer. 
10. Apêndices

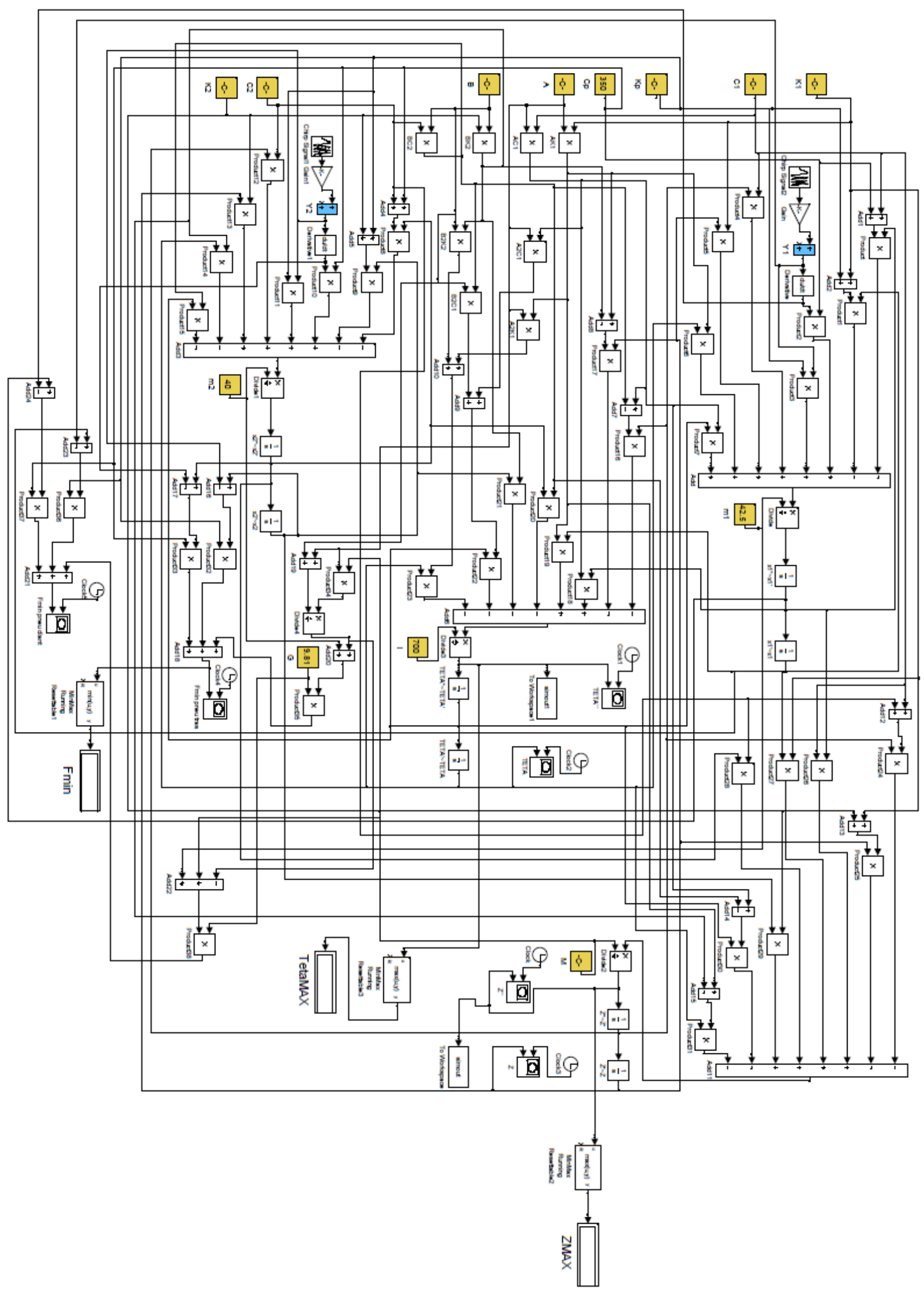

